
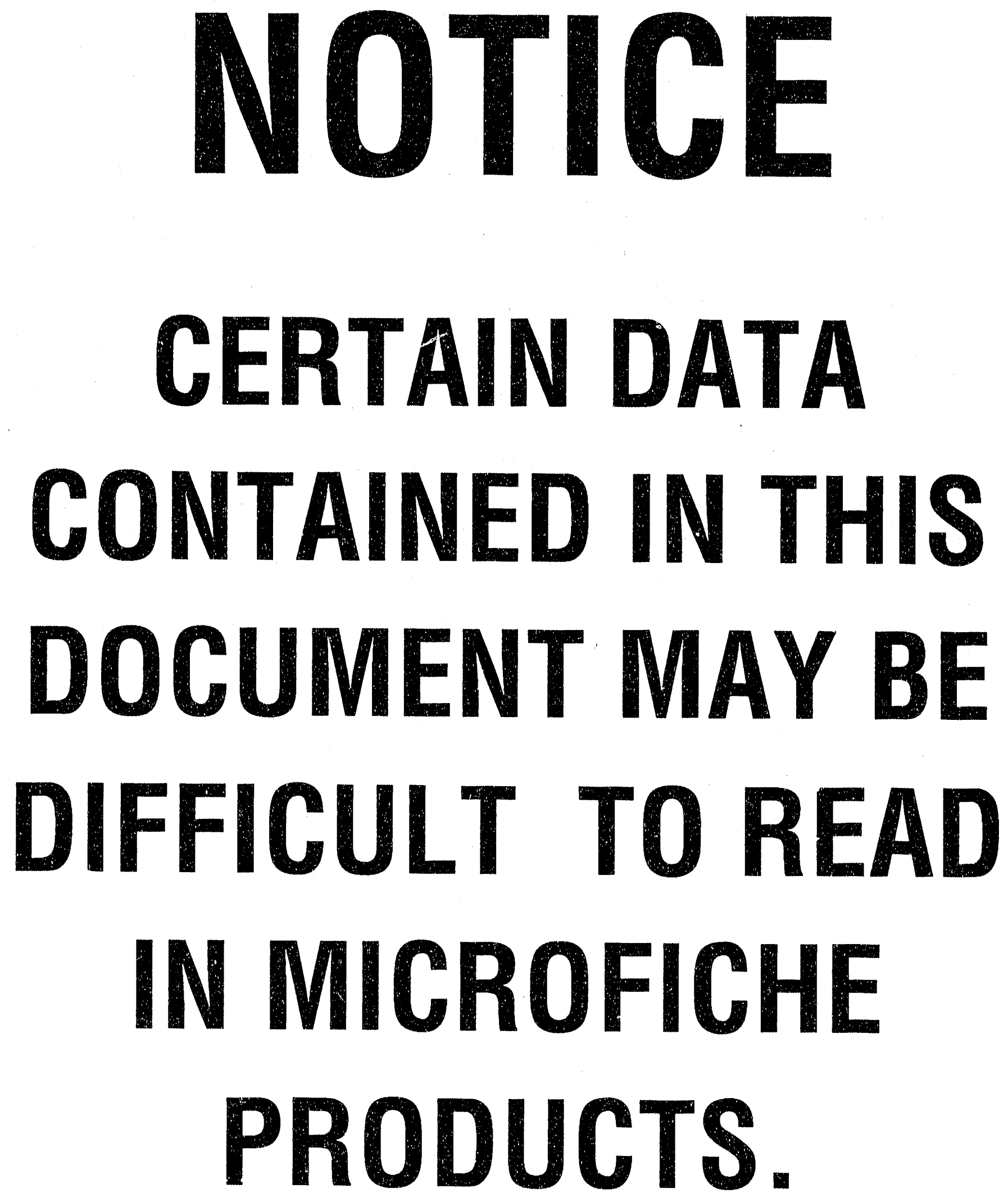


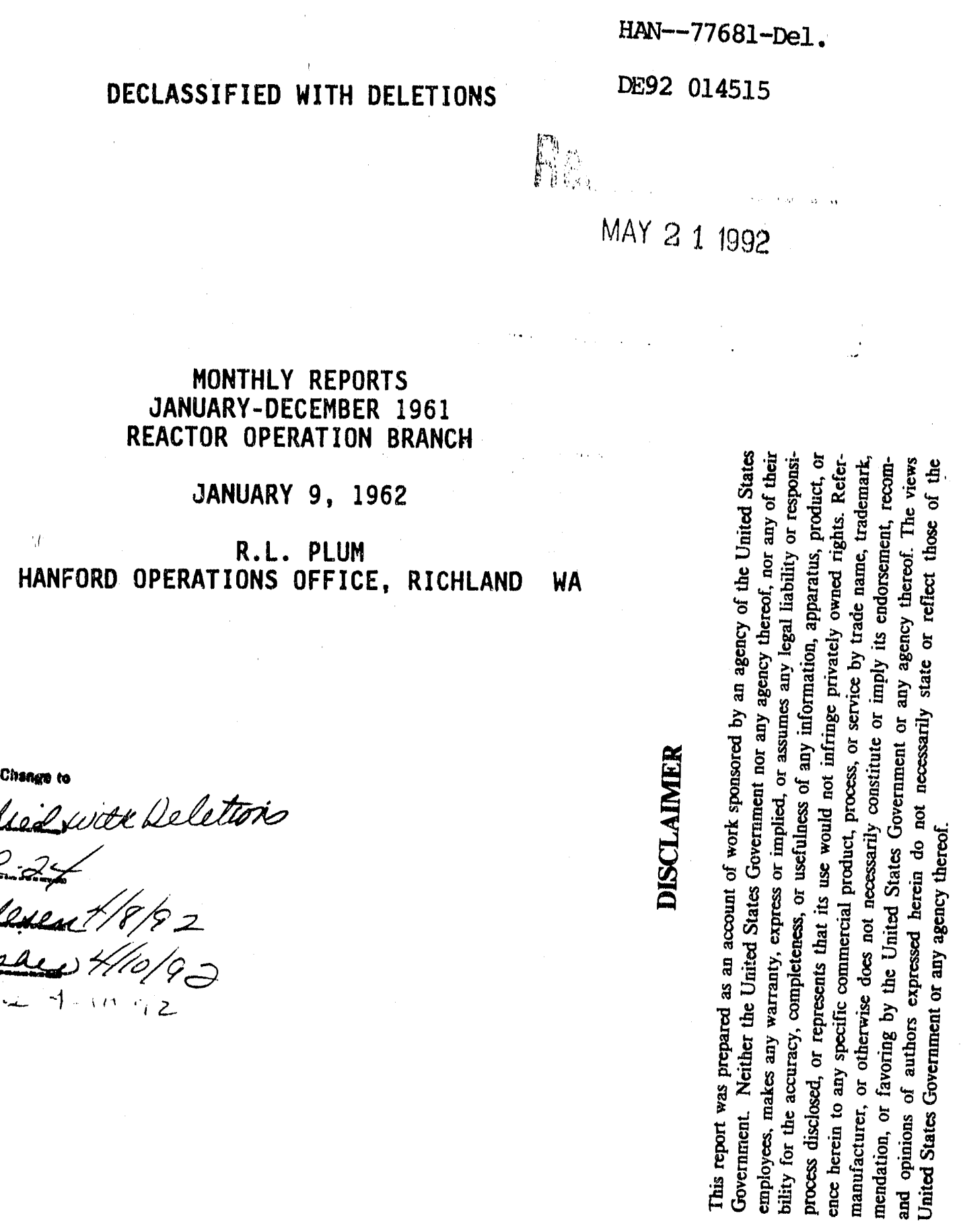

DECLASSIFIED WITH DELETIONS 


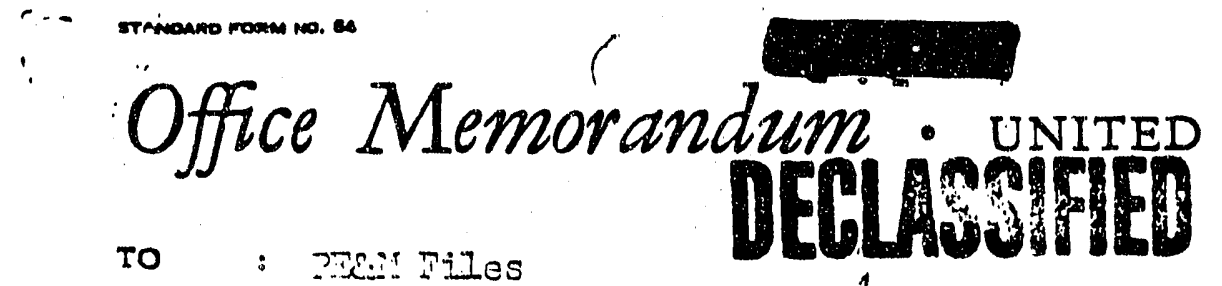

To : Tristiges

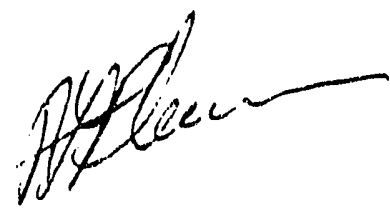

DATE: FeOMuEr, ?, 2051

FROM : R. L. TIum, Chief

Reactor 3rarich

STATES GOVERNMENT

SUBJECT: IO:MTHI REPORT - JMIULAT, 1,061

CI.:GTO:GRC

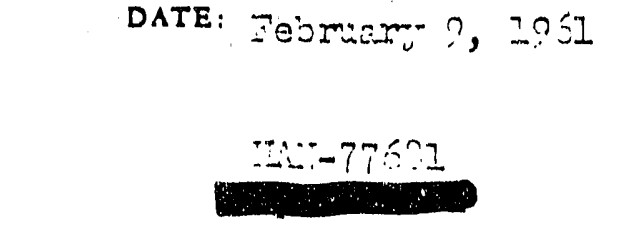

T:1

OPJRATIG ANDTITICZ

Droriuction

Reactor input production vas 6.5 per cent abore forecast; 0.1 per cent above at the six old reactors and 15.7 per cent above at the $m^{\prime}$ 's. Forecast was exceeced at the $m^{\prime}$ s due to higin time operated efficiencr and improved operating levels.

Ifficianc,

Over-all time operated efficiencr vas $7 . .5$ per cent ( 30.1 forecast); 76.7 per cent at the six old reactors and 37.7 at the $\because n s$.

Power Level

The combined reactor instantanoous porer lavel ias increased 165 megaratts (18,785 to 18,950$)$. The individual reactror record power levels vere increased 175 megavatts at iw $(3,055$ to 1,030$)$, 45 at $C(2,090$ to 2,135$), 30$ at $D(1,310$ to 1,340$)$, 15 at $B$ $(1,345$ to 1,860$), 15$ at $D R(1,835$ to 1,350$)$ and 10 at $i$ (1,835 to 1,345$)$. Input production records vere achieved at $C$ and $\pi . T$.

Poiver Level Iimit

During this report period, $B, C, D$, $F$ and $I$ reactors were limited by mpture control consicierations, D and I reactors by bulk outzet temperatures, and ...: ow the .IC acministrative limit. $C$ reactor vas also limitad by the administrative linit for a portion of this period until relaration of the 1 isC limit ras received.

\section{Fuel Rupture}

Ileven mutures, nine Inie regular metal and tio I i. enriched, were removed from the reactors. Three of the Iin regular mptures were

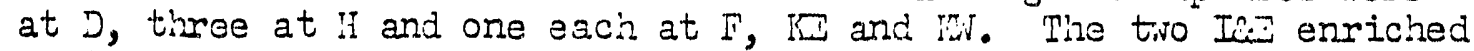
ruptures were at $D R$ and $\cdots$.

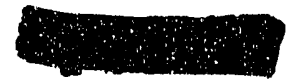


Files

Zeactor Jutares

Outages nor tix rontil of Jenuarr are as follors:

$3 \quad 2=10 T 0 R$

Data Date Outage

Dorn Jo Tours

$1 / 13 \quad 1 / 13 \quad 120.5$

$1,206 \quad 1 / 23 \quad 1.2 .2$

$\begin{array}{lll}1 / 29 & 1 / 29 & 0.5\end{array}$

C RTACTOR
$1 / 91 / 9$
0.2
$1 / 17 \quad 1 / 21 \quad 81.1$

\section{RIICTOR}
$1 / 13 \quad 1 / 17 \quad 101.7$
$1 / 21 \quad 1 / 22 \quad 38.1$
$1 / 26 \quad 1 / 28 \quad 43.9$

\section{Temariss}

¿checuled charge-discharsa, tube replacament, and miscellaneous maintenance.

Frobologoing anci miscellaneous maintenance solloring tise repair of a pigtail laal.

Repaired front pigtain leak on tube 1,092.

ünexplained panellit trip.

Scheduled charge-discharge and overboring of three process tube channels.

Removal of an Iin regular metal musture from tube 1365. Charge-discharge, tube replacement and installation of 200 reamed front face nozules.

Removal of an In $=$ regular metal (Bumper) rupture from tube 2675 .

Temovel of In regular metal (Sumper) mpture from tube 2373. Installed I3L oterbored front nozzles.

Scheduled charge-discharge.

Panellit trip

Low pressure vater trip due to improper valving at 190 Building. Leak testing and miscellaneous maintenance. 
J.. Imidman, cont.

Date Jate vutagre

Do: Un Your's

Zernarles

$1 / 12 \quad 1 / 12 \quad 1.2$

$1 / 1: 1 / 13 \quad 39.0$

$1 / 28 \quad 1 / 30 \quad 46.9$

mripped clue to a Iaulto vertical row relay.

Leair testing. Replenced Ieaking tube $3: 73$ and instarled 33 roaka $20 \pi z 135$.

Removal of and Iis inatal rupture from tiube 2657 .

$=-2 \pi, \cos 25$

$1 / 2 \quad 1 / 4 \quad 35.1$

Low pressure Panellit trip on gauge Cos:. Temoral of an In. from tube 0363 and charo-ilischarga.

$1 / 13 \quad 1 / 15 \quad 56.6$

Lealk testing.

$1 / 29$ :till down

Scheduled charge-discharge and tuive replacement.

II FEASTOR

$1 / 0 \quad 1 / 15 \quad 117.4$

Removal of an Ine renular metal rupture from tube 3731. One to tiso tubes of irradiated metal ( I I-J) rere lischarged onto the rear face elevator then the elevator moved from the "lip" to "com" position during the discharge operation. it total of 57 Iin I-metal pieces iero removec from discharge elevator. Installed los reamed front face nozzles.

$1 / 15 \quad 1 / 10 \quad 36.0$

Corrected Parler fitting leak on tube 1377.

$1 / 18 \quad 1 / 18 \quad 0.5$

Installed bajonet in air channel 1163 .

$1 / 13 \quad 1 / 19 \quad 1.2$

$1 / 19 \quad 1 / 20 \quad 25.0$

Repair broken Iug ring on front nozzle 4325.

$A$ period of insufficient reactivitr.

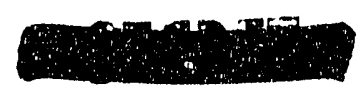


I silCTOR, cont.

Date Date Cutage

Do:m Un Iours

$1 / 23 \quad 1 / 25 \quad 34.5$

$1 / 31$ Still do:m

II 2.210TO:2

$\begin{array}{lll}1 / 13 & 1 / 17 & 75.5 \\ 1 / 19 & 1 / 21 & 33.9\end{array}$

IN RTACTOR

$1 / 23 \quad 1 / 26 \quad 72.5$
Remarks

Removal of an Iai regular metal mpture from tube 0.82 . Cizarge-dischare and miscelianeous
maintenanca.

-iemoval of an Ii:- regulan metal mapturs from tube 3379 . Charge-discharge and miscelinanous
maintenance.

Removal of an Iis regular metal mpture from tube 3167. Charge-discilarge and maintenance. Charge-discharge and maintenance following a loop trip. Four partial ilch's rere installed and ijo. 4 low-lift motor ras replaced ritil a revound upgraded motor.

Removal of an Inis I metal mpture from tube 3090 and scheduled charge-discharce. A suspected Isir regular metal rupture discharged from tube 5384 on $1 / 23$ was confirmed. 


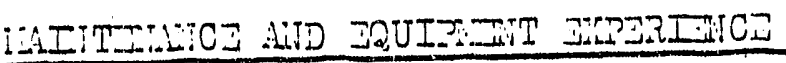

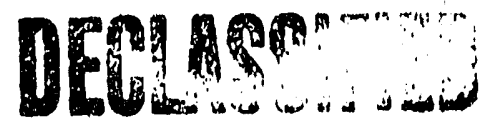

mocess Tuives

Iinety-five process tuves sere installed; $6 I$ at 3,17 at $2, ?$ at $D ?$ ?, 6 at $I$, and 2 at $I$.

Five tuive leals and three Tan jtone lealis vere corrocted. Tro of the tube lealis vers at D?, tiro at II and one at I. The Tan itone lealis vere at $3, D R$, and $i$.

Zear Jrossheader Parker Fittins Failure - 1053 and 7

Three rear face crossheader Parker fittings have recently brolion at the tiread-relief section. Analjs is of these breals indicates varrins demres of stress fatigue and cavitational effects. ineroncry repair measures for broken crossheader fittings have been iormulated. After sealing the broken fitting, a new crossheader entrance hole is arilled beside the brolken fitting. Using a Dresser Ferrice jadile, praviously prepared rith a new Parier Fitting, the unit is clamped to the crossheader over the new entrance iole. Only a slight modification of configuration is required on a helical-type connector to adjust it for use rith the service saddle entrance unit.

L500 A.P. Iotors

Two stators rith Class 3 coils were installed in 190-1 positions 4 and 8 . The first stator to be modified vitil class $A$ coils vas installed in position 2 in 190-DR.

\section{Grapiate Jistortion}

Jistortion of the grapizite stack at $C$ reactor has rendered tio rertical safety rods inoperable and has caused bindine of fire adiitional rods. Preliminary design efforts have been directed tovard jointing an existing rod assemily for flle:ibilitio" operation.

\section{3orescoping detivities}

Vertical safety rod channels 12 and 13 , DR reactor, were inspected to determine why the TIR's sere reluctant to enter the channel. The vertical liner blocks vere found to be snlit, with some blocks tilting out into the channel and others broken oif. 
Overbored process channels $095 \%$, 1453, and 14.94, o raactor, rere examined to investigate the reason for retuing difficultur. rerers

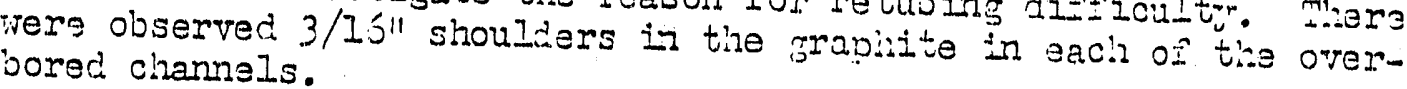

Tertical safety rod channels 50 and 39, : reactor, rere examined and j.t ras found tizat graphite filler blocl:s vere protucits into the channel approximatelir $I "$ " at 13 feet dom from the oumper Jlock.

Tertical safety rod channel LI, a reactor, ias examined to iletermine

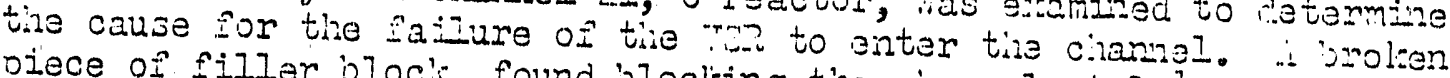
piece of filler block, found blocking tha clanmel at $22 \%$ feet $\mathrm{i} 0 \mathrm{~m}$ from the uumper block, ifas remored. The channel ras re-inspected and anotiker piece of filler block ras observed to be completely blocking the channel at 14. feet $i 0 \mathrm{~m}$ from the bumer blocl.

Poison Solines

Improvements in startup efficiencies vith increased use of supplementary control during 19,50 are pointed up by founth-quarter comparisons of
1059 and 10,60 in the follooring tajle:

Ave. Iffectivo Day Ioss

Per Startun

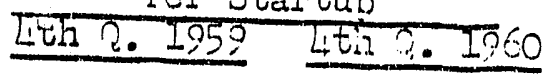

5 old Reactors

.60

$C$ and $i x$ Reactors .33

1.0 .25
Level Oper. Ifficiency, 4th 2. 19,59 Lth?.10,00

$$
93.8
$$

Vendor liaison efforts have resulted in a recent bid of under $\$ 23.00$ for poison splines. This is a $3 L .5$ per cent recluction in costs from the previous order. Liaison aimed at further decreases is

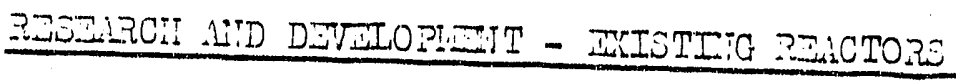

Seli-suprort Fuel Develoument

Three colums of CTIrS (overbore fuel) type fuel elements vere charged into $C$ reactor during the $1 / 17 / 61$ outage in 550-mil. oversize zircaloy smooth-bore process tubes. Each colum was equipped vith a doinstream thermocouple probe for monitoring fuel design adequacy. The reactor 

rily.

ito unusual irradiation
of self-supported fuel
of material irere rechar

Eumnar Juel Jevelopment

ill material to complete the ona-iundrac-tu's bumper fual dernoncolums of material (OIIB) undes jeen charged. Whane ars of columns of material (OIIID under PT authoriation and about 151

Three colums of uncer sim in J reactor. tia 1/13/51 outago at IidD/T. Tio column at $J$ reactor at an averase exposure of 310 model. There vere tilirteen corrosion ane vas a l-bumpered Tite first natural uranium at $د$ raactor on $1 / 3 I / 51$ at an bumer fuel element fajlure occurred OIIn, was a 3-rail solit? bumper modal, and $957 \mathrm{im} / \mathrm{m}$. The failure, a "side other" failure based on visual, and it iras classified as technical. viewing facilities. Further examination in the $D$ reactor rola played by uniform corrosion is schedulad. Irimination of the thres sent to Radiometallurgr for residual can-rall determination has
begun.

Eramination of the fual elament rhicis exhibited ellipticity measurement of 69 mils has been ited a post-irradiation changes appear to be a result of both been initiated. Dimensional core growth.

Jardivare Jevelorment

ftudy drairings of proposed inlat and outlet procass tuive assebmlies for modifing C raactor for use of self-supported fuel elements, been developed, I) proposed equipment prement. Tho concepts have Procurament specifications prototype inlet and outlet process completed for the purchase of ten size concept. Procurement requests are being prepared the existing tube
concept.

\section{Shielding Studies}

Preliminary radiation checks on the three channels at $C$ reactor overdicated dose leakage rates no higher hardware during the month insurrounding regular-size columpor from these channels than from 
tinese outer chanrels inclulas 211 boron steel at the extreme outsite and appromimately 13 ll of iron-apo: ho hrogenous material in the outer half of tile jiological silield.

\section{Columbia River IIor}

On Januarr 7,1061 , at L:23 p.m., the loss of station poirer at Iriast Zapids caused the loss of their lurdro-turbines and riren flor curtailment to $10 "$ - 12,000 cfs for loss than five minutes. Tine effect ras noticerl at the river jauge 1.6 mile jelor the dam and at the 131-3 3uilding intale.

On January 9 , at a meeting ritis tise Julic Utility jistrict at imiest lapicis, the amersency setwup at the dam vas extaminad and improvement measures sugjested by TD and Gi. Sdditional bus ties in the emergencr circuits rill be provided as rell as automatic operation of the station service cilesel senerator. It ras understood that they irould receive faborably a recomenciation for the installation of a portable diesel generator on the spilliraw
gates.

\section{River Data Talometering}

Installation of permanent equipment is complate. Deuugaing and operational tests are in progesss. Intermittent trouble had developed in the Leeds and Northrup equipment at Priest Rapids Gaging Station; hovever. Leeds and Jorthrup has agreed to replace the suspect chassis.

\section{Reactor Iffluent Studias}

The use of aluminum nitrate coaglant in place of aluminum sulfate has been of interest from the standpoint of possible effects on film buildup and corrosion provided the same turbidity level is present in process iater. Film builcup on fuel surfaces is the same rith the tro coagulates. Corrosion of process tubes coolad rith rater coagulated with both materials was monitored inth tire Probolog. iTo simificant differences in wall thiclmess were found for either class of tubes.

Final data on the reductions in effluent activity afforded by the half pile water treatment modification tests recently completed at 3 and $I$ reactors are as follows: 
. Flies

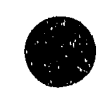

13 pom aluminum sulfate

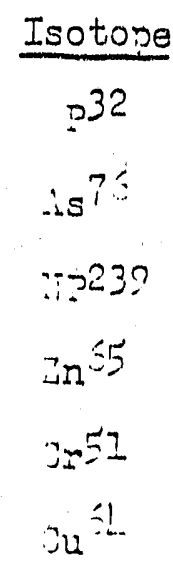

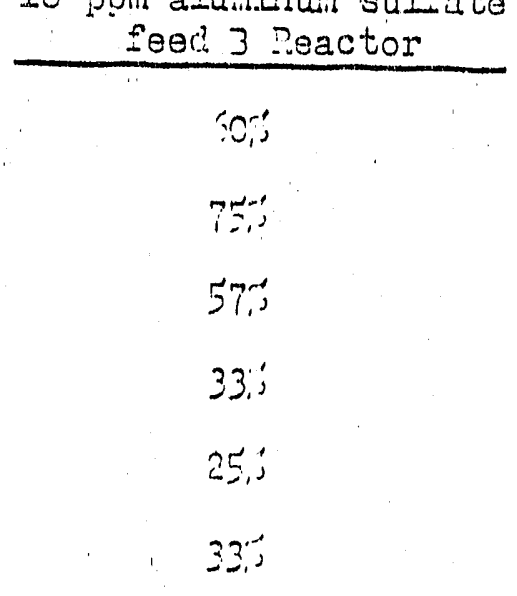

Tebruary ?, 1961

$20 \mathrm{ppm}$ aluminum nitrato feer I Reactor

m-?C?",

75:;

“5:"

$2 \pi$

इ3;'

$33 . ;$

It is expected that the addition of 1 ? $7 \mathrm{~mm}$ of alum and a filtom aic during the montis of cumst, eptember and cotober ronli racuco the peak concentration of 232 in rhitafis! to about $1.0 \%$ of that rhich otiermise rould be encountered. The potential exposure to an indiri. Hal who ents whitefish regularl voulc then be reduced to about io is of the exposure ia rould receive fitin no rater troatment. antencling tisa period o: high-alum foed to include july and november vould funther reduce this exposure to about 48,2 . The effect of alum feed rates on potential exposure from drinding jater at Pasco rill vary iithuthe lengtin of time the high feed rates are maintained.

\section{Peactor Fundamentals Training}

The iinter-Spring session for pile operators ras initiatec. iuring the

- month. This section includes pile operators from all shifts of

Reactor Processing and Jupplemental Crors Operation and several people ritin radiation monitoring assi mments. This is the second such series; shift personnel from each shift involved attend one half-day class per month for four consecutive months. Eeactor specialist calsses continued during the montin rith guest pirsicists contributing to tire lectures.

I series of four tio one-ialf' hour classes, one for each shift, is currently being presented for 1 maintenance craftsmen; attenclence has been spproximately 15 per session. Cne, tiro and one-izalf hour session of reactor fundamentals ras presented for a groun of 15 for Vaintenance Practices Operation, primarily for instmiment trainees.

\section{REACTOR IODIEICATION OROGRAI:}

\section{Reactor Overbors}

From January 13 to January 21, an on-pile demonstration of overboring

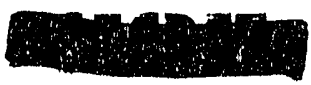


three tuives 5:0 mils, installing new oversize airconium tuives, ne: prototupe hardiars and oversize fuel elements, was comletar. Th: naw tri-bore machines rere used to bore shielding rines, thermal bloclus, and counter-bore the first graphite packing block.

Operation since startup has been satisfactorr. Tube flors obtaineci vere in very close agreement iftli those prodicted fum Iiboratoru data and iere approximately timee to four gallons ner minute hirhar tinan prodicted iy clesign calculations. Sata to date indicate that the temerature variation around the coolent amulus is molest, rhic's again supports expectation.

\section{Overbore Zarditare}

.1II hardware needed to complete a 20-tube clemonstration has no: beem received. Tour complete sets are in use on $\mathrm{C}$ reactor, timree on the c.jannels bored during the linited demonstration and one rith stanclard tube and fuel using special adaptors. Fircept for the installation of the remaining hardware, this essentialiy completes the expansion hardvare clevelopment program.

\section{Dormcomer Alequacr}

I test at $\mathrm{C}$ reactor confirmed study predictions that extsting dormcomers vere adequate to landle flow increases to $115,000 \mathrm{~mm}$, provided the downcomer trays vere perforated and indiviclual tray vents vero remoted.

\section{Overbcre Iimit}

An analysis of the safe maxinum diameter overbore for 0 reactor has been complated. Ilesults confirm previous estimates that approximately 600 mils is the marimum safe overbore rith the existing ball third safety system. This value is based on zirconium process tubes, 1700 effective central tubes. 115,000 $5 \mathrm{pm}$ flow, bulk temperature increases (AT) of $83^{\circ} \mathrm{C}$, spita and racial en: i.chment, and fuel exposures of $702-900 \mathrm{NID/T}$.

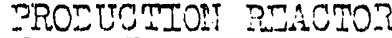

Fuel Testing - Fir Tacilities

ㄱini-1: The ten nominal IIIT-I elementis charced on December 3, 1960, under PT-IP-370-A to evaluate different heat treatments reached an exposure of $355 \mathrm{iTD} / \mathrm{T}$ vithout incicient.

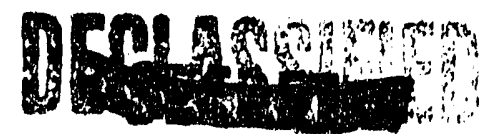




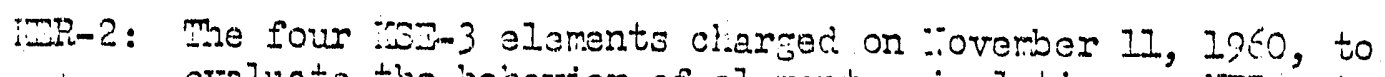
evaluate the beharior of elemerts simlating an par outer tube have reached an exposure of $135=0 \mathrm{D} / \mathrm{m}$.

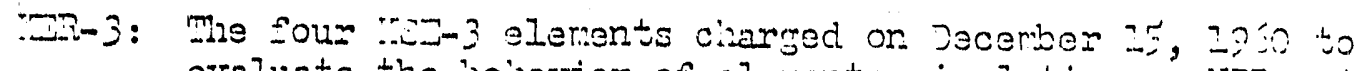
evaluate the vellavior of elements simulatine an $:$ outer tube have reached an exposure of $775: \ldots 1:-1$

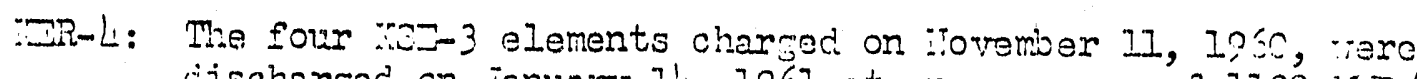

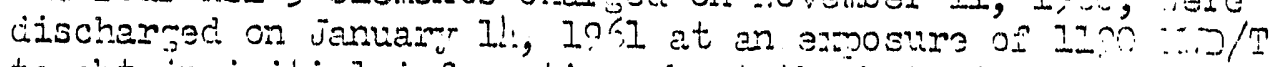
to obtain initial information about the velavior of the De-ir brazed closure. Cursory examination in tiva $105-\mathrm{J}$ vierving basin disclosec no major abnomalities. purtier examination $\because$ ill be cerried out at the Parliometallunmical Laboratory. The 100 vas rechar'ed rith four 2!." :-II elements on Januar IL, 1361, under PT-IT-377-A. Tiese elements, ihich represent the first irradiation of an actu.... ins inner fuel tube, have reached an exposurs of $70 \mathrm{IIID} / \mathrm{T}$ as of January 23,1961 .

iTomenciature
ris-3 - rar-sized single tube - enriched piecos.

NII-I - NPR-sized inner tube natural $\mathrm{U}$. 


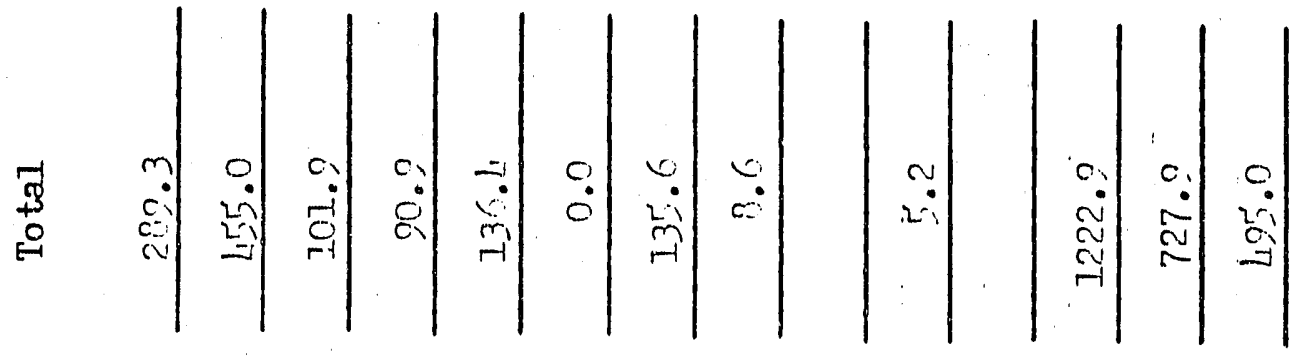

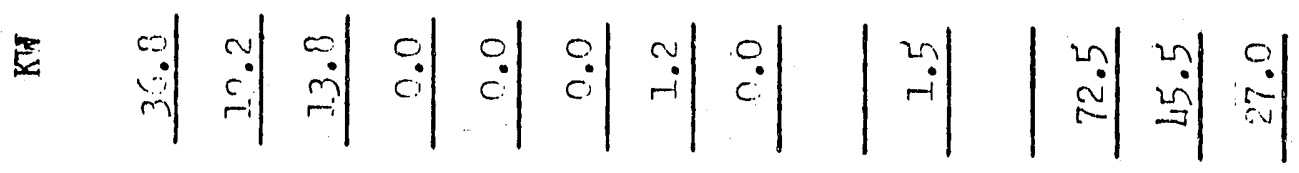

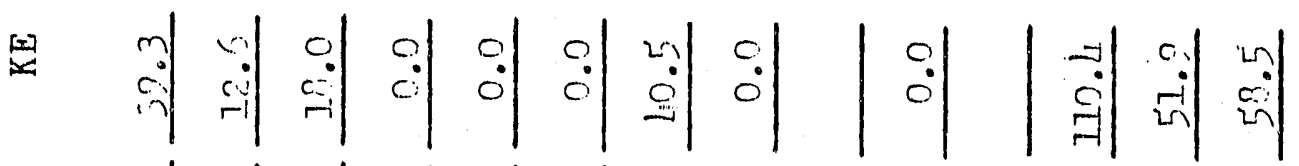

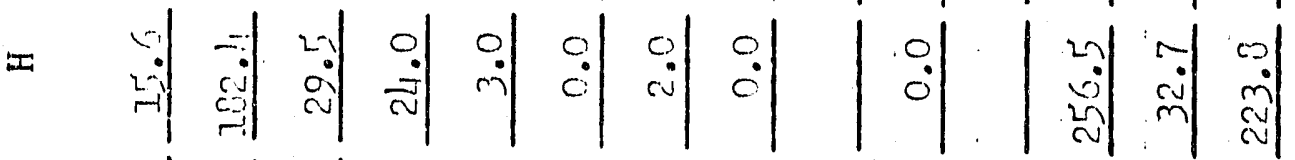

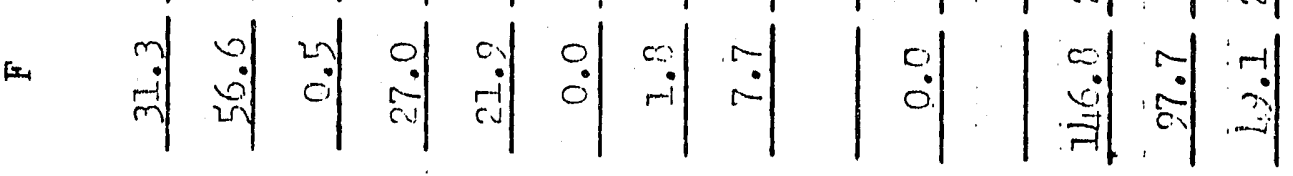

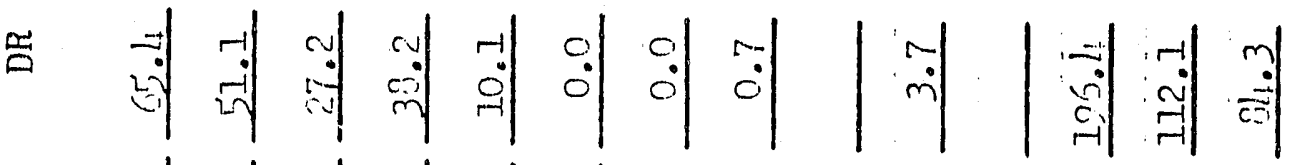

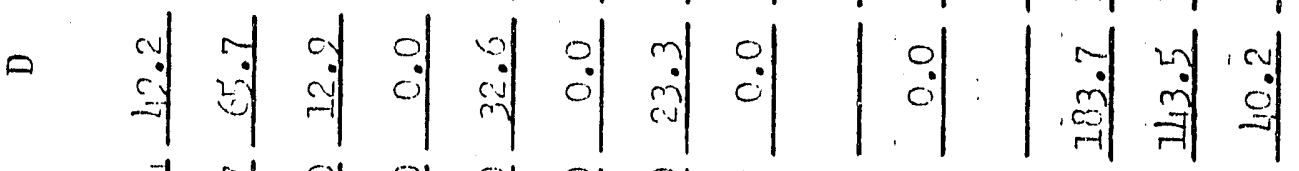

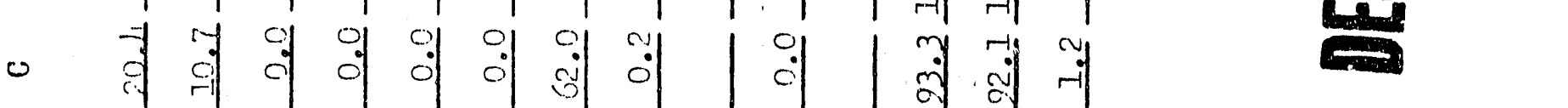

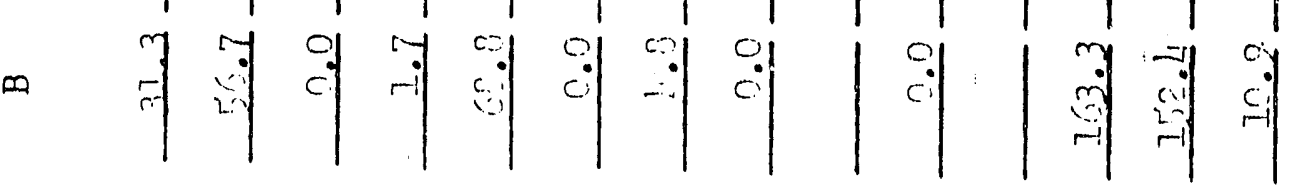

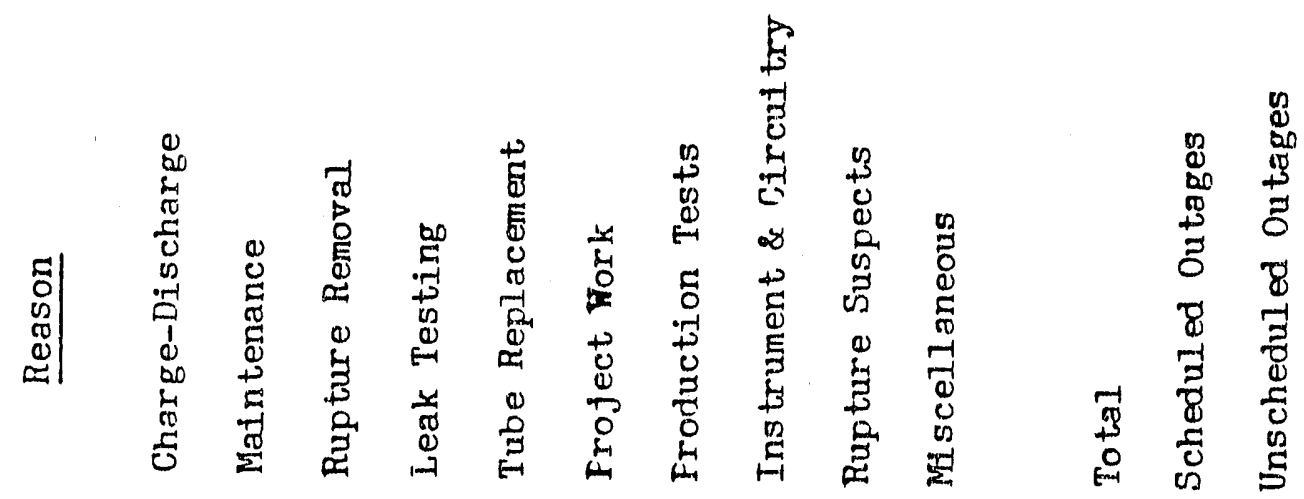

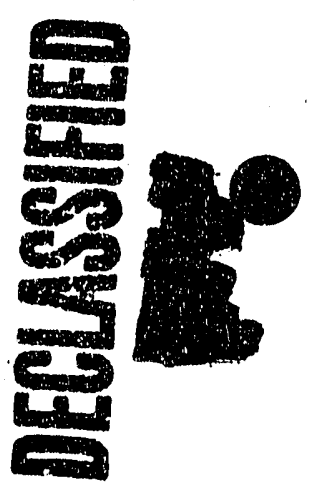




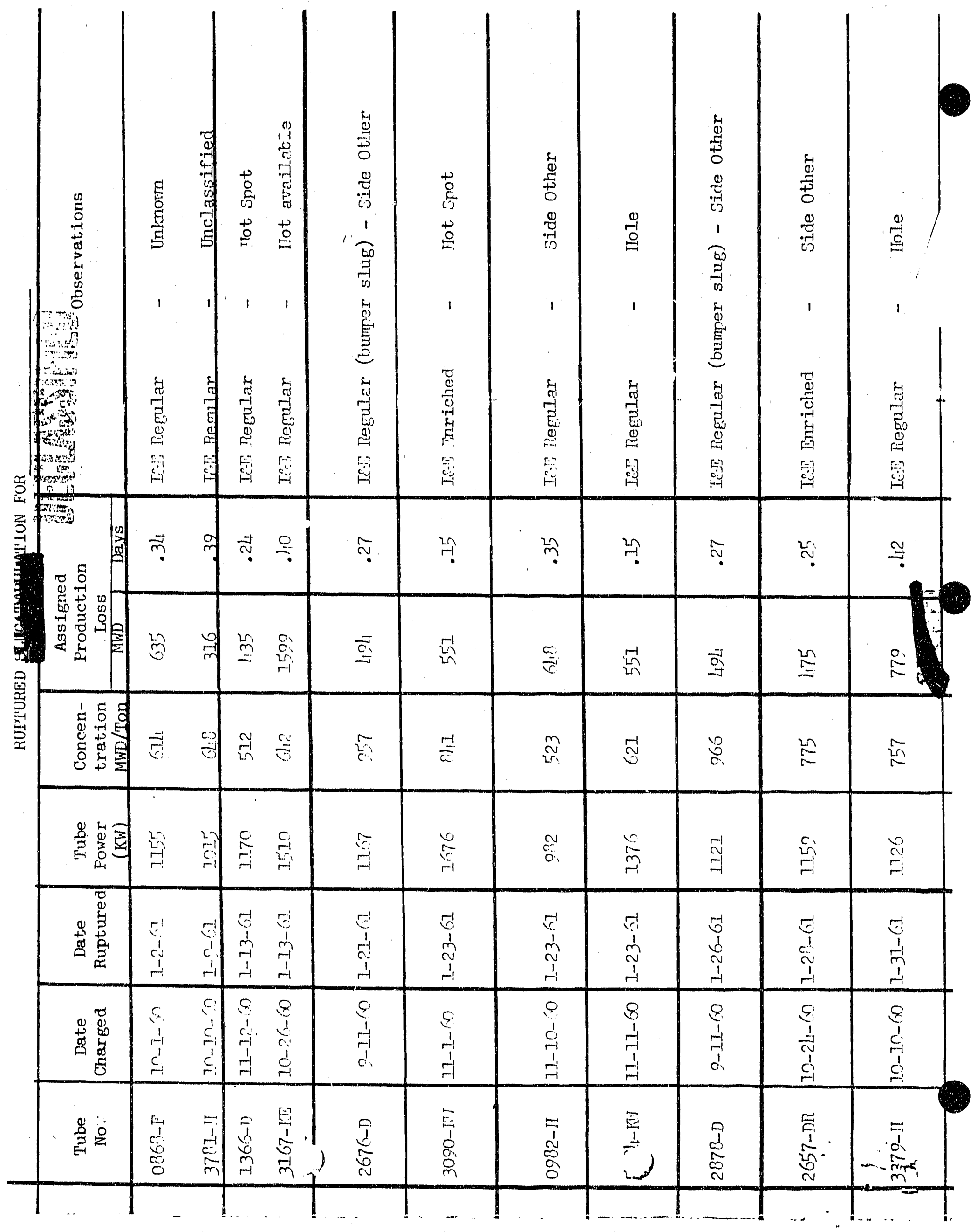




\section{serapound ronit no. Office Memorandum • united states government}

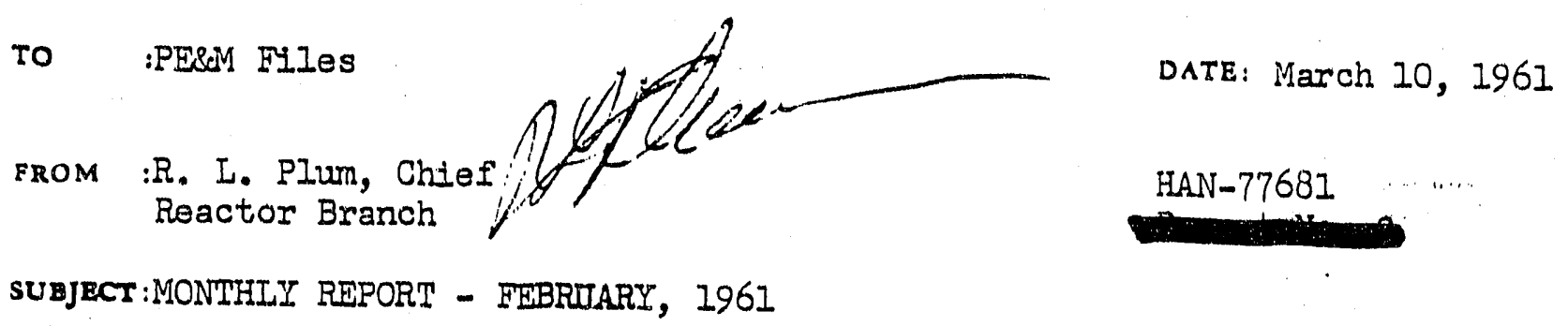

OR:GTO:GRG

THIS DOCUMENT CONSISTS OP 13 PAGES

OPERATING EXPERIENCE

Production

Reactor input production was $7.0 \%$ above forecast; $0.4 \%$ above at the six old reactors and $17.2 \%$ above at the $\mathrm{K}^{\prime} \mathrm{s}$. Forecast was exceeded at the K's due to high time operated efficiency and improved operating levels.

\section{Efficiency}

Over-all time operated efiliciency was $82.3 \%$ ( 82.3 forecast);

$80.0 \%$ at the six old reactors and $89.2 \%$ at the $K^{\prime} \mathrm{s}$.

Power Level

The combined reactor instantaneous power level was increased 275 megawatts $(18,950$ to 19,225$)$. The individual reactor record power. levels were increased 80 at KW (4000 to 4080 ), 75 at D (1840 to $1915), 70$ at $D R(1855$ to 1925$), 45$ at $C\left(2135^{\prime}\right.$ to 2180$)$ and 10 at $B(1860$ to 1870). A monthly production record was achieved at DR.

Power Level limit

During this report period the power levels of B, C, DR, F, H and KW reactors were limited by rupture control consideration and $D$ and KE (because of five-pump operation) by bulk outlet temperature restrictions.

Fuel Riptures

Six ruptures, three I\&E regular and three I\&E enriched, were removed from the reactors. Two of the I\&E rogular metal muptures were at $C$ and one at $B$. The three I\&E enriched ruptures were at
$D, H$ and $K W$. 


\section{MAINTENANCE AND EQUTPMENT TXXPRIENCE}

Tube Replacement

1. Fifty-three process tubes were installed; 26 at F, 15 at $\mathrm{H}$, 8 at $B, 3$ at $D R$, and one at $D$.

2. Three tube leaks and 10 Van Stone leaks were corrected. The tube leaks were at DR, F and H. Five Van Stone leaks were at $\mathrm{H}, 4$ at $B$, and one at $\mathrm{DR}$.

C Reactor VSR's

With the return of two VSR's to service during the month, only two VSR's continued to be inoperable, both because of blocked channels.

KER Frout and Rear Face Piping

Examination has been made of front-face piping removed from KER-3 loop (stainless steel) and of the front and rear face piping removed from KER-1 loop (carbon steel), to determine the extent of damage to the components from front and rear face water leaks. The stainless steel piping showed no significant damage; only a few minor indications of cracking were noted and these did not have the appearance of stress cracks. The carbon steel piping, however, was rather severely attacked. The exterior of the piping was roughened and severely marked with shallow pits. This attack presumably was caused by the water leaks elsewhere in the reactor. The interior of the carbon steel pipe was also pitted, the attack being more severe on the rear face than front face piping. This "interior" attack is attributed to operation with non-deoxygenated process water during several operating periods.

Rear-Face Crossheader Parker Fittings

The failed Parker fittings from tube 2561-B have been examined. Metallographic examination shows that the main break was due to fatigue, but multiple cracks starting from the roots of the threads show intergranular stress corrosion. Two recent failures have occurred in the 400 series stainless steel nuts on Zone Temperature Monitor Y-Adapters; one in 105-B and one in 105-D. Examination of these fittings is under way.

Currently a program is being developed to provide in-place nondestructive examination of Parker fittings. Criteria have been written to guide the development of suitable equipment for repairing failed Parker fittings. 
Files

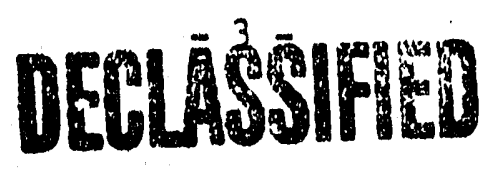

March 10, 1961

190-K Pump Failure

The third generation high-lift impeller installed January 14, 1961, in the 190-KE Main Pump House operated satisfactorily until

February 1, 1961, at which time the inboard impeller wear ring failed. This failure caused rather extensive damage to the case and wear ring on the suction side of the pump. Repalrs were made and the pump was returned to service on Febmary 14.

REACTOR OUTAGES

Date Date Outage

Down Up Hours Remarks

B REACTOR

$2 / 21 \quad 2 / 25 \quad 98.9$

Removal of an I\&E regular metal mupture from tube 1686. Charge-discharge and miscellaneous maintenance.

C REACTOR

$2 / 2 \quad 2 / 4 \quad 49.1$

Removal of an I\&E regular metal mupture from tube 3275 . Charge-discharge and miscellaneous maintenance.

$2 / 25 \quad 2 / 28 \quad 78.5$

Removal of an I\&E regular metal mupture from tube 2361. Charge-discharge and miscellaneous maintenance.

D REACTOR

$2 / 12 \quad 2 / 17 \quad 108.4$

Removal of an I\&E E-metal rupture from tube 4072. Charge-discharge and miscellaneous maintenance.

DR REACTOR

$2 / 2 \quad 2 / 4 \quad 38.1$

Tripped by the gas loop when cooling water pressure to the heat exchanger was lost. Miscellaneous maintenance performed. 
Files

$$
-4 \pi
$$

March 10, 1961

F REACTOR

$\begin{array}{lll}1 / 29 & 2 / 1 & 75.9 \\ 2 / 15 & 2 / 18 & 87.0 \\ 2 / 19 & 2 / 22 & 62.2 \\ 2 / 28 & \text { Sti11 down }\end{array}$

H REACTOR

$\begin{array}{lll}1 / 31 & 2 / 1 & 37.9 \\ 2 / 5 & 2 / 10 & 177.5 \\ 2 / 11 & 2 / 11 & 0.3\end{array}$

$\begin{array}{lll}2 / 12 & 2 / 14 & 41.9\end{array}$

$2 / 20 \quad 2 / 22 \quad 66.2$

Scheduled charge-discharge and tube
replacement. Leak testing, charge-discharge and tube
replacement. Leak testing. Water leak. Charge-discharge and
miscellaneous maintenance. Charge-discharge and leak testing following
mupture removal. Water leak, charge-discharge and maintenance.
Installed 171 overbored nozzles. Repositioned front cap on tube 1155 that
was not fully engaged on lug rings. Removal of an I\&E E-metal rupture from tube 4773. Tube replacement and miscellaneous
maintenance. Leak testing.

KE REACTOR

$\begin{array}{lll}2 / 1 & 2 / 3 & 47.8\end{array}$

$\begin{array}{lll}2 / 23 & 2 / 25 & 53.0 \\ 2 / 25 & 2 / 25 & 2.2 \\ 2 / 25 & 2 / 25 & 0.3\end{array}$

Repair of No. I high-lift pump (wearing internal damage toced, causing some internal damage to the pump) and charge-
discharge. Scheduled charge-discharge. A $1500 \mathrm{~h} . \mathrm{p}$.
motor was installed for $\# 5$ low-lift pump. Low pressure Panellit trip on tube 4665 . Panellit trip.

KIV REACTOR

$2 / 17 \quad 2 / 13 \quad 41.5$

Removal of an I\&E E-metal rupture from tube
1686. Charge-discharge and matntenanoe DE6 (4. 
RESEARCH AND DEVELOPIENT - EXISTING REACTORS

Rear Face Connectors

Samples of the flextble hose-type connectors being developed by the Materials Development Operation have been received from the vendor. Laboratory flow and vibration tests are scheduled, and a production test has been prepared for on-reactor testing of the connectors.

Remote Rear Face and Operational Charge-Discharge

On February 23 an attempt was made to discharge two tubes through remotely operated flapper caps at KE Reactor during operation simulating the operational discharge of ruptures. The test was performed according to Production Test $I P-372-K$ and was scheduled about one hour prior to a scheduled reactor shutdown. The first tube discharge was fully successful, but when the second discharge was attempted the downstream dummy slugs bridged the gap between the discharge actuator slug guide and the nozzle, and blocked the further ejection of the charge. The exact problem was not identified, since the water being ejected fogged the television picture. The bridge remained after a five-inch upward movement of the rear elevator but was broken by a smaller lateral movement of the actuator. The reactor was shut down normally and the second channel was discharged with the reactor not operating.

During the KE outage following the discharge test referred to, 67. new ball caps were installed on the reactor. There are now 67 flapper valves and 80 ball. valves; most of the latter are not equipped with actuating handles and are installed for seal tests only. Some are equipped with messenger slug seals intended to back up the ball seal with a one-use type of seal.

Process Elevator Study

Preparatory work for the weighing of front-face (charge) elevators is now in progress. Building structural prints have been reviewed, area sites have been studied, and footings have been designed for use with previously purchased compression-type weighing equipment. Material, and installation costs of these footings are being assembled. A cost comparison with the purchase value of tensiontype welghing equipment will bs made to establish the more economical approach to the elevator weighing problem. 
Process Water High-Tank Maintenance

At the request of representatives of Applied Reactor Engineering and Process Technology, recomendations for rehabilitation of the 190 storage tanks and 105 Bullding high-tanks were issued, based on a summary of current observations. Although no definite Iife expectancy can yet be assessed, it is recommended that action be taken within the near future to safeguard remaining tank life and water quality. Painting is recommended for the 190 Building tanks; an alternate recommendation for the high tanks is sand-blasting and use of an inhibitor if the cost can be reduced by recovery or re-use. The latter appears at present to be feasible, but an economic comparison has yet to be made.

Fuel Geometry Studies

The effects on tube flow of adoption of K-IV and O-III fuel elements have been studied. Adoption of $K-I V-N$ elements vice the $K-I I I-N$ elements will result in a flow increase of about $1.1 \%$; adoption of $K-I V-N B$ element vice the $K-I I I-N$ will result in about a $2.2 \%$ flow decrease. The thermal hydraulic characteristics of the 0-III-NB are identical to those of the O-II-N; however, the O-III-NB gives a net reactor flow reduction of $2.5 \%$ below the O-III-N, a flow loss which could be regained by a 0.004 -inch reduction in fuel OD.

Self-Supported Fuels

No unusual irradiation experience was noted from the eighty columns of self-supported fuel. charged into $B$ and $C$ Reactors. Nine tubes were recharged during the report period, seven at $C$ and two at $B$.

Bumpered Fuel Failures

Two bumpered fuel failures occurred in January at D Reactor. Both failures were natural uranium elements of the three-rail design, O-II-N model. The first failure occurred in tube 2676-D on.1/21/61 at an exposure of $957 \mathrm{MWD} / \mathrm{T}$ and the second in tube 2878-D on $1 / 26 / 61$ at $966 \mathrm{MND} / \mathrm{T}$. Both failures were classified as "side other" upon visual examination in the $D$ Reactor viewing facility. Failure positions were five and six, respectively, from the downstream end of the charge and both occurred in new tubes which did not have water mixer elements in the charge makeup. Neither failure had a hot-spot corrosion pattern, but each was associated with a hot area at the top outer surface. Fourteen columns of bumpered fuel charged on the same date as the two ruptures were discharged along with the second failure on $1 / 26 / 61$. This metal is presently being visually examined at the 105C Metal Examination Facility and consists of six. charges of three-rail and eight charges of four-rail material. There are 80 colums of four-rail O-II-NB remaining in D Reactor under PT authorization. 


\section{MISCELIANEOUS PROGRAMS}

Optimization of Power-House Function in Support of Reactor Safety

A preliminary survey of the 184 boiler controls was made by Power Consultant Vieller Reed and Instmument Consultant H. T. Sawrer. Mr. Sawyer is preparing a recommendation for modification to the controls to permit study of lower boliler loads. The proposed installation of auxiliary oil bumers was also discussed with these consultants.

Complaints by $F$ and D-DR Power Operations regarding the size consist of coal from one of our vendors prompted a close inspection of both the coal and the reports of screen analysis at the 200-iv sampling station. The uniform size consist of coal received from this vendor during FY-1960 was compared with the size consist of shipments during FY-1961. This showed considerable deficiency of the 3/4" $x$ No. 8 size (domestic stoker size) in the FY-196I shipments. In some cases this deficiency was 50\%. Improper firring was reported due to this characterlstic of the coal. Appropriate recommendations have been issued to make initial corrections, and a review of coal. specifications is under way to determine the best approach to recover the previous high coal quality.

\section{Water Soluble Coatings on Fuel Elemonts}

Data have been analysed from production test (IP-308-A) which was conducted to evaluate water soluble coatings for fuel elements. The conclusions are:

1. The coating protected the elements from mechanical damage.

2. The coating was washed away before reactor startup; the use of the coating caused no apparent increase in effluent activity.

3. Both coated and uncoated elements used in the test were normal in appearance after discharge. The coating had no significant effect on corrosion weight losses.

Use of Nitrogen in KE Reactor

Samples of condensate from regeneration of the silica gel dryers at $\mathrm{KE}$ and at other reactors not using the helium-nitrogen atmosphere are being analysed for nitrate content in an effort to deternine whether use of nitrogen in the reactor gas is apt to increase corrosion rates of reactor hardware.

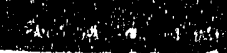


Comparison of One-out-of-two and Two-out-of-three Trip Logic in Becloman Monitor

The reasons for requiring a $2-0 f-3$ trip instead of a $1-0 f-2$ trip on the Becloman neutron monitors are as follows:

$\begin{array}{ccc}\text { Irip Logtc } & \text { False Scrams/Month } & \text { Figure of Merit } \\ 1-0 f-2 & 0.50 & 9.7 \times 10^{6} \\ 2-0 f-3 & 8.4 \times 10^{-6} & 3.24 \times 10^{6}\end{array}$

The figure of merit which is the ratio of true scrams obtained to one tme scram not obtained is the measure of protection. Although the I-Of-2 loglc wlil catch more scrams, the probability of missing one is still small. The great difference in false scram rate hardly fermits operation with the 1-of-2 logic. The figures quoted are based on current fault rates and testing intervals.

\section{Columbia River Studies}

A review of the axtificial cooling program of the Columbia River by dam regulation was completed during the month. It indicated that the 1960 program continued to be effective in producing significant benefits tu Hąnord.

Unusually high early run-off has maintained river flow at 80 100,000 cfs as compared to an average of 62,000 ofs for the 1943-1957 period. The water temperature out of Coulee has dropped to $3.4 \mathrm{C}$ as of February 27.

By securing cooperative help from the various Public Utilities Districts and govemment agencies operating dams above HAPO, it was possible to control and reduce river flow so that gravity siphons at $181-B$ and $C$ could be installed.

The latest snow cover reports still indicate lower than normal water supplies this year; 20,\% below normal in the Columbia Basin area and as much as $80 \%$ below normal in the Snake-Intermountain area. 


\section{REACTOR MODIFICATION PROGRAM}

\section{Overbore Process Th bing}

Allegheny Ludlum - Tube Reducing - Nine smooth-bore Zr-2 tubes have been recelved from this order. Three have been installed the remaining tibe, which was not three are being flanged, and being used for charging tests.

Alcoa - Thirty-five acceptable smooth-bore alumirum tubes have

Reyplilds Metals, Inc. - Thirty-seven smooth-bore aluminum and bes arrived on $2 / 21 / 61$.

Reactive Metals, Inc. - Twenty-one Zr-2 extrusions have been fabrioated and are ready for "rocking" to tubing.

\section{Orerbore Fuel Performance}

The three columns of $C-\sqrt{I}-N S$ (overbore fuel elements) charged into $C$ Reactor on $1 / 17 / 61$ are still performing satisfactorily. The average accumulated exposure is about $34 \mathrm{MWD} / \mathrm{tube}$ as of

\section{K Reactor Hardware}

A study has been initiated to evaluate methods of modifying the use of bumper fuel tube assemblies on a $K$ reactor prior to the These are: 1) ream existing nozzlethods are being considered. sleeve, and 2) replace existing noz and install a roinforoing f'or use with bumper fuel elements and with new nozzles designed use of self-supported fuel ellements.

Budget Studies

Budget studies concerning: 1) coolant backup, earthquake and bomb blast; and 2) Reactor Modification Programs at $C$ and $K$ Reactors have been completed. Coolant backup Lmprovements and Improvement Program for the reactors consistent with the Plant Modification Program zirconium tubes in existin Reactor recommends the installation of for the program at both reactors channels. The estimated cost payback period of 1.2 years. Th $\$ 15,300,000$ and indicated a 


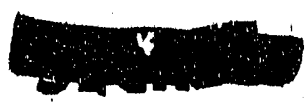

$-10-$

March 10, 1961

recommerided installation of oversize zircontum tubes in overbored process channels and expansion of the water plant to $115,000 \mathrm{gpm}$. The pilyout period for this program was approximately 1.7 years aqr. cost an estimated $\$ 14,000,000$.

\section{Tube Insertion Problems}

Short range solutions have been developed, and longer range solutions are in progress, for the tube insertion problem which was encountered on the three-tube overbore test at $c$. Reactor. It has been found, however, that the $C$ problem is partly related to the distortion of the channels; that a zirconium tube with 80 mils clearance requires about 450 poinds for insertion, after broaching, in a top-center $O$ channel; and an aluminum tube which has 20 mils clearance in the same chaninel diameter required 5300 pounds. These figures compare with four to five thousand pounds now required for insertion of standard size aluminum tubes. It follows that hand insertion of the tube, as attempted on the last outage, is not feasible, and tubes will have to be forced in the normal way.

C Overbore Hardware

Because $C$ Reactor went down 30 hours ahead of schedule on February 25, the planned overbore outage of February 27 was deferred one week. During the outage, however, it was found that the flapper safety checks in the overbore front nozzles had vibrated loose from their kinges and that in at least one case the hinge pin was broken. The design is such that the loose flapper is unable to block flow into the tube, so no flow stoppage was encountered, but the nozzle had to be removed in order to discharge the overbore tube (charge) scheduled for removal. All of the overbore nozzle flappers were removed until. design features correcting the problem can be incorporated.

\section{NEW PRODUCTION REACTOR}

Fuel Testing

KER-I - The ten nominal N-I-NI (NPR inner fuel tubes) elements charged on $12 / 8 / 60$ to evaluate different heat treatments have reached an exposure of $640 \mathrm{MWD} / \mathrm{T}$ without incident.

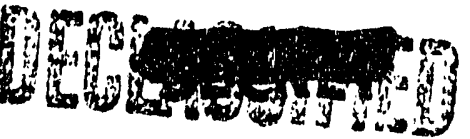


KER-2 - The four KSE3 (KER-sized simulator for the NNR outer tubes) elements charged on $11 / 11 / 60$ have reached an exposure of $1945 \mathrm{MND} / \mathrm{T}$. This test will be discharged at around $2000 \mathrm{inD} / \mathrm{T}$ to permit examination of the elements.

ISER-3 - The four ISSE3 elements charged on 12/15/60 have reached an exposure of $1440 \mathrm{MWD} / \mathrm{T}$.

KER-4 - Visual examination of the four KSE3 elements discharged on January 14, 1961, at an exposure of $1190 \mathrm{MWD} / \mathrm{T}$ in the 105-KE viewing basin and in the radiometallurgical lavoratory (one element) disclosed no obvious braze attack, warping or bumping. Sectioning will be delayed until the gamma activity has decayed further. KER-4 was recharged with four 24-inch NINI elements on $1 / 1 / 4 / 61$. These elements, which represent the first irradiation of an actual NPR inner fuel tube, have reached an exposure of $450 \mathrm{NWN} / \mathrm{T}$.

\section{Process Tubes}

Harrey Aluminum Company has delivered 313 tubes on the production order. The vendor has produced 9 out of 19 tubes on the pilot order which meet all speciflcations except the ID. 


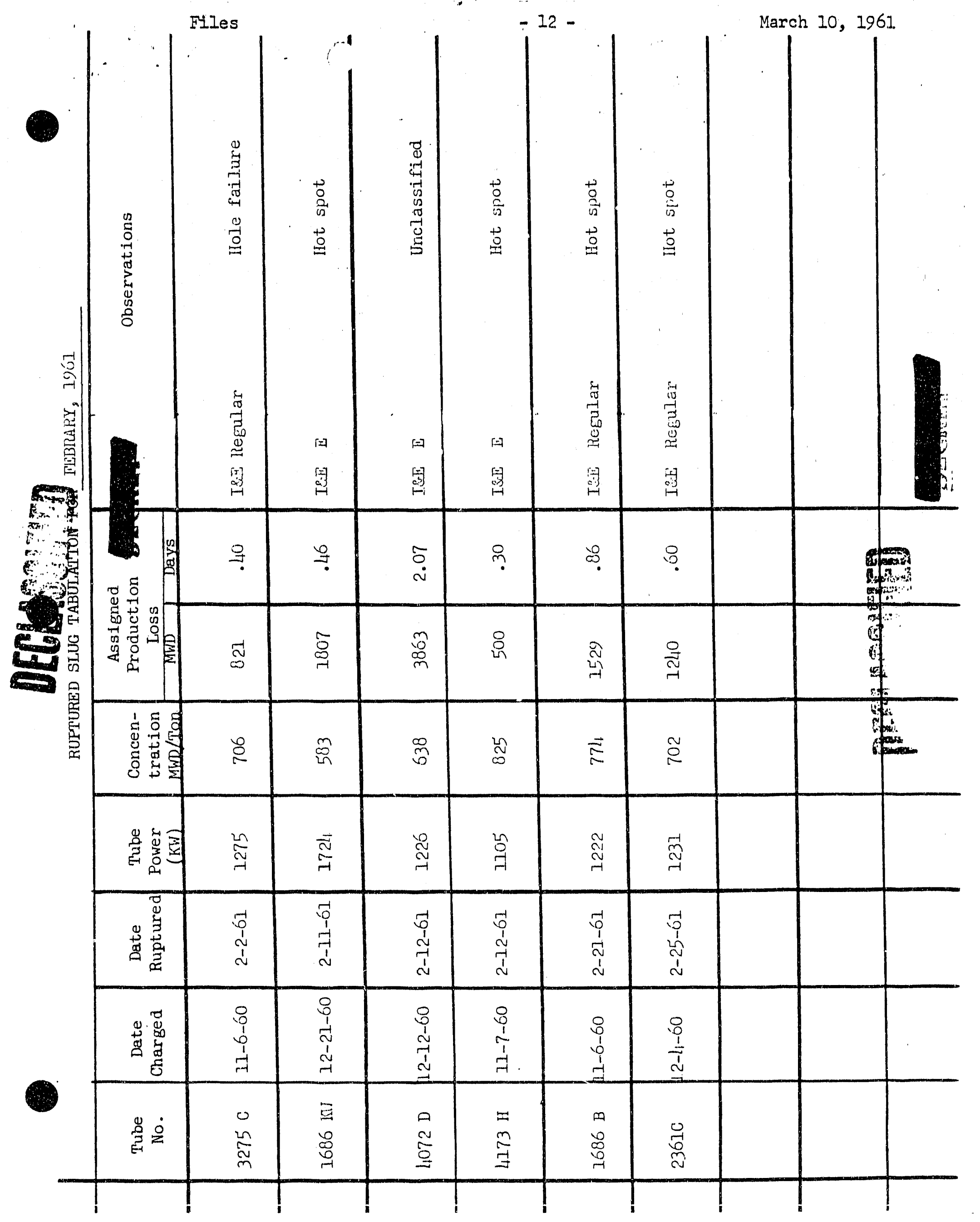




$$
\begin{aligned}
& \therefore \text { Flles } \quad-13-1 \cdots \quad \text { March 10, } 1961
\end{aligned}
$$

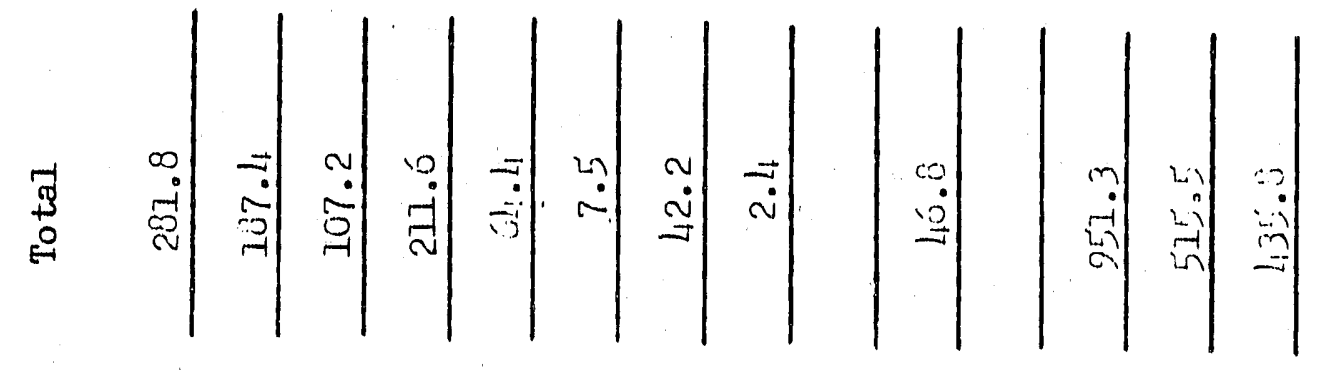

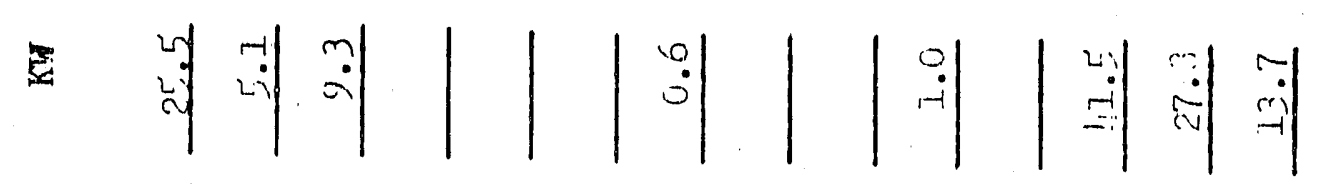

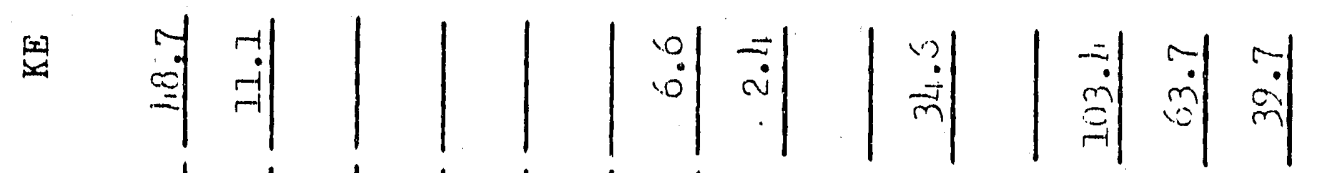

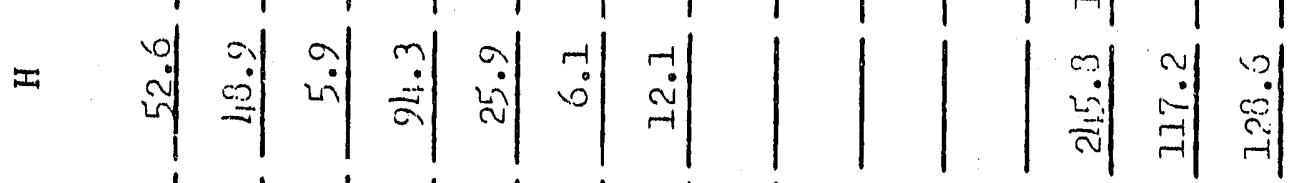

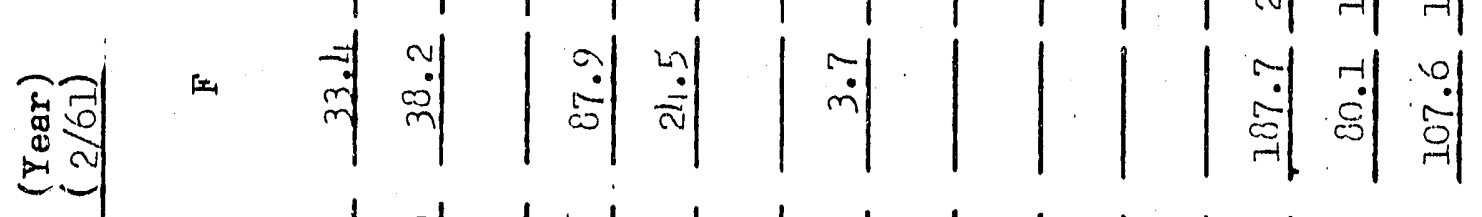

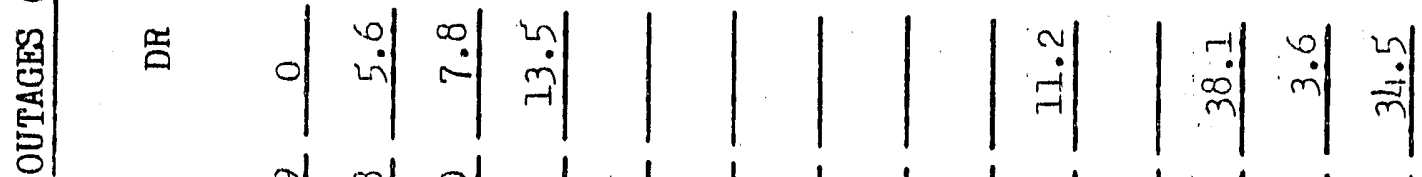

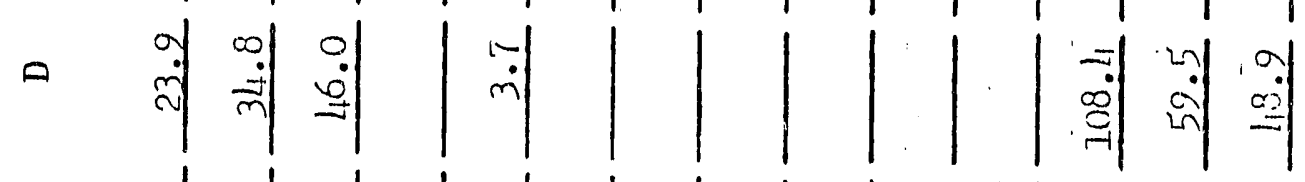

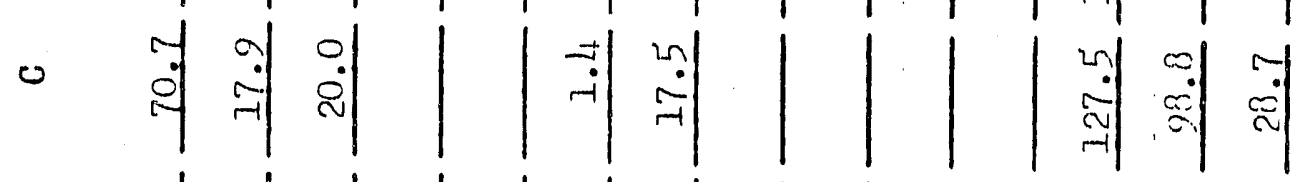

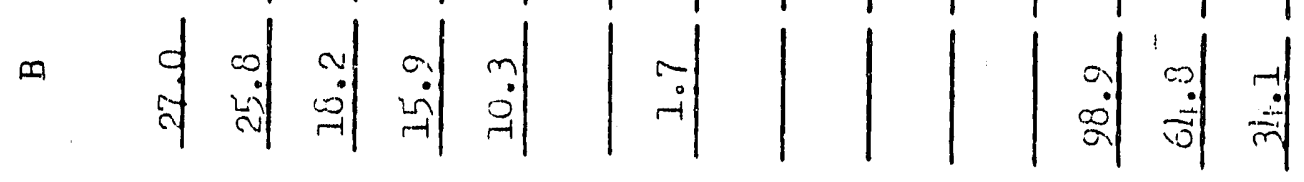

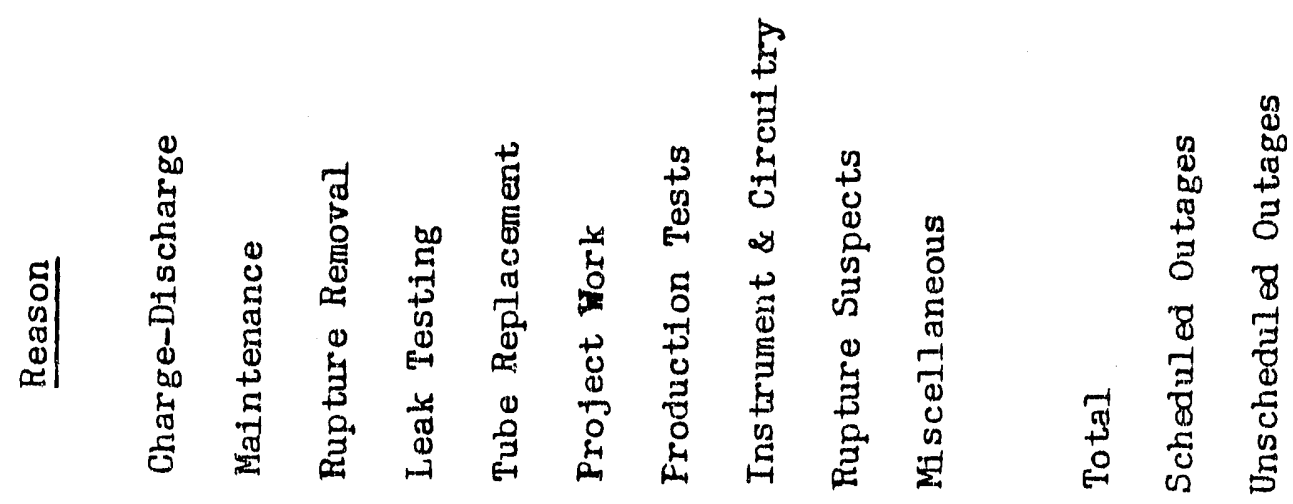




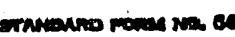 Office Memorancuctumboint}

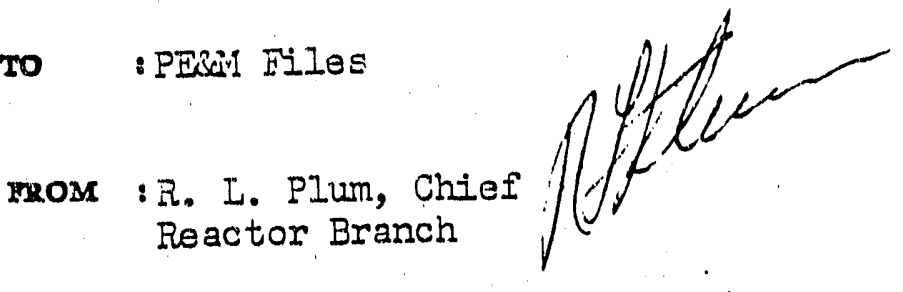

SUPJECT: MONTHLY REPOET - MARCH, 1961

OR:GTO:GRG
DATE: Apri1 10, 1961

HAN-77681

THIS DOCUMENT CONGISTS OF 14 PAGES

\section{OPERATING EXPERIENCI}

Production

Reactor input production (IN) was $2.1 \%$ below forecast; $0.1 \%$ above at the six old reactors and $5.3 \%$ below at the $\mathrm{n}^{\prime} \mathrm{s}$.

\section{Efficiency}

Over-all time operated efficiency was $75.9 \%$ ( $81 \%$ forecast), $76.7 \%$ at the six old reactors and $73.3 \%$ at the $K^{\prime} s$.

\section{Power Level}

The combined reactor instantaneous power level was increased 365 megawatts $(19,225$ to 19,590$)$. The individual reactor record power levels were increased 85 NW at $F(1850$ to 1935); 55 at $H$ (1900 to 1955); 55 at KE (4030 to L085); 35 at Kii (4080 to 4115); 30 at D (1915 to 1945$)$; and 25 at B (1870 to 1895$)$.

\section{Power Level Iimit}

Power levels were limited at all reactors during the month by rupture control considerations.

\section{Fuel Ruptures}

Twelve muptures, seven I?LE enriched and five Ifs regular, were removed from the reactors. Four of the enriched ruptures were at $\mathrm{H}$, two at $\mathrm{KW}$ and one at DR. Two of the regular metal muptures

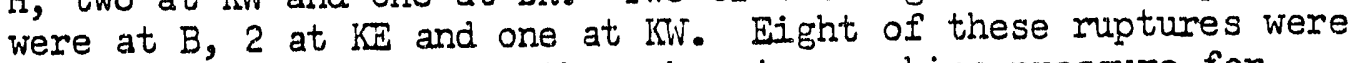
stuck, requiring greater than charging machine pressure for removal.

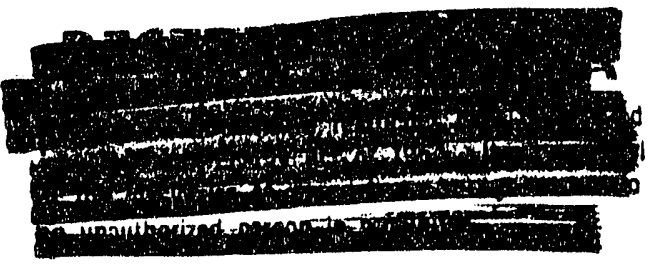




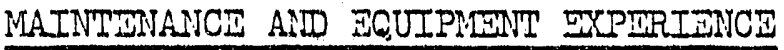

Tube Reolacement

Sixty process tubes were instalied; 44 at F, 7 at $B, 4$ at DR, 2 at $K E, 2$ at $K M$ and one at $\mathrm{H}$.

Five tube leaks and five Van Stone leaks were corrected. Three of the tube leaks were at $\mathrm{DR}$, one at $\mathrm{B}$, and one at $\mathrm{H}$. Four Van Stone leaks were at $B$ and one at $F$.

Rear-Face Crossheader Parker Fittings

Several rear-face crossheader Parker fittings recently have failed in the threaded section as a result of stress corrosion. The development of repair techniques has been initiated using Dresser service saddles with Parker-type fitting adapters. Arrangements also have been made to have the Equipment Development Operation develop tools, techniques and methods for pe rmanent repair of the Parker fittings.

4500 HP Motors

Three stators with modified Class A windings were installed during March. There are now eight Class $B$ and six modified Class A units in service. The vendor has elected to make power factor tests on completed Class A stators and has indicated the desire to make measurements of the six units already installed.

4500 HP De Laval Pumps

During a recommended inspection of sixteen of the De Laval impeliers in the CG-558 pumps, ten were found with one or more "tight cracks" in the blades. In view of the numbers of defects noted and the possibility of progress of these cracks, it was recommended that each of the units be given a Class A inspection. Related data is being collected. Two of the defective impellers have been returned to the vendor for evaluation.

Reactor Equipment Malfunctions

C-Reactor - More refined correlations between recent exposure history and measured cadmium burnout show that cadmium-113 on the tip of number $7 \mathrm{HCR}$ should be about 100\% burned out. Concurrentiy, it has been noticed that the reactivity effect re sulting from the movement of this rod indicates a very marked decrease in poisoning in the first 100-150 inches of rod insertion.

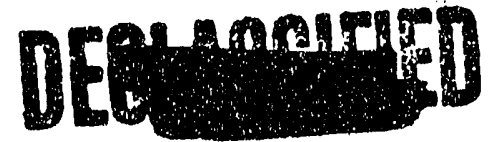


KE Reactor - With the return of number $17 \mathrm{HCR}$ to full operability only two rods now stick: HCR's 8 and 19 .

D Reactor - Three control instrument malfunctions required attention during the month: recalibration showed individual tube temperatures to be reading two degrees low, the motor on the 16-point tube outlet temperature recorder failed, and one of the subcritical monttor chambers persists in sticling.

KW Reactor - A subcritical moritor tailed on March 17; a new fission chamber was installed, returning the system to operability.

REACTOR OUTAGTS

Date Date Oatage

Down Up Hours

B Reactor

$3 / 1 \quad 3 / 3 \quad 41.2 \quad$ Leak testing and tube replacement.

$3 / 13 \quad 3 / 15 \quad 38.6 \quad$ Administrative.

$3 / 20 \quad 3 / 24 \quad 79.3$

$3 / 28 \quad 3 / 30 \quad 43.4$

C Reactor

$3 / 6-3 / 10 \quad 103.5$

$3 / 13 \quad 3 / 15 \quad 37.9 \quad$ Administrative.

$3 / 16 \quad 3 / 16 \quad 1.7$

$3 / 17 \quad 3 / 17 \quad 0.2$

$3 / 23 \quad 3 / 23 \quad 0.5$

$3 / 23 \quad 3 / 25 \quad 35.8$
Scheduled overboring of 13 channels.

Remarks

Removal of an I\&E regular metal rupture from tube 376/. Tube replacement and charge-discharge.

Removal of an ISE regular metal mpture fram tube 3362 .

Panellit trip due to a faulty rear connector: elbow on tube 1955 .

Unexplained trip on No. 1 Beckman while setting trip on No. 4 Beckman.

Manual trip to repair a rear pigtail leak on tube 1935 .

Manual trip due to flux imbalance caused by insufficient reactivity. Charge-discharge. 
Files

$\because$

D Reactor

$3 / 12 \quad 3 / 16 \quad 84.9$

$\begin{array}{lll}3 / 16 & 3 / 16 & 1.7\end{array}$

$3 / 28 \quad 3 / 30 \quad 40.0$

DR Reactor

$\begin{array}{lll}3 / 5 & 3 / 8 & 69.3\end{array}$

$3 / 13 \quad 3 / 15 \quad 38.9$

$\begin{array}{lll}3 / 28 & 3 / 30 \quad 38.3\end{array}$

3/3I Still down

F Reactor

$2 / 28 \quad 3 / 4 \quad 103.8$

$3 / 11 \quad 3 / 13 \quad 37.3$

$3 / 13 \quad 3 / 14 \quad 26.5$

$3 / 18 \quad 3 / 20 \quad 36.5$

$3 / 28 \quad 3 / 30 \quad 47.1$

H Reactor

$\begin{array}{lll}3 / 8 & 3 / 11 \quad 58.5\end{array}$

$3 / 13 \quad 3 / 15 \quad 32.3$

$3 / 15 \quad 3 / 15 \quad 0.2$
$-4-$

Apri1 10, 1961

\begin{abstract}
Scheduled charge-discharge.
Front cap leak on tube 2969.

Electrical trip caused by a constmction crane coming in contact with the $13.8 \mathrm{kV}$ line.
\end{abstract}

Removal of an IEI E-metal rupture from tube 1467. Charge-discharge and leak testing.

Administrative.

Tripped when a construction crane at is Area came in contact with the $13.8 \mathrm{iV}$ line.

Water leak.

Leak testing, tube replacement \& chargedischarge.

Charge-discharge and maintenance following a Panellit trip.

Administrative.

Charge-discharge following a Panellit trip.

Charge-discharge and leak testing.

Removal of I\&E E-metal mptures from tubes 2892 and 0571 and charge-discharge.

Administrative.

Low pressure Panellit trip on gauge 1484 
酒 Reactor (Cont'd.)

$\begin{array}{ccc}3 / 15 & 3 / 15 & 1.3 \\ 3 / 17 & 3 / 17 & 0.2 \\ 3 / 28 & 3 / 30 & 40.4\end{array}$

Rear pigtail adapter leak on tube 1484.

Unexplained Panellit trip on row 23.

Removal of an Iiet E-matal mupture from tubes 2991 and 0572, and charge-discharge.

IE Reactor

$\begin{array}{lll}3 / 8 & 3 / 11 & 72.3 \\ 3 / 11 & 3 / 11 & 0.5\end{array}$

Removal of an I\&E regular metal rupture from tube 2776 and charge-discharge.

Panellit trip on tube 4666 due to a plugged crossheader screen. Pieces of 0 ring were found on the screen.

$\begin{array}{lll}3 / 13 & 3 / 15 & 34.3 \\ 3 / 19 & 3 / 21 & 34.9\end{array}$

$\begin{array}{lll}3 / 21 & 3 / 21 & 0.5\end{array}$

$3 / 22 \quad 3 / 23 \quad 40.0$

$3 / 25 \quad 3 / 26 \quad 32.0$

$3 / 26 \quad 3 / 26 \quad 1.5$

IT. Reactor

$\begin{array}{lll}3 / 5 & 3 / 7 & 69.3\end{array}$

$\begin{array}{lll}3 / 8 & 3 / 8 & 0.5\end{array}$

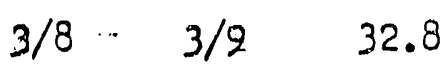

$3 / 10 \quad 3 / 11 \quad 33.9$
Administrative.

Removal of an I\&E - regular metal mpture from tube 5684 and charge-discharge.

Unexplained Panellit trip on row 56.

Tripped due to a leak on the heat exchanger outlet of loop. Replaced the shaft in No. 1 low-lift pump.

Panellit trip due to a faulty gauge on tube 5657 . Unexplained Panellit trip on Row 56.

Removal of an IfE regular metal rupture fron tube 4177 and charge-discharge.

Tightened loose orifice on tube 5655 .

Insufficient reactivity. Concluded tightening of loose orifice assembly and miscellaneous maintenance.

Removal of an I\&E E-metal mupture from tube 2178 and charge-discharge. 
Files

IN Reactor (Cont'd.)

$3 / 13 \quad 3 / 15 \quad 33.5$

$3 / 27 \quad 3 / 29 \quad 34.7$

$3 / 2 ; \quad 3 / 29 \quad 1.0$
$-6-$

Apri1 10, 1961

Administrative.

Removal of an Iid $\Xi$-metal rupture from tube 3183. Charge-discharge.

Unexplained Panellit trip.

ZESEARCH AND DEVELOPNUIT - IXISTING REACTORS

E-N Load

The fringe blanket portion of the $E-N$ loading at $H$ reactor has now been approximately one-third charged.

Analytical work has continued to better define the details of the E-N loading. For the initial 270-tube loading an E-IN length ratio of 19.3 to one has been chosen. This initial charge will provide a check on the predicitions and sufficient flexibility will be maintained in PCCF columns to handle any variation from the expected transiont.

E-N Loading and Overboring

Document HN-68697, "Comparative Return For Overbore and E-N Loadings - $B, D, F$, and DR Reactors," has been written and will be issued shortly. The results are sumarized below:

\section{Relative Returns for Overbore and E-iN Loadings}

Present Tuel Size

$\therefore \quad$ Base \& $\bar{D}-\mathrm{N}$ \&

Base Blanket Blanket

\begin{tabular}{|c|c|c|}
\hline Base & $\begin{array}{l}\text { Base \& } \\
\text { Blanket }\end{array}$ & $\begin{array}{c}E-N \& c \\
\text { Blanket }\end{array}$ \\
\hline
\end{tabular}

Pile Ave. Conv.Ratio

$1.146 \quad 1.185$

$1.308 \quad 1.336$

1.119

1.0

1.035

Daily ivet Return 
Bumper Fuel Develomment

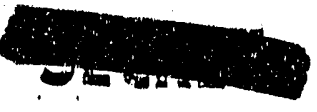

A total of 722 bumper fuel columns are charged Into D Reactor, including both natural and enrlched fuel elements.

Self-Supported Fuel Development

No unusual irradiation axpertence was noted from the self-supported fuel charged at $B$ and $C$ Reactors. Thirty-four columns were recharged during the report period ( 32 at $C$ and 2 at $B$ ). Goal exposures at $O$ are approximately $840 \mathrm{MmD} / \mathrm{T}$ and at $\mathrm{B}$ approximately $1200 \mathrm{iNT} / \mathrm{T}$.

Rear-Face Vibration $-B, D, D R, F$ and $H$ Reactors

Vibration of the crossheaders and thermally induced stress at the crossheader-riser joints are two major rear-face piping problems at the five older reactors. A test installation of crossheader. guides and flexible joints designed to alleviate these problems on No. 25 rear header at $H$ Reactor Indicates that the amplitude of low frequency vibration of this header has been reduced by at least 50\%. A comparison of strain data is not yet avallable. This prototype installation uses a joint composed of two Dresser couplings with a pipe spool piece between them. Grade A asbestosgraphite gaskets were used, with inspection planned after a period of service to assess their lntegrity under rear-face conditions.

Remote Rear-Face and Operational Charge-Discharge

Fifty-five ball and 64 flapper caps are now in service at KE reactor.

Two new balanced hydraulic chargjing machines have been received. Both machines perform satisfactorily with 20 psi tube inlet pressure, as well as at higher pressures. A side-opening, latching version of the machine is ready for testing as soon as the nozzle being made for use with it has been fabricated.

\section{Downcomer Studies}

Downcomer tray perforation at $105-B$ and $D$ made in September, 1960 for increasing hydraulic capacity was accompanied by pressure increases in the downcomer approach piping. Studies of the related hydraulics have not yielded conclusive explanations of all phenomena recorded; however, the alteration has significantiy reduced impulse stress in the downcomer structure. 


\section{Tube Conversion.}

Intial attempts were made during the week of March 20 to convert C Reactor-size $\mathrm{Zr}$ tubes to ii Reactor-size tubes. The resulting tube sections were of uniform wall thicioness and had acceptable surfaces, although the dimensions were slightly outside of speotflcations. This deficiency can be rectified by new tooling.

\section{Kr Reactor Cross-Tie Flow}

On Narch 16 a cross-tie flow at the $\mathbb{K}$ Reactor was measured with the orifice plates removed from the check valves. The result was in excellent agreement with the expected flow of $18,300 \mathrm{gal} / \mathrm{min}$.

\section{Export System}

Revised recommendations concerning the export system transient pressures when acting as a coolant backup supply were received from George R. Rich, under consultant agreement $\mathrm{CA}-262$. The revision recommendations include setting the surge suppressor trip pressures to permit tripping only when all. export system. pumps, or all but one pump, fall during normal operation. This new setting will be such that the suppressors will not be tripped by fatlure of one of the three available steam-driven export pumps during emergency operation. A suppressor trip at this time would reduce the system flow below the required flow rate.

Reactor Iffluent Activity Reduction

The results of radiochemical analyses of 105-C reactor effluent indilcate that reduced dichromate feed results in nearly proportional reduction of chromiun-5I concentrations. Some of the other radiomuclide activities seem to be reduced slightly also.

\section{REACTOR MODIFICATION PROGRAMI}

\section{Reactor Overbore}

Overboring at 105-C was terminated on March 9 with the installation of 13 of the 17 scheduled tubes. The outage was terminated due to the lack of manpower caused by unscheduled shutdowns of other reactiors.

Several problems were encountered which caused delays during the outage. These included: (1) mechanical failures of tri-bore machines; (2) aligning and operating welding equipment; (3) lack of training of operating crews; (4) general confusion caused by equipment on the elevatior; (5) lack of sustained vacuum during

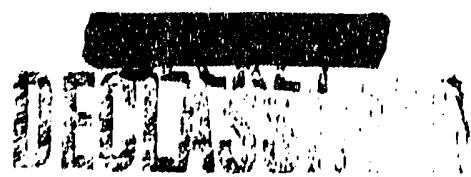


graphite boring. Steps have been taken to correct these deficienoles. Several sucoessful solutions to previous problems were demonstrated during the outage. The revised tri-bore machines were apparently successful in correcting the eccentricIty previously encountered between the counterbore and the origdnal graphite channel. Several times during the outage multiple operations vere performed successfu.ly on the elevators. Insertion of a tube in the channel with $20 \mathrm{mtl}$ clearance was successful when the channel was broached prior to tube insertion. Operation of the tri-bore machines was very encouraging after initial breakdowns.

\section{Reactor Mock-Up Facility}

A design study has been inltiated of a proposed Reactor Nock-Up Facility for use in developing overboring tools and procedures in support of the Reactor Modification program at 105-C Reactor. The proposed mock-up would include five tube rows consisting of crossheaders and reactor hardware, to be constructed in 186-D Bullding. Included within the five-row configuration will be approximately 30 process channels complete with graphite blocks, process tubes and overbore type hardware. A mock-up of the charge and discharge elevators would also be provided.

\section{Overbore Hazards Review}

A preliminary hazards review of the overbore reactor geometry is being made. Preliminary results include the fact that although flow characteristics are different in the overbore geometry the empirical model used to establish panellit pressures results in conservative settings. The margin between normal operation and sub-cooled burnout is increased in the overbore geometry as a result of lower heat flux and more positive fuel alignment.

\section{Overbore Fuel Development}

Thirteen columns of CVIN fuel elements were charged into C Reactor during the $3 / 6 / 61$ outage, bringing the total to sixteen. Six columns are equipped with downstream themocouple probes to monitor the fuel design adequacy. The sixteen channels are comprised of the following fuel-tube combinations:

Tube

Ribbed Aluminum

Smooth-Bore Aluminum

Smooth-Bore Zircaloy

\section{Fuel Type}

Bumpered ( $3 \mathrm{rail}$ )

Self-supported

Self-supported
No. Instrumentation

$22 \mathrm{~T} / \mathrm{C}$ Probes

$82 \mathrm{~T} / \mathrm{C}$ Probes

$62 \mathrm{~T} / \mathrm{C}$ Probes 


\section{Overbore Fuel Irradiation}

The first column of overbore-size self-supported fuel was discharged from 1494-C (smooth-bore zircaloy tube) on $2 / 25 / 61$ at an exposure of $168 \mathrm{MWD} / \mathrm{T}$. Post Lrradiation examination of the charge has been completed and the data are currently being processed for machtne analysis. The risual examination of the fuel elements revealed nothing unusual. The pleces exhlbited normal film patterns and scattered light corrosion pitting.

The next column tio be discharged is expected to reach 1ts goal of $400 \mathrm{i} \mathrm{ND} / \mathrm{T}$ about the end of April.

Two channels in the central zone were short-charged with 18 pieces of fuel and are expected to reach an $800 \mathrm{iniD} / \mathrm{T}$ goal in about three months.

The operating characteristics of both the original three and the additional 13 overbore-size tubes in $C$ Reactor are very nearly those expected. The maximum corrosion rate in the central hole of the short-charged, central zone tubes is calculated to be about $5 \mathrm{mils} / \mathrm{month}$. In the case of the ribbed tubes an observed "R" value of 1.24 compares with a predicted 1.20 , ("R" is the ratio of the maxdmum temperature increase in the annulus to the bulk water temperature increase in the tube).

\section{NEW PRODUCTION REACTOR}

\section{Fu.el Testing}

KER-I - The ten NINI elements (NPR inner element, normaI U) charged on December 8, 1960, to evaluate different heat treatments have reached an exposure of $885 \mathrm{kMN} / \mathrm{T}$.

KER-2 - The four ISSE-3 elements charged on November 11, 1960, to evaluate the behavior of elements simulating an NPR outer tube were discharged on February 23, 1961, at an expcsure of 1985 MID/T. Visual examination of the elements showed no obvious distortions or warp. The fuel element jackets had a light metalif appearance rather than the characteristic black oxide appearance observed on other $\mathrm{Zr}-2$ jacketed charges irradiated in pH 10 water. In addition, three elements had white discolorations of the weld beads. The loop was recharged on February 23, 1961, with four 23-inch NINI elements for evaluating NPR Inner tube behavior. These elements have reached an exposure of approximately $280 \mathrm{MND} / \mathrm{T}$.
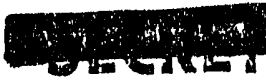


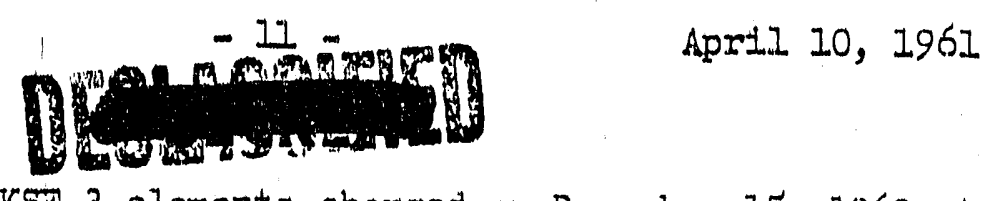

KCRR-3 - The four KSSE-3 elements charged on December 15, 1960, to evaluate the behavior of elements simulating an NPR outer tube have reached an expoaure of $2020 \mathrm{MWD} / \mathrm{T}$.

KER-4 - The four NINI elements charged on January 14, 1961 , have reached an exposure of $760 \mathrm{kWD} / \mathrm{T}$ (one of these elements failed on Apriz 8).

$$
\begin{array}{ll}
\text { Nomenclature: } & \text { KSE-3 - KER-sized single-tube enriched pleces } \\
\text { NINI - NPR-sized inner tubes natural uranium }
\end{array}
$$

\section{Effect of ivater Density on Reactivity}

Measurements of the IPR mock-up lattice parameters in the PCTR have been completed. The multiplication factor has been measured at effective water densities of .795 and .445 . Results to date are as fullows:

$\begin{array}{ccccc}\begin{array}{c}\text { Effective } \\ \mathrm{H}_{2} \mathrm{O} \\ \text { Density }\end{array} & 1.0 & 0.795 & 0.445 & 0.0 \\ \mathrm{~K} \infty & 1.075 \pm .002 & 1.065 \pm .003 & 1.043 \pm .003 & 1.015 \pm .002 \\ f & .879 \pm .003 & .893 \pm .003 & .914 \pm .003 & .941 \pm .003 \\ P & .829 \pm .007 & & & .717 \pm .011 \\ \in & 1.050 \pm .002 & & 1.076 \pm .003 \\ \eta(\text { derived }) & 1.406 & & & 1.396\end{array}$




\section{CONTAMINATION INCIDENT AT THE PCTR}

The experiment to determine the limiting critical concentration of a plutonium nitrate solution was begun in the PCTh, out it became necessary to temporarliy suspend the measurements because of a contamination incident on liarch 3 .

At the time of the Incident, a large buffer tank containing about 114 liters of plutonium solution was in position in the PCTR core. The contamination incident occurred when a smaliz end-buffer tank, which had developed a leak, was inserted into this larger buffer tank. Ore employae (physlcist) incurred some hand contamination, but decontamination was performed successfully.

The PCIR reactor room is in the final stages of being decontaminatad by personnel of Experimental Reactors Operation. Temporary wooden structures being used in the experiment that were contaminated and discarded are being replaced. The large buffer tank was removed. and decontaminated, and the smaller tanks, which were more highly contaminated, have been sent to the 23I-F Building for decontamination.

The contamination resulted because of both faulty construction of the tanks and improper 0-ring designs on the sealing plugs and end cap enclosures. The tank and jacket design indicated three separate leak seals - an 0-ring under the filling plug, another 0-ring under the cap that covered the filling plug assembly, and a taped seal around the foint where the jacket top overlapped the facket bottom. The first 0 -ring did not seal completely because of improper fabrication of the plug; the second O-ring did not seal properly because of incorrect design or cholce of O-ring material; and the taped seal around the two parts of the jacket either failed to stand up to pressura build-up in the container, or to the relatively large amounts of liquid present between the jacket and the tank wall. Modifications are being made in the end cap closure designs, fabrication and inspection, to correct defects in the overall sealing of these tanks.

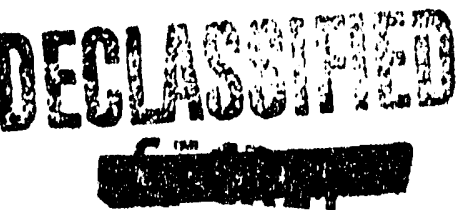




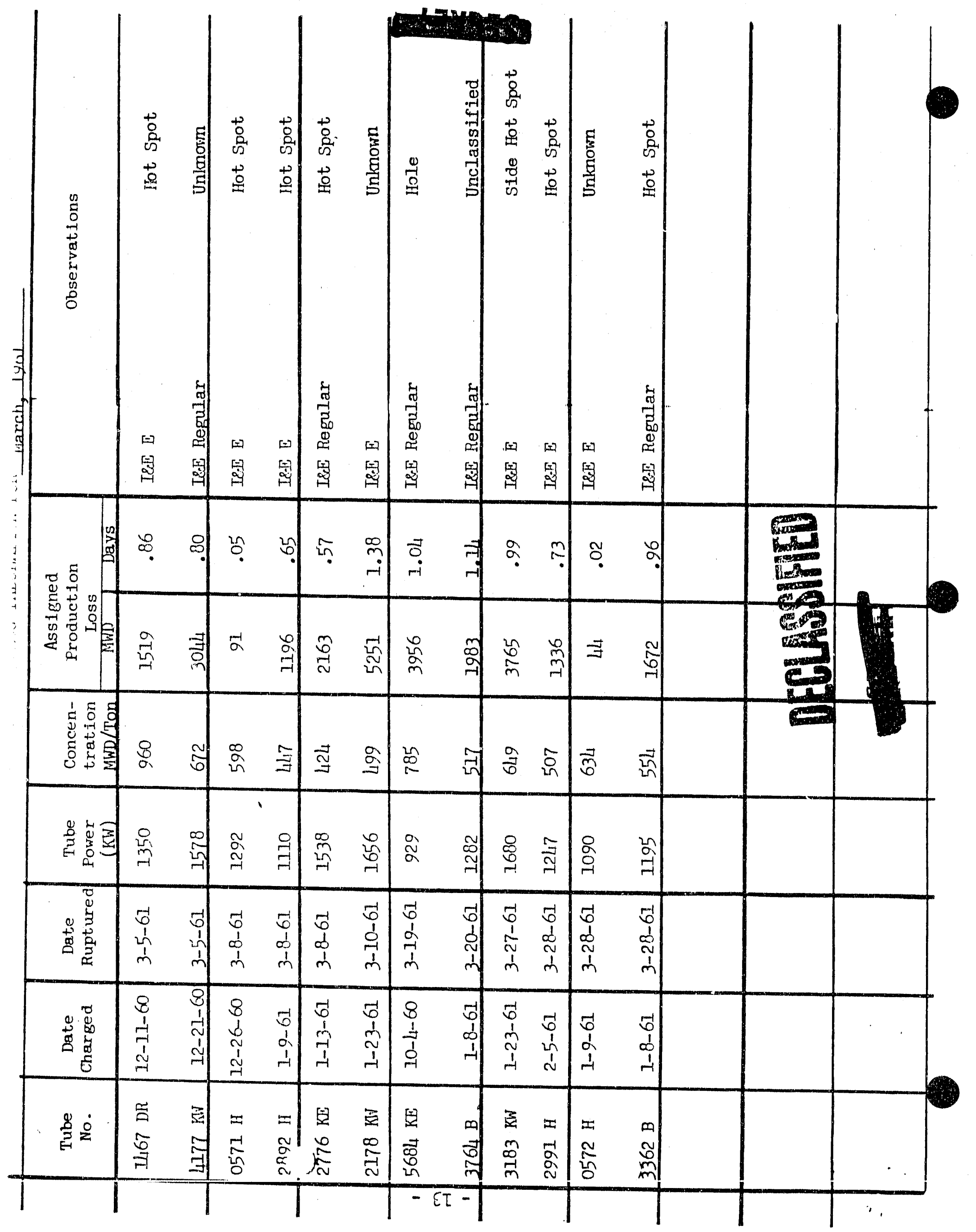




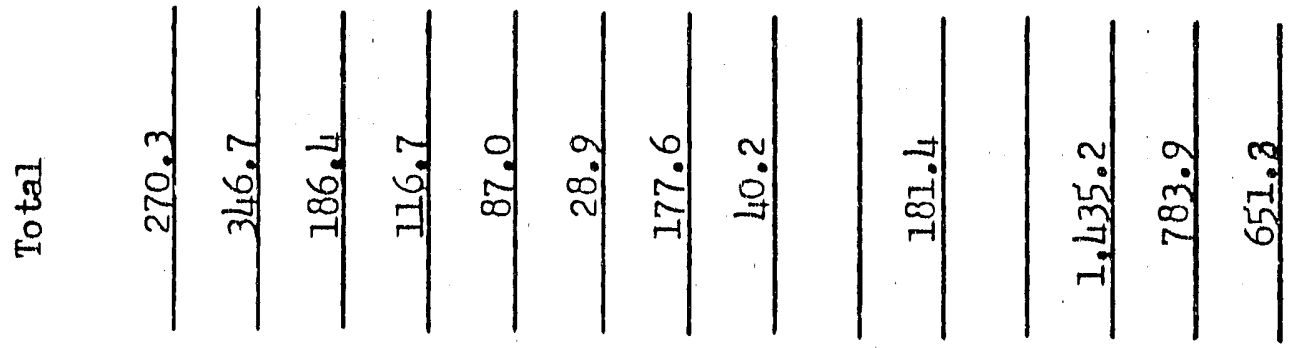

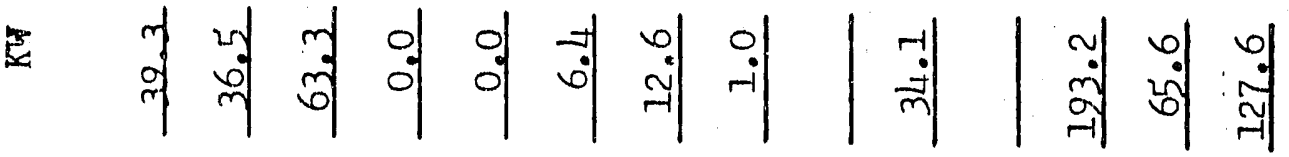

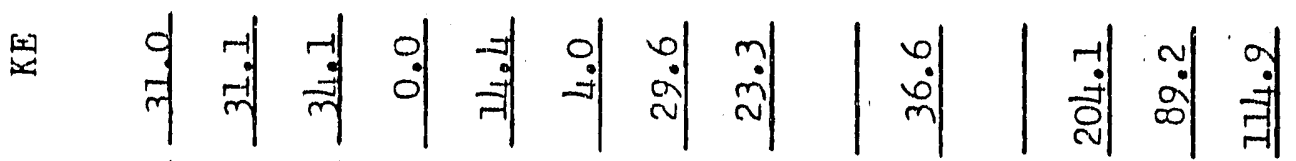

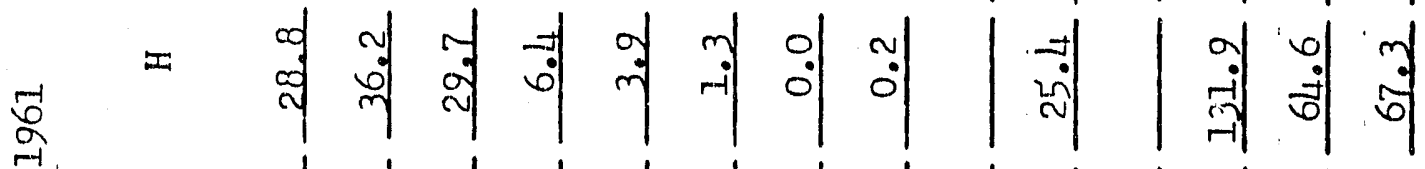

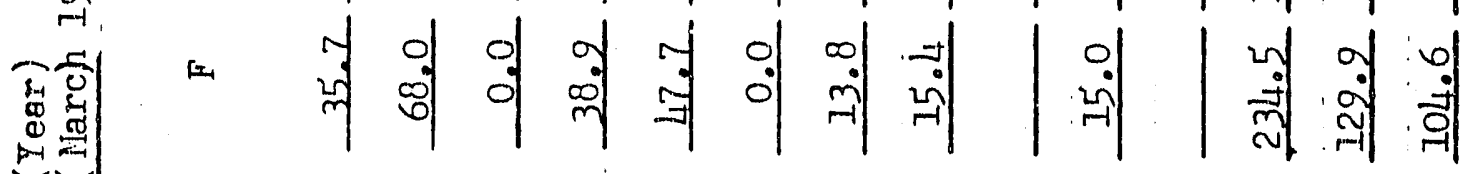

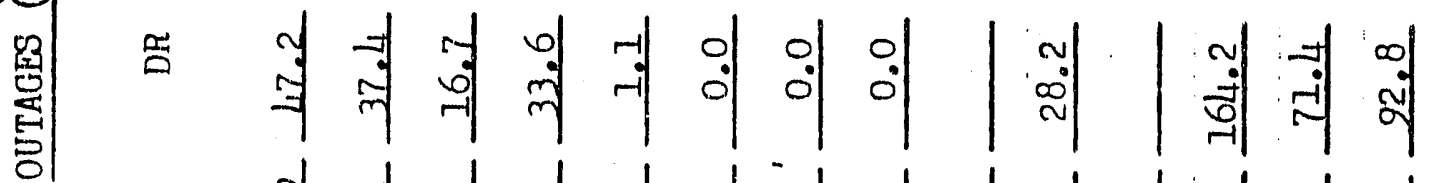

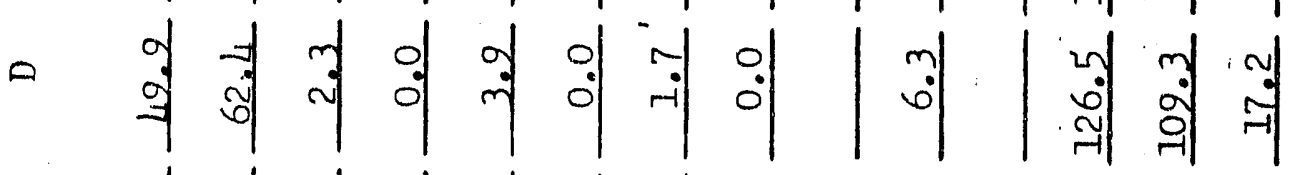

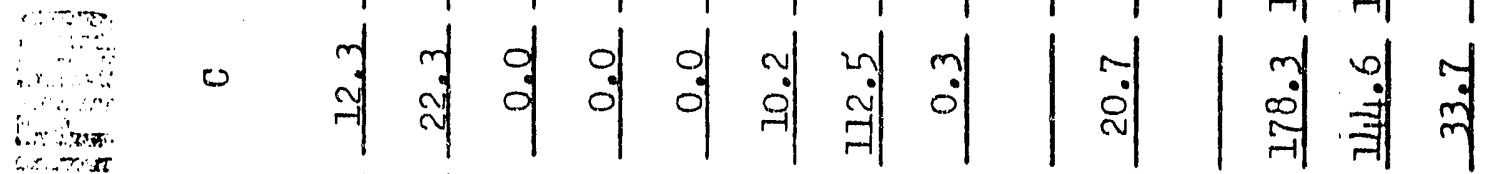

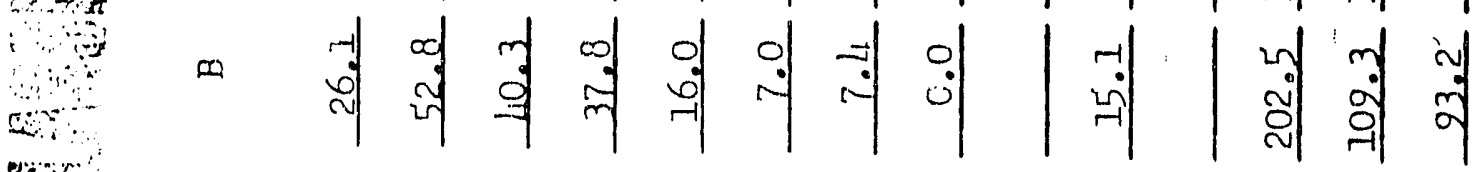

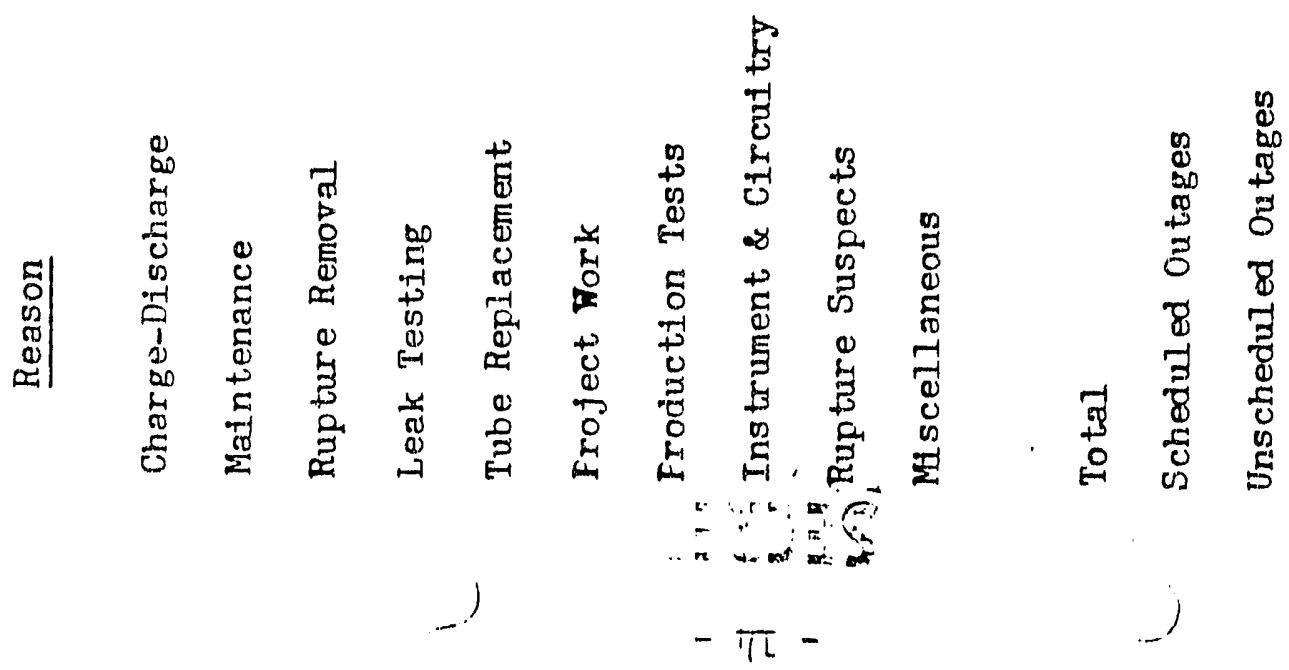




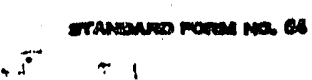

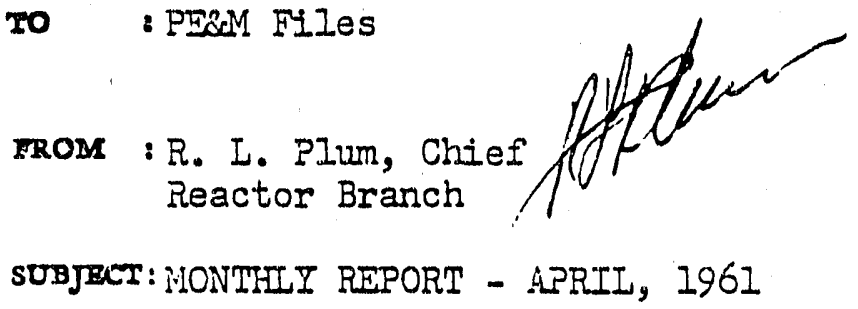

DATR: Lay 9, 1961

OR:GTO:GRG

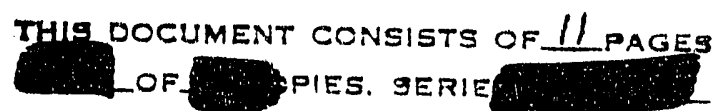

\section{OPERATTNG EEPERIENCE}

Production

Reactor input production (iND) was $2.1 \%$ above forecast, equal to forecast at the old reactors ard $5.2 \%$ above at the $\mathrm{K}^{\mathrm{P}} \mathrm{S}$.

\section{Efficiency}

Over-all time operated efficiency was $81.0 \%$ ( $82.3 \%$ forecast), $80.3 \%$ at the six old reactors and $83.1 \%$ at the $K^{\prime} s$.

\section{Power Level}

There was no increase in the combined reactor instantaneous power level or the individual reactor record power levels. Monthly production records were achieved at $B$ and $F$ reactors, exceeding their previous maxima by $0.4 \%$ and $7.4 \%$, respectively.

\section{Power Level Iimit}

During this report period the power levels, except at D Reactor, were restricted by rupture control considerations. D Reactor power levels were restricted by bulk outlet temperature.

\section{Fuel Ruptures}

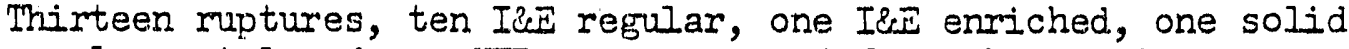
regular metal and one $\mathrm{KER}$, were removed from the reactors. Three of the I\&s regular metal ruptures were at $\mathrm{H}$, two each at $B, C$ and $D$, and one at KW. The I\&E enriched, the solid regular and the KER ruptures were at $K$.
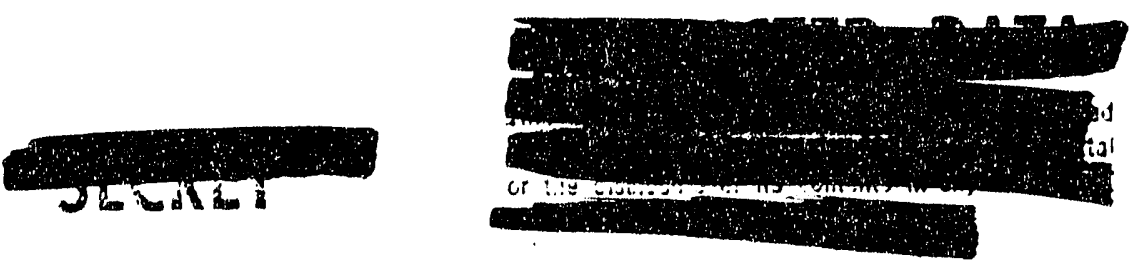
MAINTENANCE AND IQUIPIENT ERTPEITENCES

Tube Replacement and Viater Leaks

Seventy-three process tubes were insta.lled; 49 at DR, 11 at $B$, 9 at $D, 2$ at $F$, and one each at $K \Phi$ and $K I T$.

Twelve tube leaks and two Van Stone leaks were corrected. Seven of the tube leaks were at $D R, 2$ each at $D$ and $F$, and one at $H$. The two Van Stone leaks were at DR.

\section{Reactor Cadmium Control Rods}

In conjunction with the planned replacement of $C$ Reactor cadmium rods, a rod calibration test of the $\$ 7 \mathrm{HCR}$ indicated that it had lost about half its original reactivity strength, about what would be expected if the cadmium 113 were nearly 100\% burned out. Replacement of this rod and \#I and \#13 HCR's, which have been calculated to be nearing $90 \%$ burnout, is scheduled for ilay. Current plans call for the replacement of $\# 4$ and $\# 10$ rods within the next 3 or 4 months.

4500 HP De Laval Pumps

The recommended initial inspection of 32 of the subject impellers has been completed. The cracking tendency previously reported has been noted in 26 of these impellers. Three impellers in which the crack geometry indicated some potential for failure have been replaced and returned to the vendor. The inspections to date have indicated that the first-stage impellers, which according to the vendor are of a better quality than those in the second stage, show more cracks.

\section{Iar Connector Integrity}

Examination of the stainless steel front-face connector removed from KiR loop \#3 revealed significant cracks on the outside surface. The cracks are apparently stress-corrosion cracks that extend through a significant fraction of the tube wall. Since the other connectors on the loop have been subjected to the same service conditions as the one examined, early replacement will be made. In the interim, the pressures and temperatures of the stainless steel loops $(2,3$, and 4 ) have been reduced to the minimum practical values.

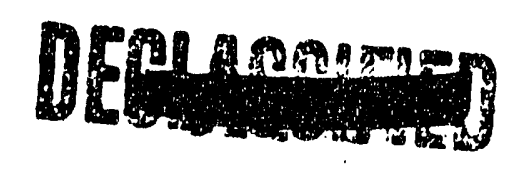


REACTOR OUTAGES

B Reactor

$\begin{array}{lccc}\begin{array}{l}\text { Date } \\ \text { Dow }\end{array} & \begin{array}{c}\text { Date } \\ \text { Up }\end{array} & \begin{array}{c}\text { Outage } \\ \text { Hours }\end{array} & \text { Remarks } \\ 4 / 6 & 4 / 8 & 37.5 & \begin{array}{c}\text { Removal of an I\&E regular metal moture } \\ \text { from tube } 3272 \text { and charge-discharge. }\end{array} \\ 4 / 22 & 4 / 25 & 75.4 & \begin{array}{r}\text { Removal of an I\&E regular metal mpture } \\ \text { from tube } 1065 \text { and charge-discharge. }\end{array}\end{array}$

C Reactor

$4 / 9 \quad 4 / 11 \quad 40.8 \quad$ Scheduled charge-discharge and overboring of channels.

4/17 4/19 36.6 Replacement of 24 cross-threaded front pigtails.

4/19 4/19 $\quad 1.0 \quad$ Panellit trip.

$4 / 214 / 23 \quad 34.2$ Removal of an I\&E regular metal rupture from tube 2269.

4/23 $4 / 23 \quad 1.3 \quad$ Leaking rear pigtail on tube 2264 .

4/30 Still down Removal of an I\&E regular metal mupture from tube 2270 .

D Reactor

4/6 4/6 0.2 Panellit trip; \#I pump at 190 burned out a coil.

$4 / 7 \quad 4 / 9 \quad 48.2 \quad$ Removal of an Ir.E regular metal mpture from tube 0893 and charge-discharge.

$4 / 9 \quad 4 / 9 \quad 0.5 \quad$ Stuck ball valve on a poison tube.

4/12 4/14 46.4 Leak testing. Replaced tubes 3477 and 3261 due to intemal leaks and seven additional process tubes. Miscellaneous maintenance. 
D Reactor (cont'd.)
$4 / 28 \cdot 4 / 30 \quad 57.8$
Removal of an I 30 regular metal moture from tube 0460 , changed 103 front nozzles, and charge-discharge.

DR Reactor
$3 / 31 \quad 4 / 2 \quad 42.6 \quad$ Leak testing.
4/4 4/6 52.2 Leak testing and tube replacement. tube, smali charge-discharge and maintenance.
4/14 4/15 $38.9 \quad$ Panellit trip due to a leaking Bourdon
$4 / 24 \quad 4 / 29 \quad 103.2$ Water leak in tube 2682. Block charge- discharge
4/30 4/30 $\quad 1.6 \quad$ Manually tripped for thermocouple repair.

F Reactor
4/17 4/19 51.5 Water leak and charge-discharge. Number 4 pump motor burned out.
$4 / 19 \quad 4 / 20 \quad 30$
Leak testing. Tube 2875 was replaced.
$4 / 30$ Still down
Repair rear pigtail leaks. Charge-discharge.

H Reactor
$4 / 4 \quad 4 / 6 \quad 49.4$
Removal of an IBE regular metal mupture from tube 2486 and charge-discharge.
$4 / 6 \quad 4 / 7 \quad 18.1$
Leak testing. Tube 2390 removed due to a leak, and channel blanked.
$4 / 24 \quad 4 / 25 \quad 44.1$
Removal of an I ceE regular metal rupture from tube 1989. Charge-discharge and installation of 165 rear pigtails and 178 broached front nozzles.
$4 / 26 \quad 4 / 26 \quad 6.7$
Removal of an I\&E regular metal rupture from tube 2857. 
KE Reactor

\begin{tabular}{|c|c|c|c|}
\hline $4 / 8$ & $4 / 10$ & 46.8 & $\begin{array}{l}\text { Charge-discharge following removal of } \\
\text { a NIy-1 mupture from iNR loop } 4 \text {. }\end{array}$ \\
\hline $4 / 10$ & $4 / 11$ & 22.4 & $\begin{array}{l}\text { Removal of an Ife E-metal mupture from } \\
\text { tube } 2461 \text {. }\end{array}$ \\
\hline $4 / 11$ & $4 / 11$ & 0.3 & Panellit trip. \\
\hline $4 / 19$ & $4 / 20$ & 34.1 & $\begin{array}{l}\text { Removal of a solid regular metal mpture } \\
\text { from tube } 5653 \text { and charge-discharge. }\end{array}$ \\
\hline $4 / 26$ & $4 / 27$ & 35.3 & $\begin{array}{l}\text { Charge-discharge and loop work following } \\
\text { a Panellit trip. }\end{array}$ \\
\hline
\end{tabular}

KW Reactor

4/16 4/19 69.8 Scheduled charge-discharge and maintenance.

$4 / 25 \quad 4 / 27 \quad 34.6 \quad$ Removal of an I\&E regular metal rupture from tube 504.5 . 
RESEARCH AIND DEVELOFIENT - EXISITNG REACTORS

Self-supported Fuel Development

No unusual irradiation experience has been noted for several months from the self-supported fuel charged at $B$ and $C$ Reactors.

The eleven-tube test facility at $B$ reactor (smooth-bore aluminum) will be closed out in the next few months due to tube corrosion.

Bumpered Fuel Develooment,

A total of 1,030 bumper fuel columns are now under irradiation at $D$ Reactor. Of this total 121 are enriched columns. The loading in D Reactor w111 be further expanded to cover the central zone over the next few weeks.

Bumper Fuel Charging lachine

The orototype bumper charging machine operated satisfactorily in tests without a fuel magazine at a rate of 42 strokes per minute. Extruded aluminum sections for fabrication of bumper fuel element magazines were received and one magazine fabricated. It will be used in further testing of the machine at higher charging rates.

Poison Spline Coilers

Spline coller installations are now complete at 105-F and $105-\mathrm{H}$, and 105-F personnel have pulled ten splines satisfactorily with their unit. It is expected that the 105-B installation will be ready for test early in May. Work was started at 105-DR, but has been delayed due to radiation conditions and an extended outage.

Operational Charge-Discharge

The program to develop an activator and valve that will permit remote opening of a rear tube closure continued. On test in the reactor are: (a) two ball caps supplied by vendors; (b) 53 HAPO-designed ball caos with 10 ring seals; (c) 63 flapper caps. There are also 30 ball caps and 25 flapper caps awaiting installation of new seals, and il ball caps ready for installation when convenient.

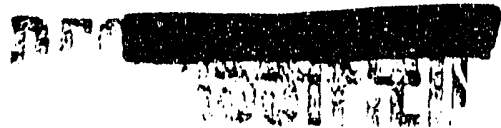


A prototype monitoring unit has been assembled which is intended to replace the Panellit function while oharging during operation. This device is designed to couple to a nozzle containing a flapper cap, monitoring the tube inlet pressure, and providing control and sequencing functions for the charger in a way that prevents procedural errors.

\section{Spline Monitoring}

It has been found to be f'easible to measure the activation contour of poison splines belng withdrawn from the reactor to give the front-to-rear neutron flux distribution in the reactor. Slug junctions are shown by breaks in the activity curve, and this fact eliminates the necessity for a motion recorder. Splinos can be monitored during reactor operation, after the reactor is shut down, or after the splines have been withdrawn for some time. For those monj.tored as they are withdrawn during operation, corrections to the readings must be calculated.

\section{Incore Flux Monitors}

Five aluminum in-core chambers failed to operate satisfactorily after they were installed in $k \pi$. The trouble is thought to be water in the connectors and cables, and efforts to dry these out are continuing.

\section{Rear-Face Connector Study}

A $3 / 4$ inch rear-face connector appears desirable in the program to improve outlet flow characteristics. Tentative design has buen established using a modified open helical configuration. Purchase orders are being placed to procure sample lots of both chromium and Inconel connectors for conducting tests.

\section{Inlet Nozzle Reinforcing Sleeve}

Results of the design testing program on the inlet nozzle reinforcing sleeve to be used on reamed nozzles at 105-B, D, DR, $F$, and $H$ reactors indicate them to be satisfactory. These sleeves were designed to strengthen the reamed nozzles used with the bumper fuel element should reaming render the present nozzle unsatisfactory. A prototyoe forged nozzle for possible use at K Beactor with the bumper fuel element is being fabricated. The design of this nozzle would permit future reaming should smoothbore zirconium process tubes and self-supported fuel replace the ribbed aluminum process tube and bumper fuel element.

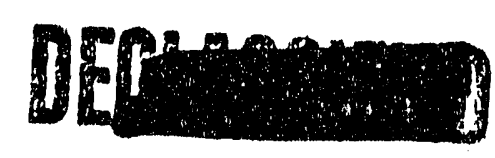


F1les

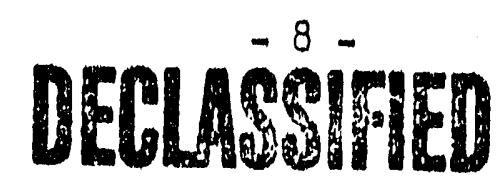

May 9, 1961

Rear Crossheader Vibration

A test installation of flexible joints and gutdes to reduce thermal stresses and suppress vibration has been in service on one rear crossheader at 105-H Reactor for about two months. The installation has been inspected three times and it shows no evidence of deterioration or leaking. Data indicate about a 50\% reduction in low-frequency vibration and a factor of three reduction in stress at the crossheader riser connection. A similar Installation has been completed on crossheader 23 .
at 105-DR Reactor.

REACTOR MTODIFICATION PROGRA I

C Reactor Overbore

On April II four process channels were overbored at $C$ Reactor, completing the 20 overbore tubes authorized. The work took 15. I hours; no machine fatled, some sequencing of operations was accomplished, and there was considerably less confusion than on the earlier outages.

Orerbore Fuel Development

Four more columns of CVIN fuel elements were charged into C reactor, bringling the total to twenty. The twenty channels are comprised of the following fuel-tube combinations:

Tube

Ribbed Aluminum Smooth-bore Aluminum Smooth-bore Zircaloy

\author{
Fuel Type
}

3-Rail bumper

Self-supported

Self-supported
Columns 2

10

8
Remarks

$2 \mathrm{~T} / \mathrm{C}$ probes

$2 \mathrm{~T} / \mathrm{C}$ probes

$2 \mathrm{~T} / \mathrm{C}$ probes

The twenty tubes are broken into two groups, one piloting high specific powers and one plloting powers typical of existing central zone tubes. The first group consists of four smooth-bore Zircaloy tubes containing 18 CVINS fuel elements. The tubes are located at the corners of a $4 \times 6$ block of tubes in the central zone and are currently operating at around $110 \mathrm{kw} / \mathrm{ft}$. The second group contains the remaining sixteen tubes and it is located at the third lattice unit from the outside edge of the reactor. These tubes operate at an average specific power of $75^{\prime} \mathrm{kw} / \mathrm{ft}$ and contain 32 fuel elements.

- The next test column to be discharged will be 0954C at an exposure of $400 \mathrm{MMD} / \mathrm{T}$. The current exposure is $372 \mathrm{MWD} / \mathrm{T}$, and the tube will reach goal about Apri.l 1.0.

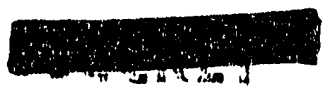




\section{NE:A PRODUCTION REACTOR}

Fuel Testing

KER-1 - The ten nominal NINI elements Lrradiated in evaluate the effect of different heat treatments on fuel distortion were discharged April 8, 1961, at an exposure of $1050 \mathrm{iND} / \mathrm{T}$. The loop was recharged with a $\mathrm{UO}_{2}$ tubular element and two $\mathrm{iS} \mathrm{I} 3$ elements to supply heat to the loop. The test was terminated Apri1. 19, 1961 at an exposure of $14_{+5} \mathrm{i} \cdot \mathrm{ND} / \mathrm{T}$ because of a serious leak in the $100 \mathrm{p}$.

IER-2 - The NIII elements reached an exposure of $635 \mathrm{iNID} / \mathrm{T}$ on ApriI 20.

KER-3 - The four KSE3 elements have reached an exposure of $26 / 45$ MTITI.

KER-4 - Four NINI. elements charged January 14, 196I, and one NIII element charged March 20, 1961, were discharged Apri1. 8, 1961, after a neutron monitor trip at an exposure of 985 on the ivivi elements and $270 \mathrm{MWD} / \mathrm{T}$ on the NIEI element. The loop was recharged With five NIFI elements. Ixamination of the five elemerits in the KE viewing basin failed to disclose the area of fallure.

\section{Graphite Procurement}

With the exception of less than 10\% of the order placed with National Carbon Company, all of the graphite for the NPR has been received. The remaining bars will be delivered in the next few weeks.

\section{Safety Studies}

A total control study was made to detemine the number of ball $3 \mathrm{X}$ channels which can be out of service in the central part of the control region and still keep the reactor sub-critical even in the case of optimum flooding of the NPR lattice. A conservative number of twelve ball $3 \mathrm{X}$ channels out of service was arrived at for the case of a $24 \mathrm{lb} / \mathrm{ft}$ fuel element.
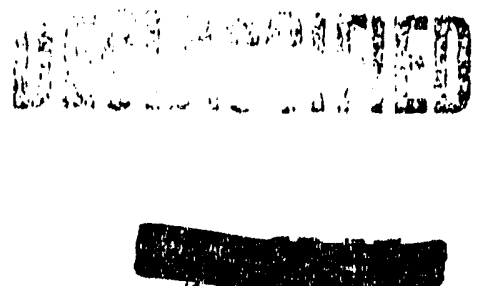


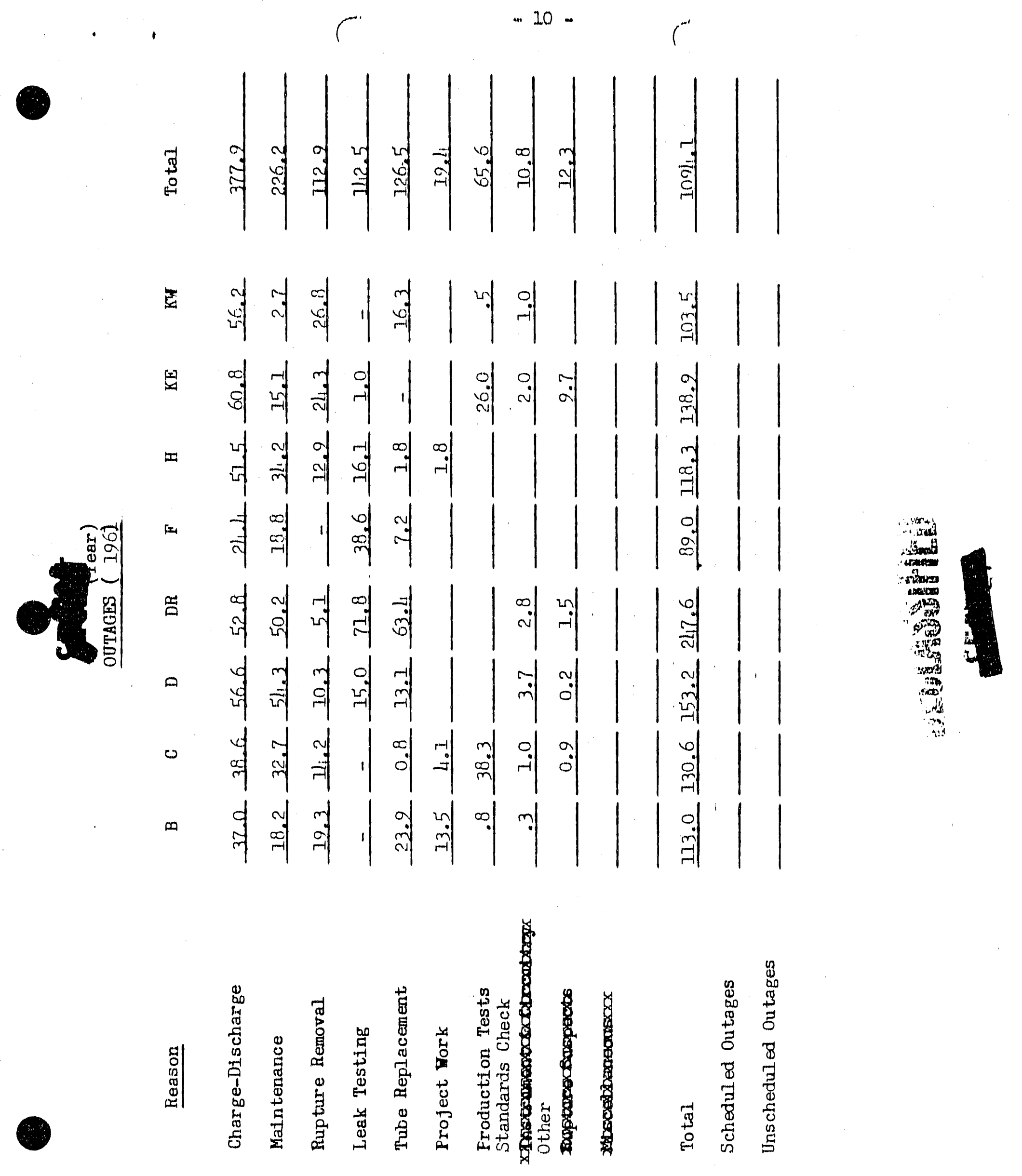




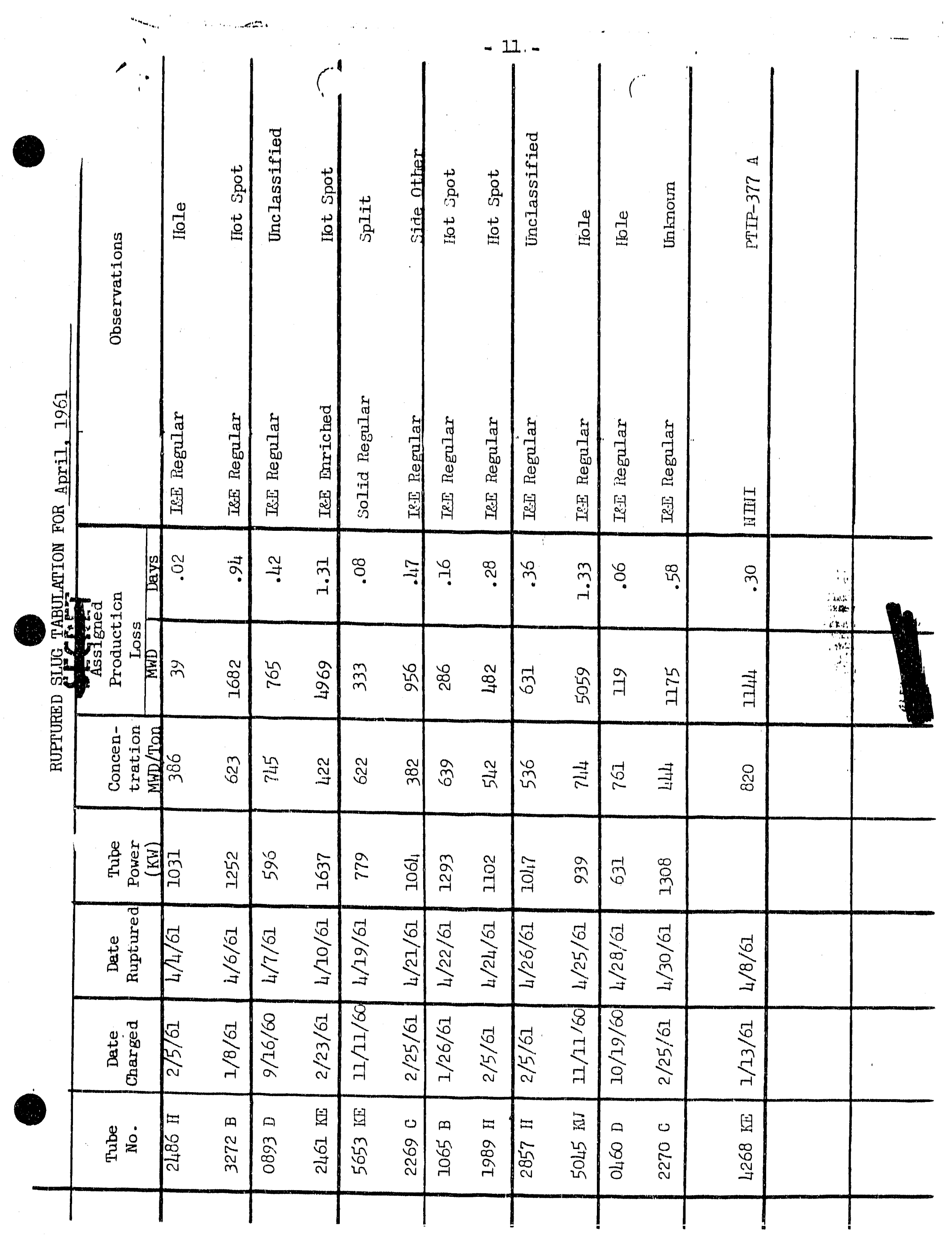




\section{Office Memorandum • united states government}

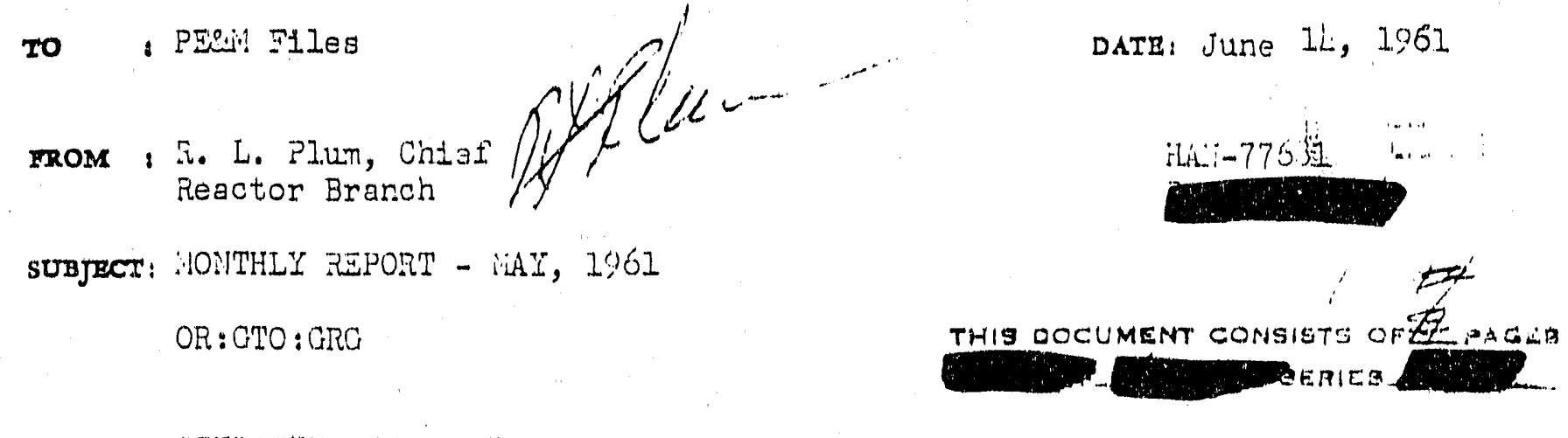

\section{OPERSTINIG EXPIRIEYCE}

Production

Reactor input production (Win) was $100.0 \%$ of' forecast. Production at the six old reactors was $6.2 \%$ below forecast and at the $k^{1} \mathrm{~s}$

8. 3ï above.

\section{Efficiency}

Overall time operated efflclency was $77.0 \%$ ( $31.7 \%$ forecast), 73. $3 \%$ at the six old reactors and $36.9^{\circ}$, at the $K^{\prime} s$. Afficiency was low at the six old reactors due to tube renlacement and faulty front and rear face hardware.

\section{Power Level}

There was no increase in the combined reactor instantaneous power level or the individual reactor record power levels.

Power Level Limit

During most of liay, the power levels at C, DR, H, KI and $\mathrm{KN}$ reactors were restricted by rupture control considerations. Power levels at $B$ and $D$ reactors were restricted by bulk outlet temperature conditions and at $F$ reactor by graphy te temperature.

Fuel Ruptures

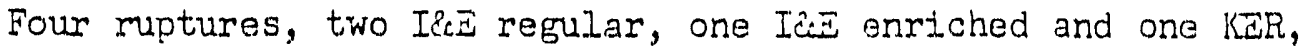
were removed from the reactors. The two regular metal muptures were at $B$ and the enriched at DR. This represents the best rupture experience since September, 1960, significantly lower than the monthly average of ten during the flrst four months of 1961.
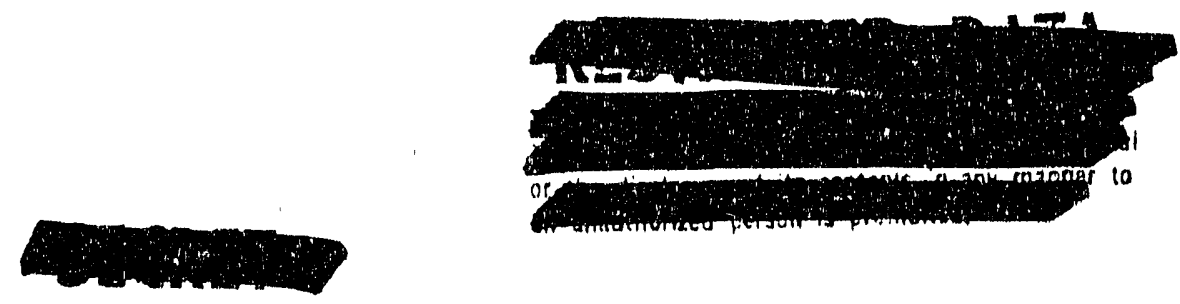


\section{WAINTESANCE AID EQUTPNENT EXPLRIENCE}

\section{Tube Renlacoment and iater Leaks}

One hundred fifty-three process tubes were installed, 45 at $F$, 43 at $H, 30$ at $B, 29$ at DR, 5 at $D$ and one at C. Seven tube leaks and nine Van Stone leaks were corrected. Four of the tube leaks were at $D R$, two at $C$ and onc at $D$. The Van Stone leaks were at $\mathrm{B}, \mathrm{DR}$ and.H (three each).

\section{Reactor Cadmium Control Rods}

Replacement of the ten cadmium horizontal control rods remaining from C Reactor startup in 1952 was begun with installation of a new boron rod in the number 7 position.

Rod calibration tests of numbers 1 and $13 \mathrm{HCR}^{\prime} \mathrm{s}$, whose tips reached a calculated burnout of 100\% during May, confirmed that the last 100 inches of the rod tips have lost reactivity strength during the past two months. Numbers 3 and 15 HCR's have reached a calculated 90; bumout of the cadmium. These four HCR's are scheduled to be replaced, one each outage, by the end of August. The rod to be replaced will be held out of service to permit radioactive decay during the operating period preceding its replacement. The other five HCR's wi.J not exceed a calculated 90\% bumout (the point at which control effectiveness would start to diminish) during 1961, but they are scheduled for replacement later this year.

\section{Vertical Safety Rod Rehabilitiation}

iork concerning the rehabilitation of the vertical safety rods and the collection of graphite distortion data at $C$ rector continued. Effurts to clear graphite obstructions from the channels for vertical safety rods No. 41 and 53 were partially successful. ChanneI No. 58 was cleared sufficiently to permit the safety rod to be returned to service, Although channel No. Lll was cleared of complete Blockage, protrusion of both graphite filler blocks into the channel remains a problem. Pieces of graphite in the bottom of the channels preclude the use of the BaIl $3 \mathrm{X}$ safety system in either channel at this time by preventing ball recovery with normal procedures. Additionai data regarding the extent of the graphite distortion at $105 \mathrm{C}$ reactor will be collected during the next scheduled outage.

\section{RESEARCH AND DEVELOPMENT - FXISTING REACTORS}

Self-Supported Fuel Development

Thirty-two columns of CIVNS fuel elements were discharged from 
regular C size smooth-bore zirconium tubes at goal exposure during the report period. Nothing unusual was encountered
during the discharge.

The smooth-bore aluminum tube SSFY test program at $B$ reactor has been closed out due to excessive tube corrosion reactor were removed during the May 22, 1961 tube corrosion. All tubes

Bumpered Fuel Development

$D$ reactor currently contains about 1015 naturat

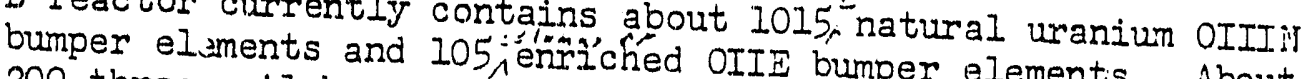
200 three-rail bumper fuel incident.

A prototype magazine charging machine for bumper fuel elements was demonstrated 1 ay 18, in the 189-D Laboratory. A charging time of 40 seconds per tube was achieved. Current efforts are directed toward fabrication of supplemental equipment required for loading the fuel clips into the charging machine.

Isotopic Composition of Irradiated Fuels

The adoption of a specification on Pu-240 concentration has led to some calculations of Pu-240 buildup rates - particularly for the case of the overbore geometry proposed for $C$ reactor. The following conclusions can be drawn from the calculations:

a. The pile average Pu-2LO from C reactor for $800 \mathrm{MWD} / \mathrm{T}$ goal exposure and $40 \mathrm{C}$ average graphite temperature with current enrichment is calculated to be $6.5 \%$. For the same conditions in the overbore geometry, the same calculations indicate the Pu-240 concentration would be $6.2 \%$. The total Pu-240 plus $\mathrm{Pu}-24 \mathrm{l}$ would remain the same, about $7.2 \%$.

b. Cross checks of calculations (Flex. I Program) with measured Pu-2LO concentrations at $800 \mathrm{MND} / \mathrm{T}$ for $\mathrm{B}$ reactor and for $\mathrm{K}$ reactors show excellent agreement.

c. The slope of the $\mathrm{Pu}-240$ versus average graphite temperature curre at about $800 \mathrm{lmW} / \mathrm{T}$ shows that varying the graphite temperature by $100 \mathrm{C}$ produces a change in Pu-240 concentration

The Np-238 and Pu-238 isotopic compositions as a function of forposure in the Hanford reactors has been recalculated, correcting for a small error in the enriched fuel cases and further comparing the twelve two-ton balts with measured valves now available from determine if the exposure onversion ratio tests. This was done to from the Pu-238 composition the fuel could be back calculated fuel. One can conclude that in the plutonium from the irradiated

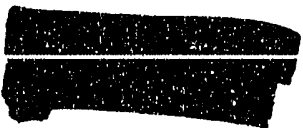


calculate exposure from Pu-238 composition, since it is not possible to correctly calculate the $\mathrm{Pu}-238$ from the exposure directly. For example; compare the following cases for natural uranium fuel:

\section{Exposure}

(a) $445 \mathrm{MIND} / \mathrm{T}$

(b) 465

(a) 800

(b) 830

(a) $\mathrm{H}$ reactor

(b) $\mathrm{K}$ reactor

\section{E-N Loading}

The striped core portion of the E-N loading was charged at $H$ reactor during the outage of May 21, 1961. The fringe blanket portion of the loading had been completed on April 4, 1961. Subsequent operation has shown that the pile reactivity is close to the predicted value and that flattening efficiency has dropped about $6 \%$, also as expected.

\section{Rear Crossheader Vibration}

Two prototype flexible joint installations are being evaluated as potential solutions to reactor rear header vibration and thermally induced stress problems. An installation made on header \#25 at $105 \mathrm{H}$ reactor about three months ago has been inspected for the fourth time and is functioning satisfactorily. A second installatior. made recentiy on he ader \#23 at $105 \mathrm{DR}$ reactor was inspected after one week of service and showed no evidence of leaking. These installations are to be disassembled periodically for gasket in. - spection. The graphite asbestos gasket at the $\mathrm{H}$ installation looked satisfactory at the first inspection.

Crossheader Replacement

The removal of a complete crossheader from 105 DR reactor for metallurgical and mechanical examination has been authorized under Production Test IP-352-AE. Design criteria have been established for the replacement assembly which provides for using enlarged fittings and connectors but which also provides for easily returning to existing size hardware.

\section{Safety Calculations}

First runs were completed of the spatially dependent speed-ofcontrol calculations. These computations are designed to investigate cases in which the safety control system is only partially effective. Preliminary results show that in normal equilibrium pile conditions, the failure of two adjacent VSR's does not cautse the speed-of-control criterion to be exceeded.

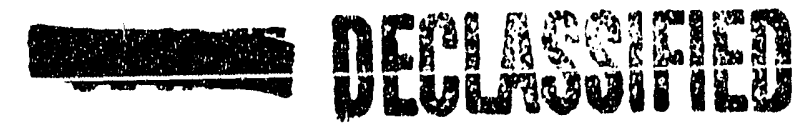




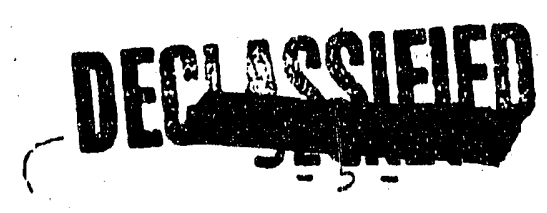

As the conditions assumed become more severe, the situation becomes less clear cut and further investigation is planned. It appears that the current restriction which prohibits having two adjacent rods out of service is satisfactory.

\section{REACTOR MODIFICATION PROGRAM}

C Reactor Overbore

Analytical studies supporting the $105 \mathrm{C}$ reactor overbore program continued. Preliminary results indicate that: 1) boring the tube channel 25 mils or greater above the process tube O.D. has slight effect on graphite temperatures at larger specific heat generation rates, 2) composition of the reactor atmosphere should not exceed 50, helium if minimum graphite temperatures are to be maintained and 3) coring, to be effective, should range from 200 to 300 $\mathrm{mils}$ and extend three to eight feet beyond the gunbarrel both front and rear.

Design tests have been prepared in support of the proposed 40 tube overbore program. These tests provide for testing the outlet gas seals, evaluation of the forged lug ring, evaluation of rear connectors and testing the rear nozzle water seal at the tube to nozzle joint.

A front nozzle with captive venturi-pigtail and a flapper was removed from tube 3874 of the $105 \mathrm{C}$ reactor examination. It had been in service six and one-half months. The only deterioration noted was some galvanic attack of an aluminum seat near the brass flapper base. The examination completes the production test (PT-34l-AP) which authorized installation of this nozzle (designed for $0.200 "$ overbore) for test of concepts only.

Overbore Fuel Development

The second column of overbore-size fuel, CVINS in a smooth-bore zirconium tube, was discharged from tube $0954 \mathrm{C}$ on April 30, 1961 at an exposure of $402 \mathrm{MWD} / \mathrm{T}$. The tube was charged on January 17, 1961 and was scheduled for a goal exposure of $400 \mathrm{MwD} / \mathrm{T}$. Visual examination revealed a few areas of light corrosion attack and four pieces with film patterns; otherwise the general overall appearance was good with nothing unusual noted. Dimensional measurements have been completed, however, they have not yet been processed through the machine program. All twenty columns are continuing to perform satisfactorily. 


\section{NEW PRODUCTION REACTOR}

Fuel Testing

KER-1: A thermocouple train including an instrumented $\mathrm{Zr}-2$ jacketed fuel rod to measure the temperatures effects of crud film deposition on fuel element heat transfer surfaces subsequent to decontamination of a carbon steel system was charged on May 11, 1961. Shortly after reactor startup on $\mathrm{May} 12,1961$, the instrumented fuel element failed. The failure appears to be associated with the design of the element, although the precise mechanism of failure is not known.

KER-2: The five NINI elements, PT-IP-377A, reached an exposure of $1060 \mathrm{M}: \mathrm{DD} / \mathrm{T}$ on May 20, 1961. The irradiation continues to be uneventful.

KER-3: The four KSE-3 elements reached an exposure of 3370 MWD/T on May 20, 1961. These elements, which simulate the behavior of an $\mathrm{N}$ reactor fuel element outer tube, will be discharged at the next reactor outage.

KER-4: The 10op was discharged and will remain empty until after modification of the loop to permit irradiation of full sized $N$ reactor fuel elements.

The failed element in the charge of $\mathrm{N}$ reactor inner fuel tubes that was discharged from KER-4 on April 8 , 1961, has been identified as the NIEI element at an exposure of $270 \mathrm{MND} / \mathrm{T}$. The element has been sent to the Radiometallurgy Laboratory to determine the nature of the failure.

\section{Process Tubes}

The chemical composition specifications for the NPR zircaloy process tubes were altered to permit a silicon concentration of up to 250 parts per milizon. The former specification for silicon was 100 PPM.

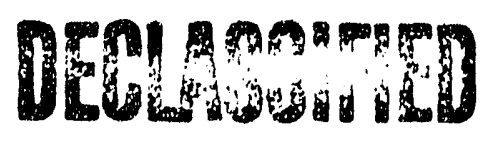

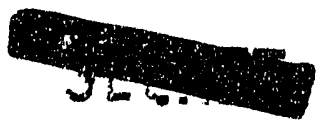




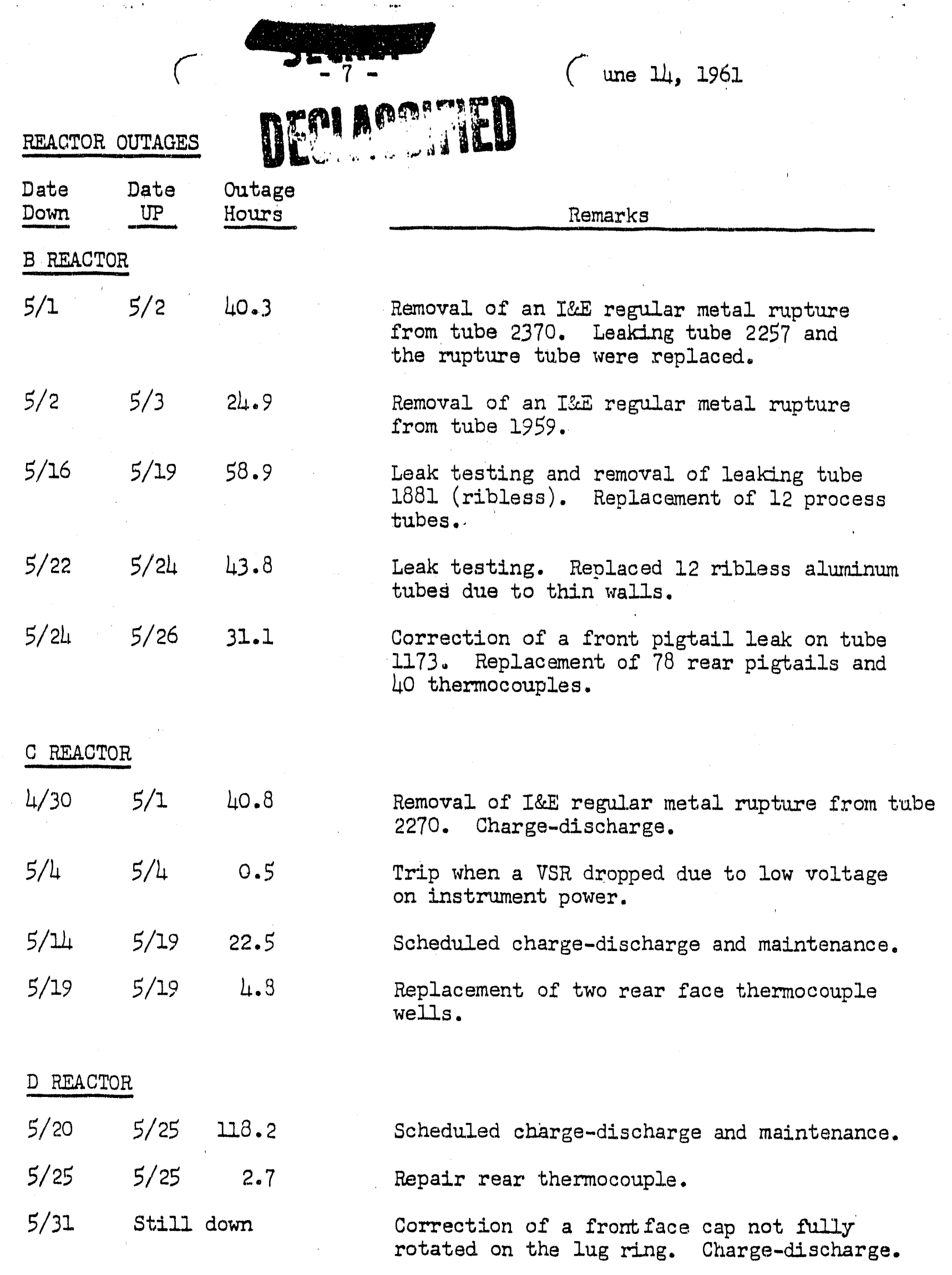


$\begin{array}{lll}\text { Date } & \text { Date } & \text { Outage } \\ \text { Down } & \text { Up } & \text { Hours }\end{array}$

- Dp Hours

DR REACTOR

$5 / 4 \quad 5 / 6 \quad 54.8$

$5 / 17 \quad 5 / 19 \quad 39.8$

$5 / 28 \quad 5 / 30 \quad 55.5$

F REACTOR

$4 / 30 \quad 5 / 3 \quad 62.6$

$5 / 4 \quad 5 / 5 \quad 32.8$

$5 / 8 \quad 5 / 11 \quad 63.5$

$5 / 25 \quad 5 / 28 \quad 69.0$

H REACTOR

$\begin{array}{lll}5 / 3 & 5 / 3 \quad 0.2\end{array}$

$5 / 3 \quad 5 / 8 \quad 175.7$

$5 / 14 \quad 5 / 14 \quad 0.2$

$5 / 14 \quad 5 / 15 \quad 32.7$

$5 / 16 \quad 5 / 16 \quad 0.2$

$5 / 21 \quad 5 / 28 \quad 168.5$

$5 / 28 \quad 5 / 29 \quad 3.7$
Rear pigtail leaks. Charge-discharge and maintenance.

Panellit trip on gauge 3557. Miscellaneous maintenanoe.

Panellit trip. Replacement of 33 process tubes.

Trip due to a leaking rear pigtail. Chargedischarge and tube replacement.

Water leak. Replacement of 17 tubes, inoluding three leakers.

Removal of I\&E E metal rupture from tube 2657 and charge-discharge.

Leak testing. Removal and replacement of 12 tubes.

Remarks 


\begin{tabular}{lll} 
Date & $\begin{array}{c}\text { Date } \\
\text { Outage } \\
\text { Down }\end{array}$ & Hourg \\
\hline
\end{tabular}

KE REACTOR

$\begin{array}{rrr}5 / 10 & 5 / 12 & 40.8 \\ 5 / 12 & 5 / 13 & 2.6 \\ 5 / 26 & 5 / 29 & 56.5 \\ 5 / 29 & 5 / 29 & 3.5\end{array}$

KER LOop 3 trip. Charge-discharge. Removal of a mipture from KER Loop 1. Repalr of nine front gunbarrel flanges, (tru-arc) rings and charge-discharge.

KW TREACTOR

$\begin{array}{llrl}5 / 1 & 5 / 2 & 34.6 & \begin{array}{l}\text { Tripped by oscillating Panellit gauge } \\ \text { 0873. Charge-discharge. }\end{array} \\ 5 / 3 & 5 / 3 & 0.3 & \text { Unexplained Panellit trip. } \\ 5 / 25 & 5 / 27 & 56.2 & \text { Scheduled charge-discharge and malntenance. } \\ 5 / 27 & 5 / 27 & 0.7 & \text { Panellit trip due to an oscillating guage. }\end{array}$




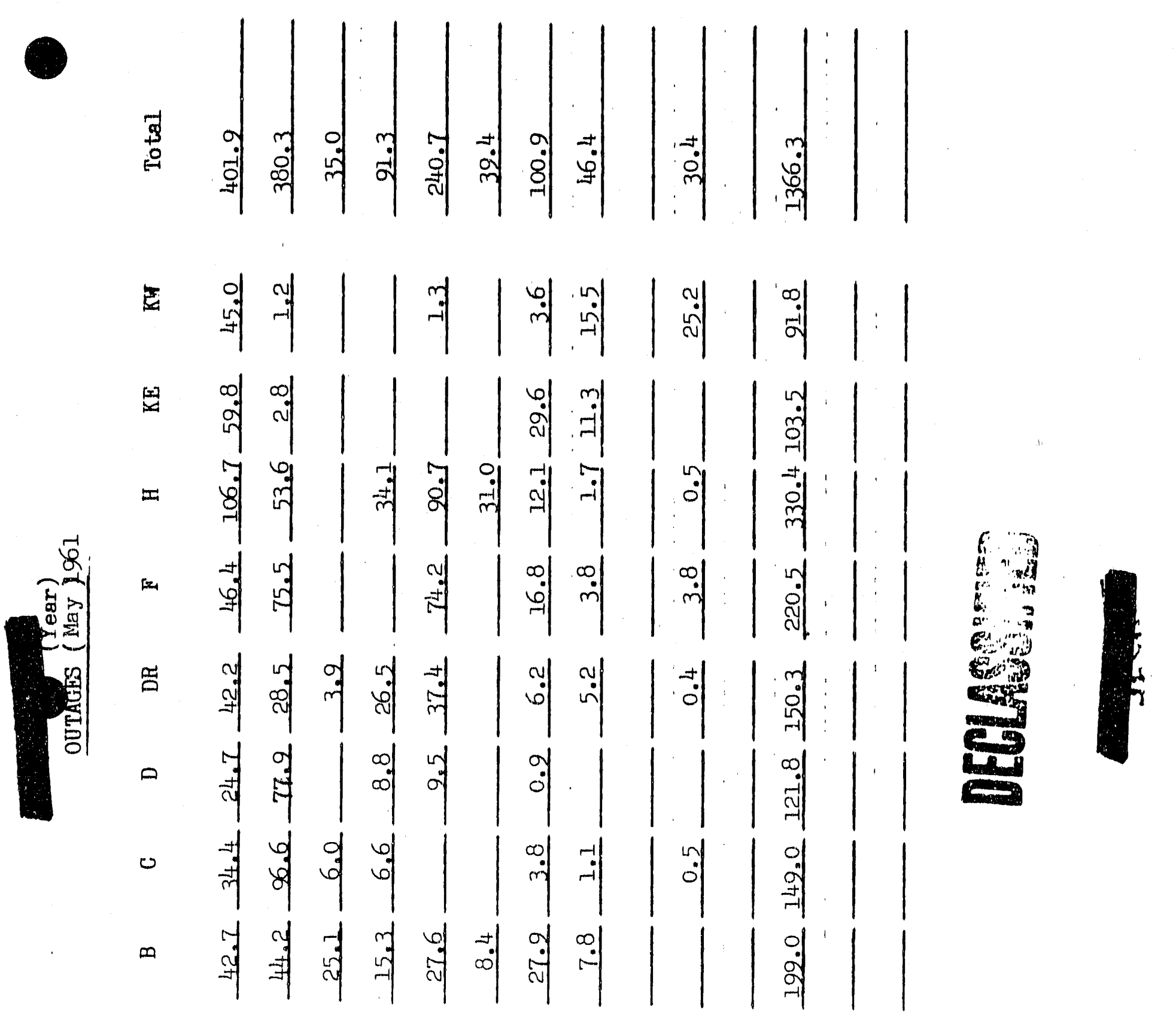

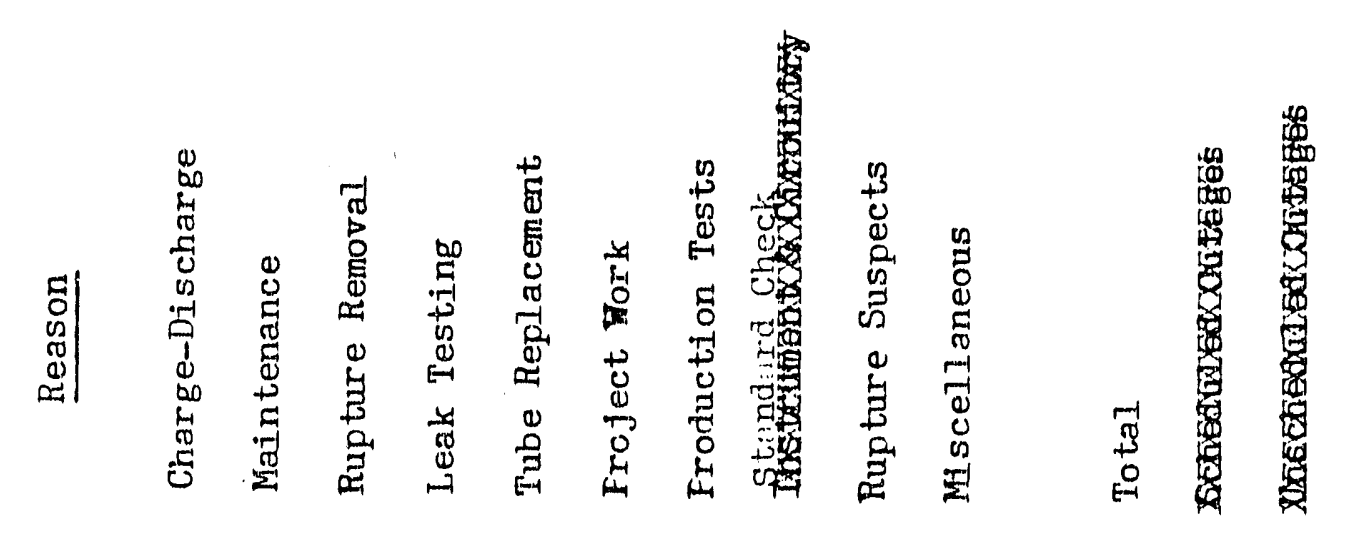




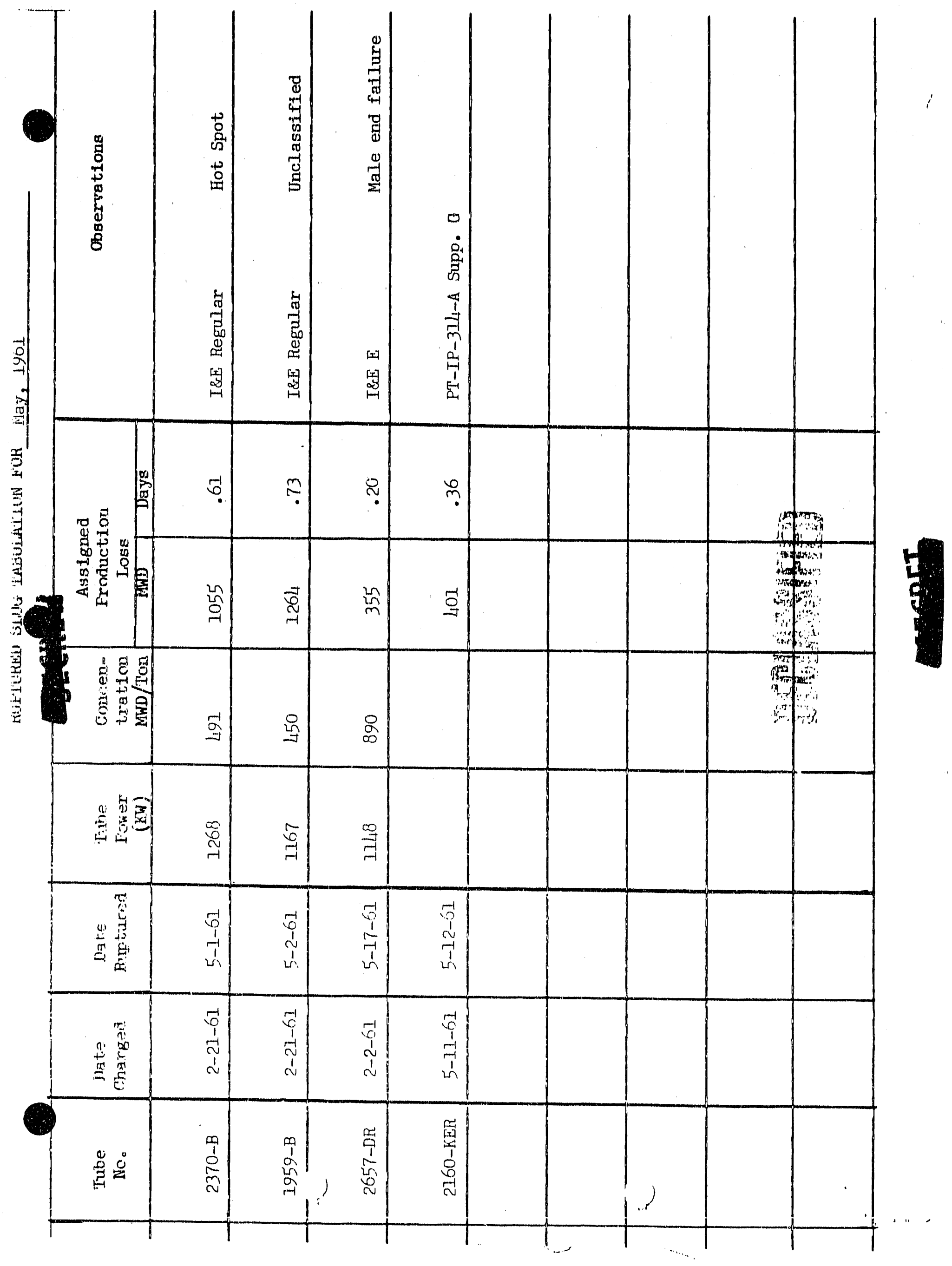




\section{$-$ Office Memorandum • UNITED \\ STATES GOVERNMENT}

\author{
ro Production DIVIsion Files \\ mom : R. L. Plum, Chtef \\ . Reactor Operations/Brarloh \\ SUBJECT: NONTHLY RAPORT - JUNE, 1961 \\ OR:GTO:JPS
}

DATB: JU1y 13, 1961

HAN -77531

\section{THIS DOCUMENT CONSIGTS OF-IL PAGES
NOS LOFE COPIES. IERIES}

\section{OPERAIING IXTERINTCE}

Production

Reactor injut production (ivid) was $0.3,4$ above forecast; $5.1 ; j$

below at the si: old reactors and $7.9 \%$ above at the in

\section{Iffletency}

Overall time operated efflciency was $73.2 \%$ (33.0\% foreoast; $75.9 \%$ at the six old reactors and $35.0 \%$ at the $\left.K^{\prime}{ }^{\circ}\right)$. Ifficiencr was low at the old reactors due largely to water leaks and tube replacemerit.

\section{Power Level}

There was no increase in the combined reactor instantaneous power level or the indivtdual reactor reoord power levels.

Power Level Iimits

The power levelss at all reactors are currently lintted by bulk outlet temperature restrictions.

Fuel. Ruptures

Seven ruptures - four Irs regular metal, two In: anrlched, and one solid regular - vero removed from the reactors. The IEs regular metal muptures vere at $B, C, D R$ and $I$; the Iow erirlohed, at $F$ and $\mathrm{H}$; and the solid regular, at $\mathrm{C}$.

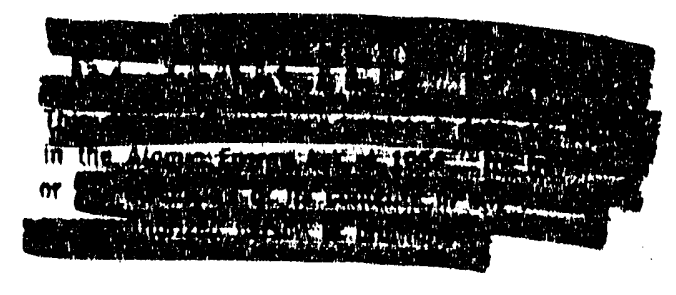




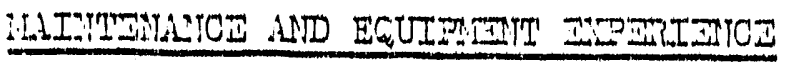

Tuke Replacement and ilater Leaks

One hundred and seventy-ntine prooess tubes vere installed; 112 at $D, 42$ at 3,17 at DR, 3 at $C, 3$ at $\Gamma$, one at each $H$ and KMi.

Ilever proooss tubo leaks were corrected; 2 at $i, 2$ at $C$,

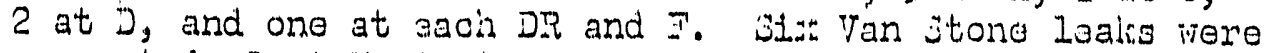
corrected; 3 at $I, 2$ at $D$ and one at $I$.

De Iaval Pumo Impeliers

Inspections to determine the condition of the existing Impellers (each pump has two) which were Instalied betiveen February, 1959 and April, 1960 have boen completed on 32 of the $40 \mathrm{De}$ Laval process water pumps. Cracks of sufficient magnitude to warrant replaoement have thus far been found in 5 of these impellers. A repair program has been inttiated to supplement the supply of" replacement impellers.

\section{Vertical Safiety Rods}

Four VSR's at O Reactor were replaced w1th smaller B-plle type VSR's to prevent rod sticling due to obstructions in the top shield and graphite stack. The loss of control effectiveness due to this change is quite small and roadily complies vitin saiety criteria.

REACTOR OUTAGES

$\begin{aligned} & \text { Date } \\ & \text { Dow } \\ & \text { B Reactor }\end{aligned}$ Outage
Hours

6/17. 6/22 $116.7 \quad$ Removal of an Iner regular metal rupture from tube 0967, charge-discharge and tube replacement.

$6 / 22 \quad 6 / 22 \quad 2.4 \quad$ Rear face cap leak.

$6 / 26 \quad 6 / 28 \quad 37.2 \quad$ High pressure panellit trip on tube 2683. iliscellaneous maintenance and a small charge-discharge. 
C Reaotor

\begin{tabular}{lll}
$6 / 5$ & $6 / 8$ & 61.1 \\
$6 / 3$ & $6 / 3$ & 2.1 \\
$6 / 8$ & $6 / 3$ & 0.4 \\
$6 / 9$ & $6 / 11$ & 31.3 \\
$6 / 16$ & $6 / 17$ & 36.7 \\
$6 / 20$ & $6 / 22$ & 37.7 \\
$6 / 26$ & $6 / 28$ & 42.7 \\
Deactor & \\
\hline $5 / 31$ & $6 / 3$ & 68.9 \\
6 & & \\
$6 / 3$ & $6 / 4$ & 3.6 \\
$6 / 11$ & $6 / 13$ & 44.9 \\
$6 / 25$ & $6 / 30$ & 107.7
\end{tabular}

Removal of an Ifie regular metal rupture from tube 3766. Litscellaneous maintenance and charge-discharge.

Panel It trip due to the plgtall coming loose from rear nozele 1557.

ranual trip for temporaturo control.

Removal of a solld regular metal rupture from tube 2352 .

Leak testing. Leaking tube 4170 replaced.

Leak testing

Leak testing. Tube 2566 replaced.

DR Reactor
$6 / 6 \quad 6 / 8$
62.4
Leak testing and tube replacement.
$6 / 9 \quad 6 / 10 \quad 26.4$
Removal of an Ises rogular metal rupture from tube 2986.
$6 / 12 \quad 6 / 14 \quad 35.3$ Repair of broken Iug ring on front nozzlo 1563. Charge-discharge.
Comection of a front face oap not fully rotated on the Iug ring. Charge-discharge and tube replacement.

High pressure Panellit trip on tube 3882 .

Leak teating; charge dischargo: and tube replac ement.

Scheduled charge-discharge and tube replac ement. 
FHIO

$-4-$

July 13, 1961

I. Roactor

$6 / 12 \quad 6 / 16 \quad 32.9$

Removal of a stuck IR-I-I motal moturs from tube 3457. Charge-discharicg and miscolianeous maintenanoo.

$6 / 19 \quad 6 / 21 \quad 38.0$

Tripped due to a faulty clrout broalrer at iifdray. Leak tosting and cirariadischanco.

$5 / 24 \quad 6 / 25 \quad 41.6$

Removal of an rĩ regular metal rioture from tube 225 .

$6 / 23 \quad 6 / 28 \quad 0.2$

Panelilt trip dus to a ruptured rear plgtall on tube lu370.

H. Reactor

$6 / 0 \quad 6 / 6$

0.2

Panellit trip due to a rear phigtall fallure on trube 3691.

$5 / 6 \quad 6 / 6 \quad 0.1$

Unexplatned trip on Nos. 2, 3 and 4 Becimans.

$6 / 7 \quad 6 / 8 \quad 32.4$

Leak testing.

$6 / 18 \quad 6 / 20 \quad 47.5$

Removal of stuck I I tube 2367. Leak terting.

$6 / 21 \quad 6 / 21 \quad 0.4$

Tripped when flow to PCC: tube 2079 was reduced prior to bypassing the Panelitt gauge.

$6 / 21 \quad 6 / 22 \quad 22.9$

Tripped due to a rear connector leak on tube 0673. Leak testing.

$6 / 27 \quad 6 / 29 \quad 53.4$

Leak testing.

$6 / 29 \quad 6 / 30 \quad 1.3$

Correction of two lealing front face caps.

II Reactor

$\begin{array}{lll}6 / 7 & 6 / 9 & 35.7 \\ 6 / 20 & 6 / 23 & 61.1\end{array}$

Trip by tidR 100p 1. Charge-discharge.

Faulty tru-arc ring. Charge-discharge and misoelianeous maintenarice.

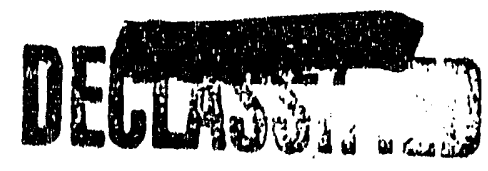


Ni. Reactor

$6 / 9 \quad 35.0 \quad$ Unexplained Panellit trip. Charge-
discharge.

$0 / 27$ Still dom Scheduled charoje-discharge and maintenance.

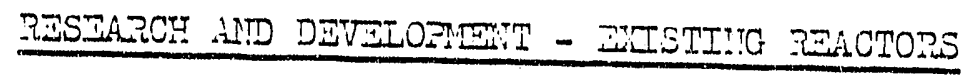

Self-suoported Thuel Development

Five columns were discharged from $C$ Reactor at goal exposure during the report pertod (about $800 \mathrm{MiD} / \mathrm{T}$ ). To date, 154 charges of CIVIS fuel elements have passed through the 69-tube facility. iith the exception of a single reluctant charge last fall, no charge-discharge or suel performance problems

Bumper Fuel Development

D Reactor currentIy contains about 1115 tubes of bumpered fuel elements and approximately 600 have been discharged. Data from an extensive probing program indicates that new tubes as high as row 43 at $D$ Reactor can be charged satisfactorily wi.th the present bumper fuel.

An enriched uranium bumper fuel element charged into H Reactor as part of the $E-N$ load failed on $6 / 18 / 61$ at $31 / 4 \mathrm{MID} / \mathrm{T}$. Visual examination of the failure at the $\mathrm{H}$ Reactor technical vieving facility revealed a male-end failure. No unusual hot spot patterns were noted, indicating that the failure was not attributable to the $I-1$ loadins. There were no indications that the presence of bumper projections had any relation to the failure mechanism. The mutured piece is being scheduled for further destructive examination in Radiometallurg.

\section{E-N Loading}

The equilibrium reactivity status of the I-N loading at H Reactor indicates that the initial reactirity matching has been slightly conserrative and the long term loss effect wili probably not be as great as predicted. Eight $\mathrm{Y}$-metal poison columns were charged at the end of June to provide a more optimum reactivity status. Equilibrium operation has been smooth but reductions in startup 
levels vere required by additional reactivity. A production test for partial rod calibrations is being prepared and ili better define the reactivity aspects of this load. One rupture has been experienced in the loading, due to an end-closure failure.

\section{Remotely Operated Tube Closure}

The current test facility at ni.: now consists of 91 ball caps and 54 flapper caps. :Ine tuives of fuel at goal exposure vere flushed from the reactor shortly after shutcom June 3 . The remote actuator functioned satisfactorily.

\section{Charge-ilhile-Operating}

Prototype operational charging equipment on an out-of-reactor K-size tube demonstrated satisfactory operation. The charging unit utilized water pressure from the inlet nozzle as its source of power. The nozzle is closed by a flapper-checls.

Figh Speed Scanning Temperature Fonitor Prototype - CGI-302

The demonstration system has operated more than 137 days at HiPO. Tests will continue to prove out improved amplifiers which were substituted for the original units, to better the system response.

\section{Reactor Poison Splines}

A number of engineering changes and successful efforts to interest additional vendors has resulted in a reduction in cost of splines from $\$ 70$ to siightly over $\$ 17$ each.

\section{Tube Resizing}

Tube Reducing Corporation has resized three sections of standard size $\mathrm{Zr}$ process tubing to K Reactor size tubes. All of the test sections rere dimensionally accertable but excessive die piclup resulted in an unacceptable outer surface. Development is continuing.

\section{Accountability Studies}

The final report on the comparison and normalization of the accountability program to the 12 two-ton test batch data and to bulk separations results vas completed during this report period and published (HN-69999). The normalization is planned 
to reduce the veighted average of previous IDD jield predictions by 1.6,5 for natural uranium and 1.1,j for I-metal. ID Jredictions would still be expected to exceed CPD recovery by approxinately $0.5 \%$ on the average. Iredicted Pu-2LO isotope percentiages as a function of exposure in the normalized calculations have shom close agreement with both batch test and buli: separation results.

DPACTOR: :ODITICATIOR: DROGRLA:

C Overbore Test Iacility

Computations of relative power generations in overtore fuel elements in the planned 40-channel test facility at $C$ Reactor proceeded. Power generations are not expected to exceed those now experienced in the single isolated colurns. It appears that the minimum nower generation would be about 30,3 higher than that of the present size C-Reactor fuel. Computations are also being made on enriched columns for which higher power generations would be expected.

Overbore Fuel Development

Two columns of overbore size fuel, CVINS in smooth-bore zirconium process tubes, were discharged from tubes $3363-\mathrm{C}$ and $3366-\mathrm{C}$ on $6 / 5 / 61$. The fuel columns, 18 fuel elements per charge, operated at maximum specific porvers up to $113 \mathrm{~km} / \mathrm{ft}$ and were discharged at an average exposure of $662 \mathrm{MMD} / \mathrm{T}$. Visual examination revealed 20 of the 36 elements contained signs of heat corrosion and flow patterns. Only one piece was described as having relatively severe can wall corrosion attack within a hot area; the rest of the corrosion patterns vere described as film patterns with light to medium corrosion attack. No bump or elliptical surfaces were noted. All dimensional measurement data excent post irradiation height have been completed. The data indicate a slight diametral growth of about $5 \mathrm{mils}$ at the middle of the fuel elements; the ends have decreased a similar amount on the average. The results to date are consistent with the pre-test predictions.

Overbore Tool Desion

Design effort concerned with the test to overbore additional process tube channels at 105-C Reactor has been concerned with tool design. Prototjpes of tube pressurization leak testing tools and charging machine adapters are undergoing test. Development work on a rolled Van Stone flange on the overbore zircaloy tube from $C$ Reactor is under way. A tube displacement measuring device is being fabricated which will allow both horizontal and vertical distortion data to be obtained. 
C Overbore Tubes

Ten zirconium tubes for the $C$ overbore facility have been fabricated, accepted and shipyed to Hanford. The sizizment includes scrap pieces to be used for training purnoses. The remaining six tubes on this order are lindergolns inspection at the Reactive iletals Plant. An additional orcer has been placed to assure adequate supply for the additional 4,0 -tivive overvore planned for ilugust or jeptemicer.

CGI-3LL - 100 is Coolant Baclauo

Initial tests of the steam turbine driven purp and rear for installation in the 190 Building have been 'omplete? and results appear satisfactory.

A sub-contract was awarded to George A. Grant Company to construct the new midway pump station structure. Ircavation was started on June 16, 1961.

CGI-383 - Increased Process Tiater Flow - 100 in

Detailed design is $96 / 3$ complete. A contract for the 181-is submersible pumps has been awarded to Byron-Jaclsson.

CGI-339 - Nodification to Fuel Element Test Facilities 1706-iER

There is a decided lag in actual construction completion as compared with scheduled completion on this project. This la: is due to the delay in the canned-rotor pump delivery. The vendor is experiencing leakage problems in the inal testing. It is expected that the problem will be corrected shortlig.

CGI-933 - Vater Treatment Pilot Plant - 100 ir Area

Directive authorizing total funds was issued June 19, 1961. Design work was started on June 27, 1961 and the Design Criteria were issued on June 28, 1961.

\section{NE!: PRODUC'TION REACTOR}

KER Facility High Temperature Testing

IER-I - IER-I was charged on May 28, 1961, with five 17-inch NIII elements, two of which have capped jacket defects for future failure testing in the PRTS Rupture Loop. The average exposure of this material was $405 \mathrm{iT:D/T}$ on June $20,1961$.

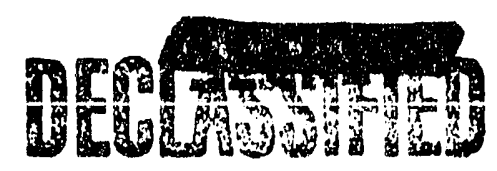


IIS-2 - A 23-inch iIII elament las addad to the charga of fivo

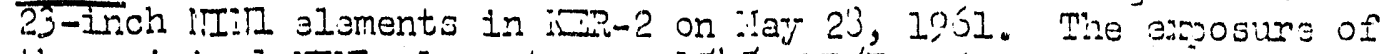

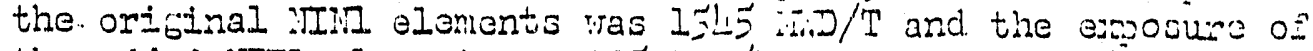

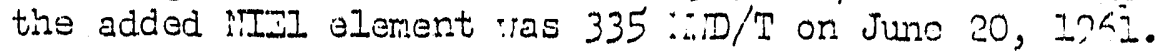

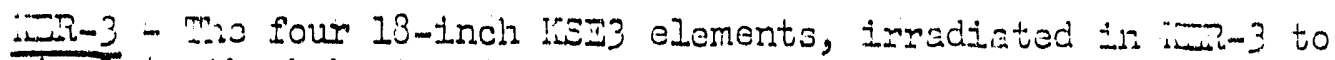
sinulate the beliavior of an : Reacton outer Fuel tuce rere discinaned rithout incident on Yay 27, 1,051 at an exposure or

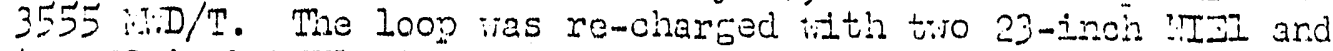
two 23-inch :T:M elomento. Cn the folloting startup of the reactor on lay 2?, hich neutron activity vas observed. The reactor vas shut dow and tine elonents vere diccharged. Tha suspected rupture was not confirmed. Loon 3 ilill remain empt;" for CGI-339 modification.

Non-4 - The loop is out of service until after modification.

Irradiation of ar Clad Enriched I'J Tuel Ilsments in if Reactors

The first two pilot fuel charges tere charged into In: Reactor on llay 25, 1961. The columns are 45 pieces long (pieces are approximately fll IonG), equipped vith down stream themocouple probes, and are located in the near-center fringe enrichment. Current exposure is estimated at 200 iI.TD/T and the two tubes should reach their scheduled goal exposure around JuIJ 15, 1961. 

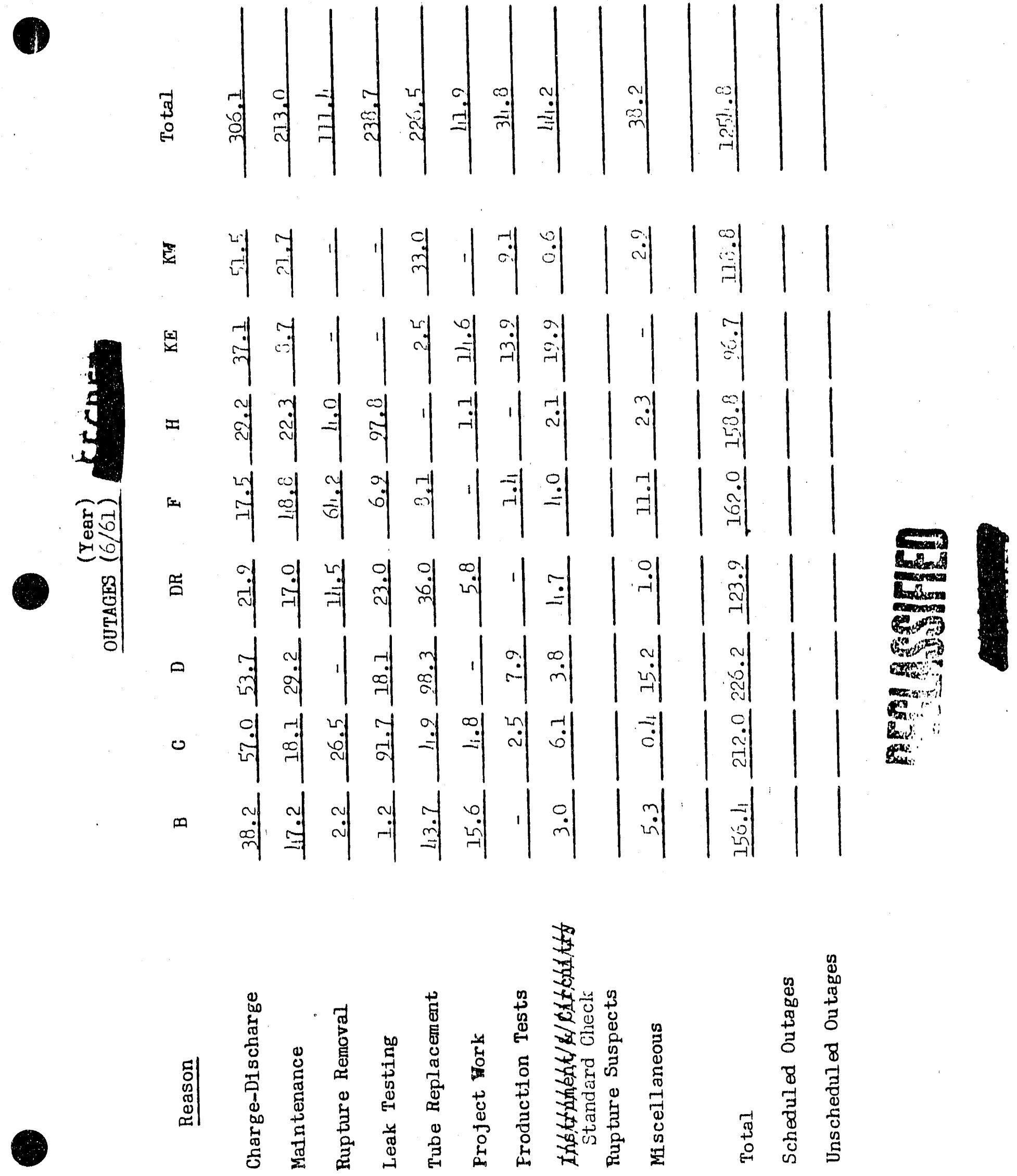


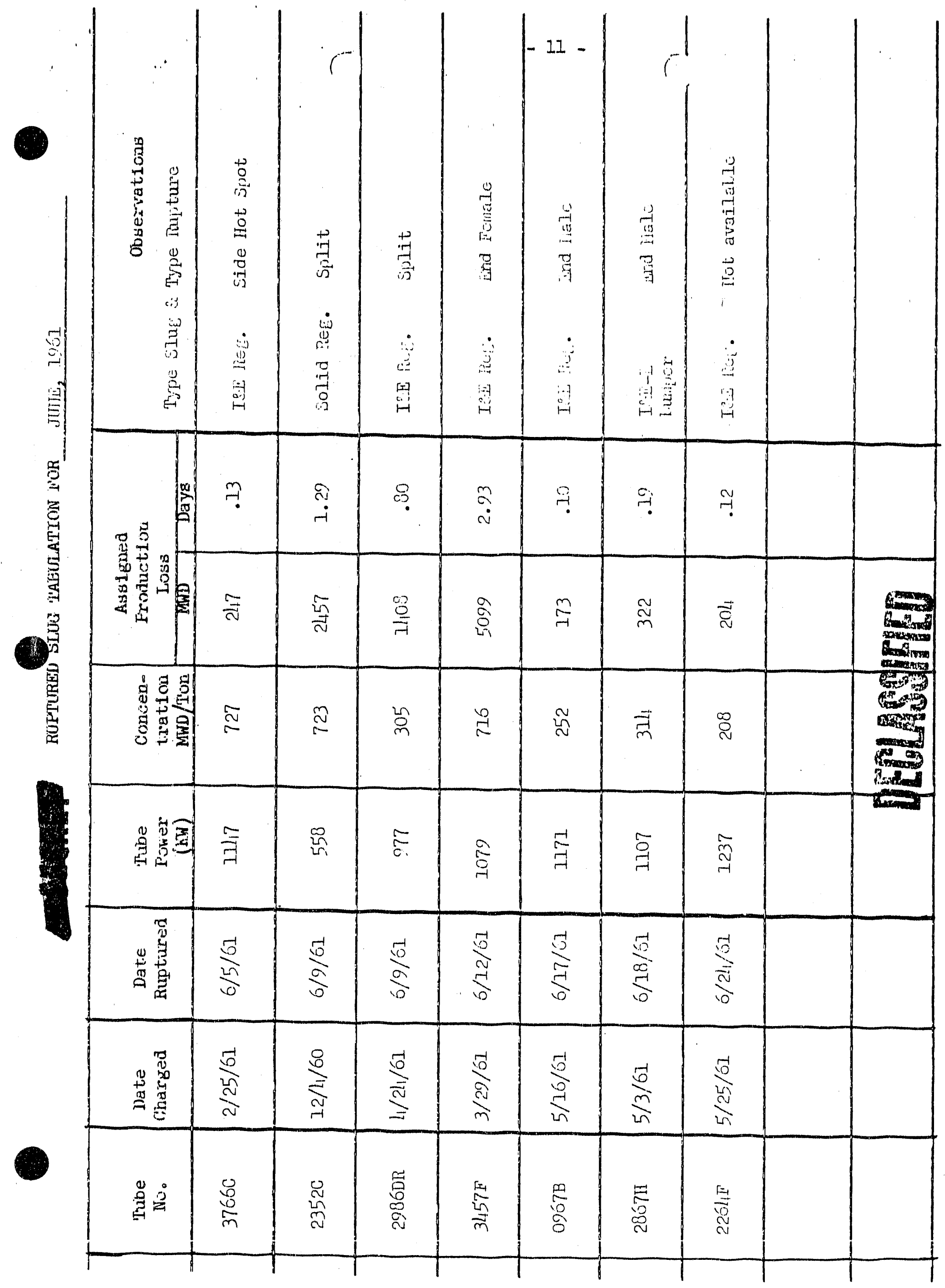


To: Files

FROM : R. I. Plum, Chief

Reactor Operations Jranch

SUBJECT: V:ONTILI RTPORT - JULI, 1961

OR:GTO: JPS r

STATES GOVERNMENT

DATB: Lufust 3, 1961

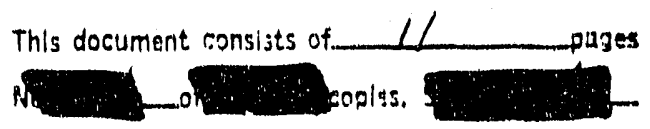

$: 251-77683$

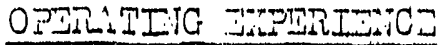

Production

Reactor input produotion (15) was 0.3 per cent below forecast; 8.7 per cent belor at the six old reactors and 10.1 per cent above at the $\mathbb{K}^{\prime} \mathrm{s}$.

\section{Ifficiency}

Over-all time operated eificiency was 76.4 per cent ( 31.4 per cent forecast); 72.3 per cent at the six old reactors and 88.7 at the $\mathrm{r}^{\prime} \mathrm{s}$. Ifficiency ras low at the old reactors due to water leaks, tube replacement and the dropoing of $3 x$ system balls at $D R$ reactor.

\section{Power LeveI}

There was no increase in the combined reactor instantaneous power level or the individual reactor record porrer levels. A monthly production record ivas achieved at $C$ reactor, exceeding the previous maximum by 7.3 per cent.

Fuel iuptures

One mupture, Io. regular metal at F, occurred during JuIy. This represents the loriest number of ruptures in the history of eight-reactor operation.

DR Reactor - 3.2 Ball Drop

The reactor was scrammed as a result of power intermption at the $151 \mathrm{D}$ sub-station. Improper calibration of the liercoid switches sensing riser pressure resulted in a Ball $3 \mathrm{~K}$ trip. ג11 VSR's were removed to facilitate the ball removal; -total control requirements jere maintained by charging $57 \mathrm{Fb}-\mathrm{Cd}$ columns and 127 effective splines; because all the splines would not go in full length, 178 splines were actually used.
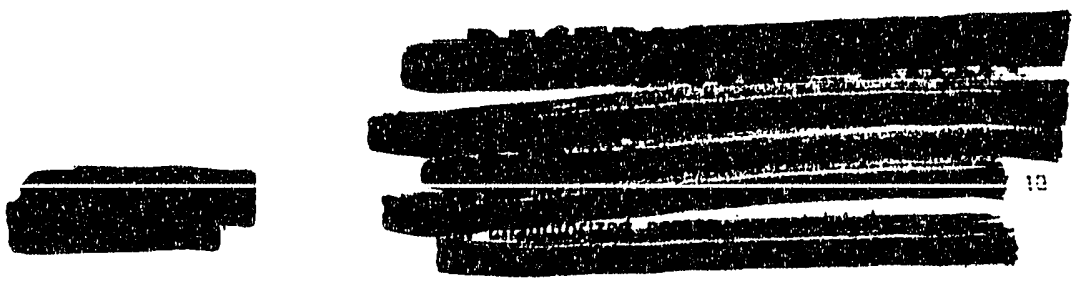
Backup prooodures inoluded partial withdraval (availabilitur) of icis and routine monitoring of loir level noutron monitors.

The initial critical configuration on Julir 21 following the ten dar ball recovery outage indilcated a loss of orer one per cont $k$ in reactivitj; operation sas initiated at reduced level and flux traverses taken in an atternt to determine the extant to shich the loss vas attributable to $3 \pi$ balls and/or rater.

\section{River Cooling Prorram}

The river cooling program ias put in effect Jul" 26, 1961 at Grand Coulee Jam. Inventory of cold ratar available vas materiallir reduced because of flooc control manijulations brr the Coms of ingineers. This resulted in the early release of large quantities of cold vater normally available for our cooling program.

\section{Reactor Effluent ictivity Reduction}

The high-alum feed process ras adopted at all areas according to the schedule shown belor. il one-to-tiro reok time lag betizeen changes in alum feed rate and consequent change in $A .95$ and p32 concentrations has been observed. This has prolonged optimization studies at $100 \mathrm{I}$ area and has changed monitoring criteria.

IIigh-ilum Feed idoption

\begin{tabular}{|c|c|c|c|}
\hline & JulJ 1 & $100 \pi$ & "ay I \\
\hline $100 \mathrm{C}$ & JuIJ 1 & $100 \mathrm{II}$ & Jintry \\
\hline 1000 & JulJ 15 & $100 \mathrm{ins}$ & Jule'T \\
\hline $100 \mathrm{DR}$ & JuIJ 15 & $100 \mathrm{inj}$ & $\operatorname{Ju} \perp=5$ \\
\hline
\end{tabular}

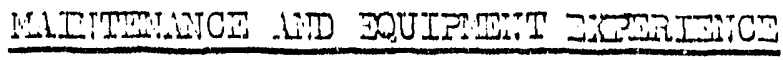

Tube Replacoment and Vater Leaks

Tho hundred twenty seven ne: process tubes were installed; 63 at $B, 58$ at $D, 51$ at $F, 50$ at DR, 3 at $C$ and one each at $\mathrm{KT}$ and KW.

Eighteen tube and seven Van Stone leaks were corrected. Five of the tube leaks were at D, flve at DR and two each at $B, C, F$ and $H$. Three of the Van Stone leaks were at $D$, three at $F$ and one at $B$.

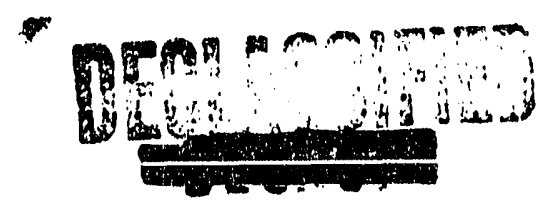


Incidents of difficult tube insertion during routine maintenance operations are being investigated. It has been found that graphite tube blochs are longitudinally split, that this occurs in channels which ill not pass a $1.730 "$ plue gange aftas $13 \% 4$. passed a 1.7LO" broach. The Inference is that the blocks ispring open to pass the broach and close behind 1 t to clamp the tube. it prolininary attemt at drizling before tube insertion rith

a 1.740" end min appear to have been successful.

InoL I OutfaII Itne EIociare

Durtng the Jul Lth holthar vechend, I araa personnel obserred high fllois in the overflo: f'Iume at 190! 1. . To trace of the outfall Ine openings could be found on the river bottom, and soundings siow that the genaral elevation of the river bed in that area is five or sir feet higher than during installation of the outfall Iine. On iugust 3 the upstream Iino cleared itself, and it is now carrying the entire effluent floir.

\section{Graphite Distortion}

Graphite distortion data colleotion continued at $105 \mathrm{C}$ and DR reactors. TSR channel No. 57 at C reactor was borescoped and found to be completelJ blocked about 38 feet down from the top of the reactor. Five 7.32 chaniels at $D R$ reactor vere inspected with the borescope. Broken blocks vere obsemred on $s i x$ to eleven per cent of the graphite layers in channels in the rod pattern fringes.

\section{REMCTOR OUT:LES}

Date Date Outage

Down Up ilours

B REICTOR

$7 / 24 \quad 7 / 30 \quad 150.2$

C REICTOR

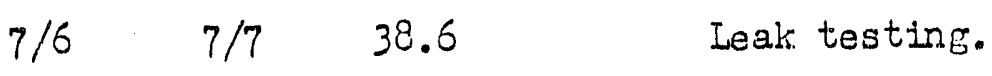
replacement.

Remarkss

Scheduled charge-discharge and tube 


\section{Files}

Date Date Outage

Doim Up Iours

D IIICTOR

$\begin{array}{lll}7 / 4 & 7 / 6 \quad 40.3\end{array}$

$7 / 11 \quad 7 / 13 \quad 47.1$

$7 / 20 \quad 7 / 24 \quad 36.3$

$7 / 24 \quad 7 / 2.5 \quad 40.1$

DR REICTOR

$\begin{array}{lll}7 / 1 & 7 / 2 & 47.2 \\ 7 / 5 & 7 / 9 & 55.5 \\ 7 / 11 & 7 / 21 & 237.8\end{array}$

$\begin{array}{lll}7 / 21 & 7 / 22 . & 27.7\end{array}$

$7 / 27 \quad 7 / 30 \quad 61.5$

$7 / 30 \quad 7 / 30 \quad 0.4$

F R INCTOR

$7 / 1 \quad 7 / 3 \quad 52.9$

$7 / 10 \quad 7 / 14 \quad 95.9$
$-4,-$

August 8, 1.961
Remarks

Leak testing. ileplacemont of four

loaking tubes.

Fower fallurg trip. Thbe raplacoment.

iator Leak. Charge-discharso and

miscalianoous matutonatoo.

Improperly positionad front faco cas. ieplacoment of 20 tubes.

Leak testing. Replaced five process tubes.

Leak testing. Replaced trenty seven process tubes.

Power fatlure when a relay at 151 substation was shorted out during testing. i $50 \mathrm{psi}$ drop in vater pressure folloring trip resulted in the $3 \pi$ system balls dropping into the VSR channels. The ball drop iras caused by an improper pressure trip setting resulting from the rrong identification of mercoids. Ball recovery.

Lack of reactivity. Charged enrichment and completed leak testing.

Inrichment adjustment, removal of balls from channels with electromagnet and tube replacement.

Panellit trip.

Removal of an Ire regular metal rupture from tube 2485 and charge-discharge.

Scheduled charge-discharge, tube replacement and maintenance. 
Dato Dato Outage

Dom Up Jouns

IF IEICTOil, cont.

$7 / 17 \quad 7 / 20 \quad 73.2$

$7,20 \quad 7 / 20 \quad 1.3$

$7 / 27 \quad 7 / 23 \quad 52.5$

$7 / 27 \quad 7 / 30 \quad 62.0$

$\begin{array}{lll}7 / 30 & 7 / 31 & 10.0\end{array}$

7/31. Still dorn

I REACTOR

$7 / 7 \quad 7 / 9 \cdot 45.4$

$7 / 10 \quad 7 / 10 \quad 1.3$

$\begin{array}{lll}7 / 18 & 7 / 18 & 0.3\end{array}$

IEI REICTOR

$7 / 17 \quad 7 / 20 \quad 83.2$

$7 / 31$ Still dom

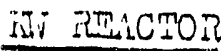

$6 / 27 \quad 7 / 1 \quad 87.4$

$\begin{array}{lll}7 / 1 & 7 / 1 & 1.1\end{array}$

$7 / 11 \quad 7 / 12 \quad 35.3$

$7 /$ I4 $\quad 7 / 15 \quad 3.5$
$-5-$

dugrust $8,1,061$
Loak testing.

ilepalr leak on splino ap 1169.

Iaals tasting.

Lor prossure panelitt trip on tube 3063

diue to a Ioali - tube remored. Charrodtscharge and probologetng of 97 process tubes.

Charge enrtohment in ret zone.

Charge additional enriohment.

Ieair testing.

Repair leaks on two front orossheader caps.

Tripped due to a rear pigtail fallure on 0778.

Scheduled charge-discharge and maintenance. Panelilt trip. Charge-discharge is in progross.

Soheduled charge-discharge and maintenance. Replace ortfices and plgtalls on three trabes due to high pressure.

Panellit trip. Charge-discharge.

Unexplained Panellit trip. 


\section{Self-O prorted Thuel Development}

Produotion test IP-409-im IP ;nich authorizes Irradiation test ing of iVIT fuel elements in smooth-bore alrcaloy-2 tubes has been approved. Tro charces itlil be loaded durtng the next iin.i outage.

\section{Jumer Tue I. Jovelonment}

Ten colums of natural urantum Inت bumper fuel olements and ten colums of non-bumpered control elements vers charged into Iis reactor on June 27,1961 under supplement is UI PT-Z2-103-iL-F. the fuel elementa are wit size itth three $50 \mathrm{mil}$-high collapsible bridge-rail bumpers on each end of the fuel element on $90^{\circ}$ contiars and in Iine. Tho of the bumper charges are equipped rith domstream thermocouple probes.

To date 700 tubes of bumper material have been succossfully Irradiated and disoharged from D reactor; 1, 411 tubes are currontli under irradiation.

\section{Charge-iThile-Operating}

Three 105 IS reactor tubes were discharged during operation JuIy 5. A.II discharges were through ball caps and were accomplished successfully. There was no evidence of non-controllable porel" croling following the discharge.

A Nark TI flapper was instaliled on the rear and a flapper nozzle on the front of one tube in IR reactor under provisions of PT IP-417-ji. This Production test permits charging of non-fissionable materials during operation. One such charge-discharge cycle was accomplished while the reactor ras starting up.

\section{Recrcle Program}

Study of the effect on reautor operation of recycling enriched uranium continued during the month. A production test to authorize spectal plcliup of irradiated recycled fuel has been signed and issued.

inalyses have been made on once-recroled fuel prior to its second irradiation. Prelininary results indicated the weight per cent of U-236 for three samples is as follows: $0.0085 \pm 0.0005$, $0.0081 \pm .0005,0.0093 \pm .0005$.

\section{Irir Loadting}

Iquilibrium operation with the fill load continues to be stable with the present load approximately midway through its exposure

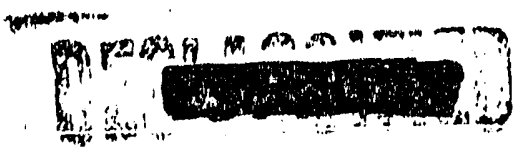


"arrole. IIght additlonal tubes of LI-iI have been charged to absorb excess reactivity of the initial load.

in evaluation was made of the looal and total control affactireness of the I plle with the I-it loading as charger. This calculation agrees with prevtous conclusions on the adequacy of the vertical safety system for carrying out this loading in the II reactor.

Jubsequent to the sainartum transtent the hot long-term ragetivitur ohanges in the I-il loadirs have been essentialiy zero. Indluations to date are that the next cycle of the "juil load should have an adclitional target plece in evor fifth tubo. Jiline flum traverses

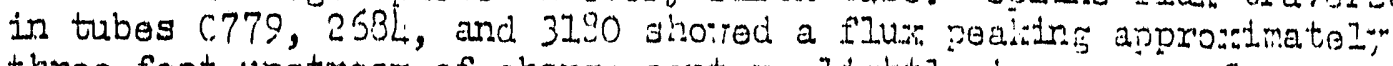
three feet uystream of sharge center alightly in excess of a cosino patterm marimum.

Shlalding Studies

The current rather high I-reactor top shield temperature can be attributed to the higher concentration of $\mathrm{CO}_{2}$ permittad by the lower speciftc pover durling the sumer months. During the operatiner mun at 7.or level following the Dil ball drop, top shield temperatures reached $177 \mathrm{C}$ ith a 100 jer cent $\mathrm{CO}_{2}$ atmosphere but uth maximum specific tube porfers onlir about tro-thirds normal. These observations confirm earlier conclusions on the effectireness of holium in improving thermal and blological shield conductivity.

\section{PTE:CTOR YODITICATIONT PROGRII}

Orerbore Tool and issembly Develonment

The following new equipment or improvements to existing machines are being fabricated: (a) lodifications to the tri-bore machine. lodifications accomplishod have reduced the cutting time from more than 15 minutes to 10 minutes. (b) ile: Jraphite dril1 designed to eliminate the noed for coordination with the rear face. (c) Cunbarrel removal equipment. (d) il jombination corincoverboring cutter, permitting the chamel to be bored with tio different diameters, one larger than the gunbarrel.

Otrerbore Fuel Detelonment

There have been no Joading changos during this report period artd all trenty overbore-size fuel colums in $\mathrm{C}$ reactor are contiming to perform satisfactorilJ.

dill required postmirradiation measurements have been completed for the four fuel columns which have been discharged to date. 
- I mazimum reight loss of about 20 grams has been reported for domstream fuel elements from the tio short-charged (18 pieces) central zone tubes discharged on June 5, 1962 at an average exposure of $662: \mathrm{Ym} / \mathrm{T}$. Thenty grams is equivalent to about 7 mils of aluminum loss uniformly distributed over the fuel element surface.

\section{Reactor Overbore Conversion Iratio}

The theoretical neutron balance for the cold clean pile indicates a 21.4 per cent relative increase in the atom/atom canversion ratio for the proposed overbore lattica. The relative incrase in the hot pile is slightly lower - 13.9 per cent, and the exposure dependence on the conversion ratio is not expected to be mich different for the tro cases. The relative gain in Grams Pu per : ID :NiIl be some:fhat less tian that in atom/atom conversion ratio due to the larger fission rate in $U-238$ in the overbore pile. The appropriate relative gain in the grams/ INiD conversion ratio is 12 per cent.

ITU PRODUCTION RTEKCTOR

\section{IER Tacility High Temperature Testing}

Three 17-inch IIII elements and two 17-inch NIII elements with capped defects for failure testing in the PRTT Inpture loop have been irradiated in ITR-I to an average exposure of $86519 \mathrm{~T} / \mathrm{T}$. Tro more 17-inch NIII elements with capped jacket defects vere adced to the charge on JuIT 19, 1961, thus providing failure test elements at two different exposures (approximatelJ 2000 and $1000 \mathrm{MJ} / \mathrm{T}$ ) when the irradiation is completed.

Tive 23-inch, III elements in ivi-2 have reached an eiposure of 1915 MND/T as of JuIr 2L, 1961. One 23-inch VIII element added to the charge on $\mathrm{Yay} 29$, 1961 has an exposure of $720 \mathrm{ND} / \mathrm{T}$. on JuIy 19, 196I, a second 23 inch NIII element vas added to the loading. The procedure should provice elements at about 3000,2000 and $1000 \mathrm{iTD} / \mathrm{T}$ ithen the colum is discharged.

Co-extruded ICJ Tuel Development

The initial two tubes of co-extruded IRE fuel elements which were charged into $\mathrm{Ki}$ reactor on $\mathrm{May} 2 \%$. 1961 reached $420 \mathrm{~N} / \mathrm{D} / \mathrm{T}$ exposure on about July 20, 1961. These two charges vere goaled for $400 \mathrm{MD} / \mathrm{T}$ and vill be discharged at the next outage. Five additional colums $\mathrm{Nill}$ be added at that time.

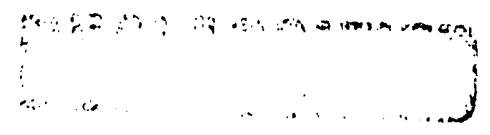


Tast Teutron Inergr Dissipation in iT Reactor Process Tubes

The Yonte-Carlo program used to determine fast neutron damage

in IIPR graphite has also enabled the determination of the onor dissipated in the process tubes. Th enersy dissipatod jor

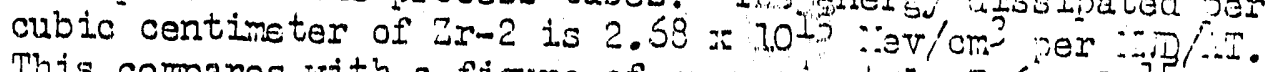
This compares vith a figure of approxtmately $7.5: 1015$ in tha graphite.

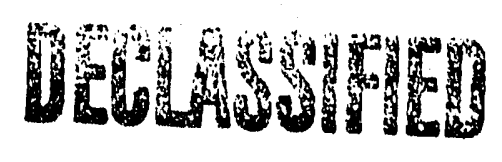




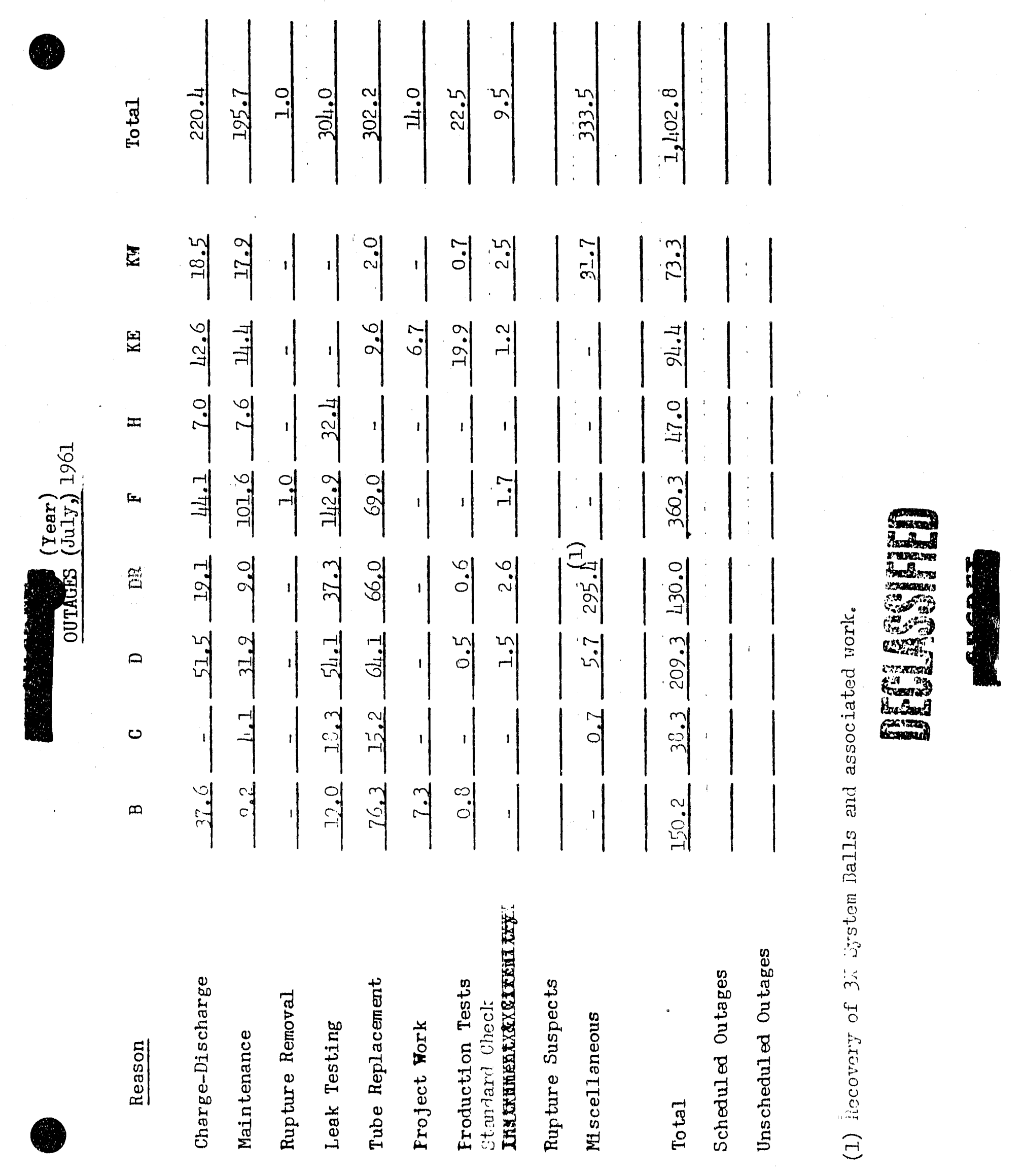




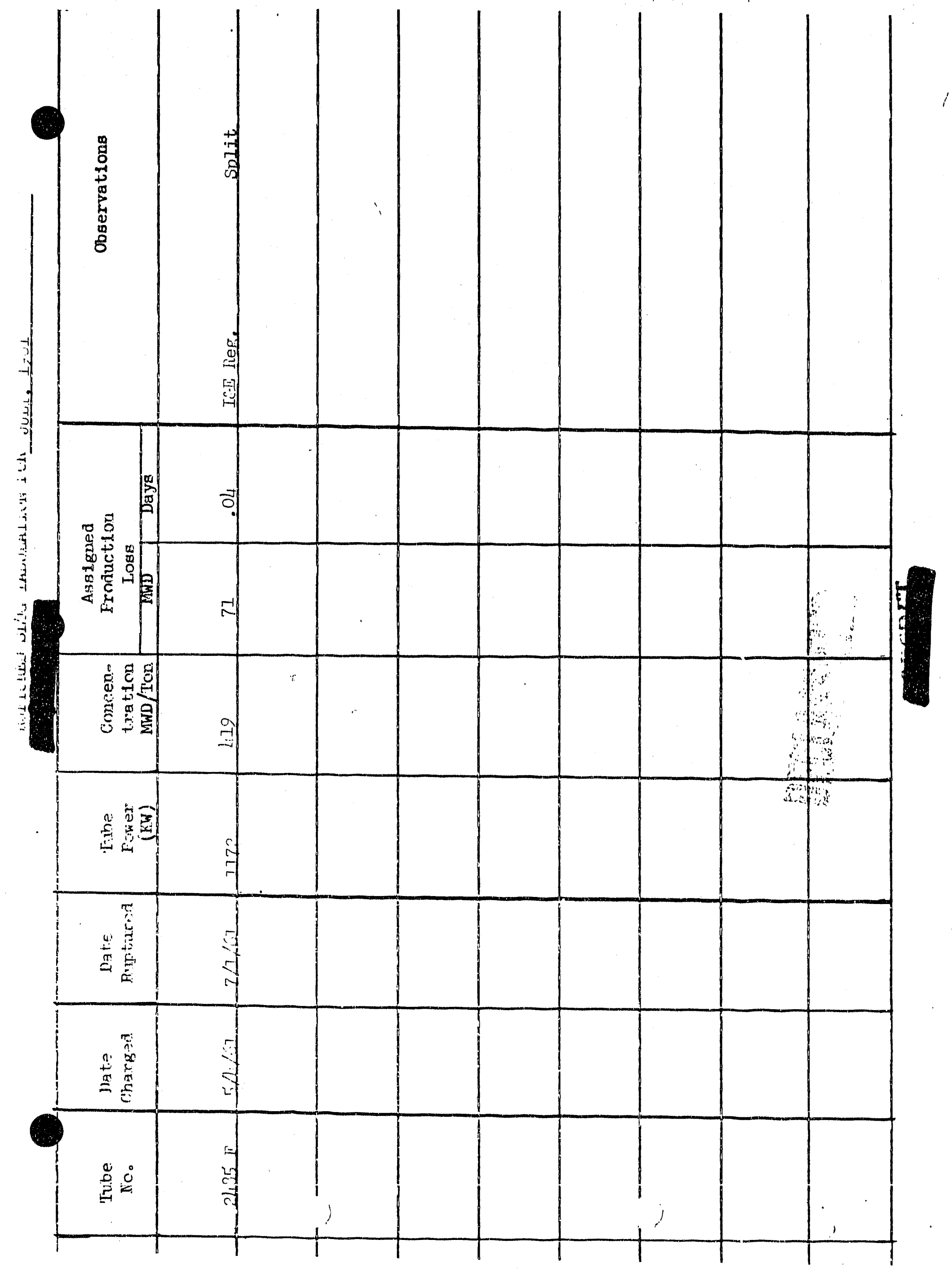




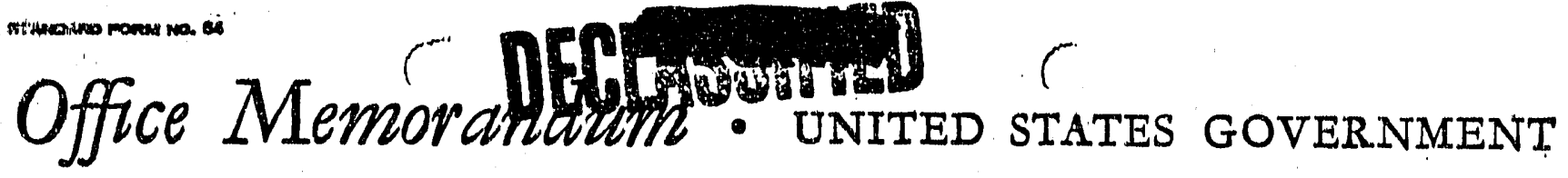

To: Files

FROM : R. L. Plum, Chief

Reactor Operations/Branch

SOBJECT: NONTHLY REPORT - AUGUST, 1961

OR: GTO:JPS

DATR: September 12, 1961

OPERATIITG EXOERIZNCE

Production

Reactor input production (IND) was $2.2 \%$ below forecast; $11.6 \%$

below at the six old reactors and $12.2 \%$ above at the $K^{1} s$.

Efficiency

Over-all time operated efficiency was $77.0 \%$ (79.0\% forecast);

$75.3 \%$ at the six old reactors and $32.2 \%$ at the $K^{\prime} s$. Efficiency

was Ior at the oid reactors due largely to process tube water

leaks.

Power Level

There was no increase in the combined reactor instantaneous power level or the individual reactor record power levels.

Power Level Limits

The power levels at all reactors are currently limited by bulk outlet temperature restrictions.

Fuel Ruptures

Six mptures, three IüE regular metal and three IúE enriched, were removed from the reactors. Tho of the I\&E regular metal ruptures were at $D R$ and one at $D$. Two Iid enriched ruptures were removed from $\mathrm{H}$ and one from KK $\mathrm{K}$.

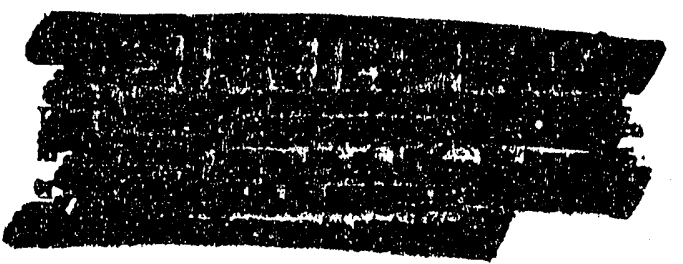




\section{Reactivity Loss - F Reactor}

The thactivity loss from the $F$ Reactor tube leak on July 27

was the most severe experienced to date. Rapid drying was

accomplished, however, by extensive use of enrichment and

supplementary control, and bulik limit operation was achieved

by mid-August.

Reactivity Loss - DR Reactor

The large reactivity loss observed at the DR Reactor following the Ball $3 \mathrm{X}$ drop in JUlJ continued; operating levels approaching bulk limits were achleved the latter part of August after successive additions of enrichment in a relatively uniform array.

The enrichment investment required to compensate the reactivity loss following the ball droo indicates a continuing loss of at least $15 \mathrm{mk}$. Only very minor gains were made following water removal and iritial ball removal attempts by means of a magnet. Radial temperature maps and longitudinal spline flux traverses to date have not indicated any gross, localized poison effects.

Initial enrichment was added centrally to permit specific levels capable of water removal. from the graphite, and the operating level under these conditions was approximately 800 iN early in the month. Two subsequent enrichment steps permitted operation near 1500 iTw near the end of the month. The present enrichment inventory of 460 colums is approximately $200^{\circ}$ greater than normal during the high-exposure portion of the block discharge cycle.

Equioment was expedited to remove many scattered balls remaining in 105-DR Reactor. The most successful devices were a pair of powerful electromagnets equipped with a microphone to register the collection of balls and a TV camera which can be lowered into the VSR holes to give a complete view of the channel.

\section{MATITENANTCE AND EQUTPMENT EXPERIENCE}

1. One hundred and thirty-five new process tubes were installed; 93 at $D, 20$ at $H, 7$ at each $B, D R$ and $F$, and one at $K E$.

2. Fourteen tube and 7 Van Stone leaks were corrected. Five of the tube leaks were at $\mathrm{H}, 4$ at $B, 3$ at $D, I$ at $F$, and $I$ at $K W$. Five of the Van Stone leaks were at $B$ and 2 were at $H$.

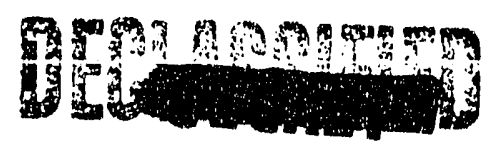


TSR's, 100 C Reactor

105-B Reactor type vertical rods have been installed in VER channels Nos. LI and 22, bringing to six the number of "B" rods in serrice at $C$ Reactor. Rod drop measurements subsequent to "B" rod installation indicate all VSR's to be operating within insertion times specified by Process Standards.

\section{4-H Outfall Iine Blockage}

Essentially complete blockage of the 1904-H outfall lines was detected in July through observations of unusual reactor effluent discharge through the overflow flume at the shoreline. Obserrations early this month at the overflow flume indicate a partial or total removal of the restrictions had taken place. It has not yet been determined whether the blockage has been completely removed; however, it appears that the outfall lines are discharging the reactor effluent satisfactorily. A fathometer surrey made this month indicated that the river bed was generally 3-4 feet lower in elevation than during surveys made on July 18-19, although still 1-2 feet higher than indicated on construction drawings. No trace of any depression around the end of the lines, as shown in the drawings, could be found. An inspection of the apron below the concrete flume revealed that, although some cracking of the concrete riprap had occurred, the apron appeared to be in good condition. The only evident scouring had occurred on one side of the apron adjucent to the shore, and this hole has now been filled by large rock. Further investigation of the over-all problem is continuing.

\section{HP Motor Stator Program}

Three stators with modified class A windings were installed. In addition to the elght class $B$ units, nineteen modified class A stators are now in service. A revised schedule indicating completion of the rewinding program in early 1962 has been issued.

\section{De Laval Pump Impellers}

The impellers (two per pump) in 38 of the $40 \mathrm{De}$ Laval purnps have now been inspected. Defects sufficient to recomend replacement have been found in 24 impellers. Of these, 10 have already been changed. One reworked impeller has been placed in service and currently 9 others are at the vendor's plant awaiting repair.

In an effort to reduce the maintenance time required to make the actual change-out of a defective impeller, a complete it ating pump unit is made ready and available for use prior to disassembly of a purm for inspection. 
Files

$-4-$

Seotember 12, 1961

REACTOR OUTAGES

$\begin{array}{lll}\text { Date } & \text { Date } & \text { Outage } \\ \text { Down } & \text { Uours }\end{array}$

Down Up Hours

Remarks

B Reactor.

$8 / 14 \quad 8 / 15 \quad 0.3$

Tripped by a power surge on the BPA system due to lightning.

$8 / 15 \quad 8 / 16 \quad 42.2$

Tripped when a VSR dropped to the lower position. Charge-discharge and miscellaneous maintenance.

$8 / 17 \quad 8 / 19 \quad 34.0$

Leak testing and miscellaneous maintenance.

$8 / 21 \quad 8 / 23 \quad 57.1$

Leak testing and miscellaneous maintenance. Three leaking tubes reolaced. Seven pumps in use due to the motor on ivo. 3 burning out.

$8 / 28 \quad 8 / 30 \quad 37.9$

Leak testing and miscellaneous maintenance.

C Reactor

$8 / 1 \quad 8 / 4 \quad 88.4$

Scheduled charge-discharge and maintenance.

$8 / 14 \quad 8 / 15 \quad 0.2$

Tripped by a power surge on the BPA system due to Iightning.

$8 / 19 \quad 8 / 25 \quad 159.8 \quad$ Scheduled overboring.

$8 / 30 \quad 8 / 31 \quad 43.4$

Abnormally high pressure on overbored tube 3165.

D Reactor
$8 / 6 \quad 8 / 10 \quad 99.1$
Water leak. Charge-discharge and tube replacement.

$8 / 18 \quad 8 / 20 \quad 51.8$

Water leak. Charge-discharge.

$8 / 24 \quad 8 / 24 \quad 0.4$

Unexplained Panellit trip.

8/29 Still down

Removal of an I\&E regular metal (bumper) mupture from tube 1163. Charge-discharge and tube replacement. 
Files

\section{S DECLEA}

DR Reactor

8/9 8/11 $47.7 \quad$ Panellit trip. Charge-discharge and miscellaneous malntenance.

$8 / 14 \quad 8 / 16 \quad 38.1$

Charging of additional enrichment and replacement of 7 process tubes.

$8 / 23 \quad 8 / 25 \quad 40.5$

Gas loop trip. Hiscellaneous maintenance.

8/31 Stil工

down

Removal of I R regular metal muptures from tubes 2470 and 2478 .

F Reactor

$7 / 31 \quad 8 / 1 \quad 17.4$

Charging of additional en:-ichment.

$8 / 23$

$8 / 26 \quad 73.4$

Leak testing and charge-discharge.

H Reactor

$8 / 3 \quad 8 / 6 \quad 93.4 \quad$ Leak testing and tube replacement.

$\begin{array}{llll}8 / 6 & 8 / 7 & 2.3 & \text { Repair of leaking front pigtails on tubes }\end{array}$ 2290 and 2655.

$8 / 7 \quad 8 / 7 \quad 0.7 \quad$ Low pressure Panellit trip on tube 2391.

$8 / 7 \quad 8 / 7 \quad 3.0 \quad$ Hi.gh pressure Panellit trip on tube 2391. Discharged metal and replaced Venturi and front pigtail.

$8 / 7 \quad 8 / 8 \quad 21.6$

Removal of an Is. E-metal rupture from tube 2476.

$8 / 15 \quad 8 / 16 \quad 38.2 \quad$ Leak testing.

$8 / 30 \quad 9 / 1 \quad 35.7 \quad$ Removal of an I\&E E-metal rupture (bumper) from tube 1379. Charge-discharge and miscellaneous maintenance. 
KE Reactor

$\begin{array}{llll}7 / 31 & 8 / 2 & 40.9 & \begin{array}{c}\text { Panellit trip. Charge-discharge and } \\ \text { miscellaneous maintenance. }\end{array} \\ 8 / 8 & 8 / 10 & 41.3 & \begin{array}{l}\text { Panellit trip. liscellaneous maintenance. } \\ 8 / 30\end{array} \\ \begin{array}{r}\text { Still } \\ \text { down }\end{array} & \text { Scheduled charge-discharge. }\end{array}$

III Reactor:
$8 / 14 \quad 8 / 17 \quad 79.9$
Scheduled charge-discharge and miscellaneous maintenance.
$8 / 24 \quad 8 / 26 \quad 40.7$
$8 / 26 \quad 8 / 27 \quad 39.5 \quad$ Leak testing.
Removal of an I\&E E-metal rupture from tube 1363 and leak testing.

\section{RESEARCH AND DEVELOPNENT - EXISTING REACTORS}

Derational Fueling Facility

105 KE Reactor was scrammed by an operational fueling test on July. 31. The scram resulted from circuit difficulties connected with a time delay that is not required for uranium charging but was desirable for the dumy charging of this experiment. During the subsequent startup August 2, two successful cycles were completed. Two more cycles were performed after an unrelated outage August 9. On one of these, a minor malfunotion in the charging machine made it necessary to discharge the half-charged tube and start over.

\section{E-N Load}

A major contributing factor to the continued stable operation wi.th the $\mathrm{E}-\mathrm{N}$ load has been the lack of change in hot reactivity during the operating cycle; no hot reactivity loss trend has been observed up to an urantum exposure of $690 \mathrm{MWD} / \mathrm{T}$. In the exposure range of 600-700 $\mathrm{M} \cdot \mathrm{WD} / \mathrm{T}$, the cold reactivity l.oss rate has been about one nks per 50 MND/T increase in exposure. The recomended charge pattern for the next core cycle of the $E-I N$

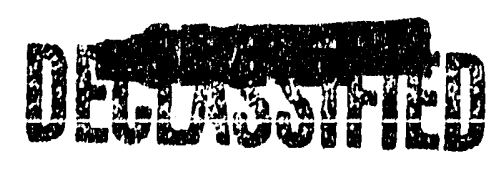


loading will increase the ratio of lithium-aluminum to enriched slugs slightily - from $16 \mathrm{~N}$ slugs per 5 columns to 17. The observed lack of hot reaotivity losses during the first cycle will permit uniform reactivity reduction equivalent to the number of lithium-aluminum poison.coliunns loaded during the first oycle.

Overbore Fuel Develooment

Eight columns of overbore size fue. were discharged and lecharged without difficulty at C Reactor during the $8 / 1 / 61$ outage. Column makeup and discharge exposures were as follows :

\begin{tabular}{|c|c|c|c|c|c|}
\hline $\begin{array}{l}\text { Thube } \\
\text { No. }\end{array}$ & $\begin{array}{l}\text { Type } \\
\text { Tube }\end{array}$ & Pieces & $\begin{array}{c}\text { Charge } \\
\text { Date } \\
\end{array}$ & Discharge & Eixro osures \\
\hline 2863 & $S B-Z x$ & 18 & 4-9-ó1 & $828 \cdot M T / T$ & \\
\hline 2866 & $S B-Z r$ & 18 & 4-9-61 & $770 \mathrm{MND} / \mathrm{T}$ & . \\
\hline 1453 & $\mathrm{SB}-\mathrm{Zr}$ & 32 & $1-17-61$ & $776 \mathrm{MND} / \mathrm{T}$ & \\
\hline 1494 & $S B-Z r$ & 32 & $2-25-61$ & $643 \mathrm{IND} / \mathrm{T}$ & (and cycle) \\
\hline 4463 & $S B-A I$ & 32 & $3-6-61$ & $616 \mathrm{NWD} / \mathrm{T}$ & \\
\hline 4472 & $S B-A I$ & 32 & $3-6-61$ & $640 \mathrm{MND} / \mathrm{T}$ & \\
\hline 4475 & Ribbed AI & 32 & $3-6-61$ & $648 \mathrm{iNND} / \mathrm{T}$ & (bumper) \\
\hline 4478 & Ribbed AI & 32 & $3-6-6 I$ & $646 \mathrm{MND} / \mathrm{T}$ & (bumper) \\
\hline
\end{tabular}

Visual observations have revealed some hot-spots and hot-areas. of medium severity. No hot-spots or hot-areas were observed in the two high-powered charges. Iight surface bumping, metal e.llipticity and some corrosion were observed. of 186 elements observed, only 6 showed corrosion penetration greater than 10 mils.

Channel 1494-C was equipped with an overbore size smooth-bore Zircaloy-2 process tube and fitted with Design I hardware during the $8 / 1 / 61$ outage. The tube was charged with 18 cVINS elements. 
Self-Supported Iruel Develonment

Thirty-three columns of CIVNS fuel were discharged and recharged during the $3 / 1 / 61$ outage at $C$ Reactor without difficulty. Six. columns were oicked up especially for post-Lrradiation examination, and five new monttor columns were charged. Tho $K$-size smooth-bore Zircaloy-2 process tubes were installed and charged with kivi self-supported fuel elenents at $k T$ Reactor during the $8 / 14 / 61$ outage.

\section{Bumper Fuel Development}

The ten columns of KITN bumper fuel elements which were charged In KN Reactor on 6/27/61 are estimated to be at about $400 \mathrm{NTN} / \mathrm{T}$, 33\% of scheduled goal exposure.

Twenty-six columns of OIIIITB fluel elements were charged into $D$ Reactor on $8 / 6 / 61$ under authorlzation of PT-310. The test is designed to evaluate the dimensional stability of fuel element. cores segregated by the UT-2 (Nark 2 ultrasonic tester) on the basis of uranium grain size. There are eight columns of large grain material, nine columns with a variation of grain size, and nine columns with small grains. Nine of the twenty-six columns are equipped with downstream thermocouple trains to evaluate the performance of the burnper fuel element in new ribbed process tubes with: 1) no mixers, 2) mixers in 10th position, 3) mixers in 7 th and 15 th positions.

To date, 1075 tubes of bumper material. have been successfulily irradiated and discharged from D Reactor; 1423 tubes are currently under irradiation.

\section{Coextruded I\&e Fuel}

The initial two columns of coextruded fuel elements which were charged into IWW Reactor on 6/25/61 were discharged during the $8 / 14 / 61$ outage at an average exposure of $680 \mathrm{MND} / \mathrm{T}$. Six columns. were charged during the outage.

\section{REACTOR MODIFICATION PROGRAM}

C Reactor Overbore

An overbored process tube assembly consisting of zircaloy process tube, prototype Lnlot clantp nozzle and fixed outlet nozzle assemblies was installed August 3, 1961, in overbored process tube channel No. 1464 at 105 C Reactor. 


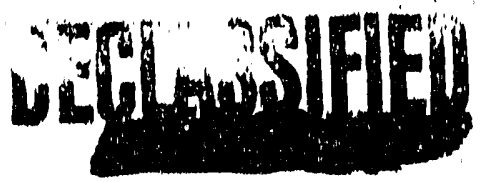

$-9$.

Sevtember 12, 1961

During the 0 Reactor outage the weelc of August 20 , the firgt 20 of a 40-tube block of proo s tube channels were overbored, large Zfroaloy-2 tubes instulled, and outfitted with overbore clamp-hozgle hardware, and loaded with large-sized fuel elements.

Subsequent to the reactor startup followlng the outage a high Inlet water pressure on one of the overbored tubes required the reactor to be shut down. The ensuing investigation revealed that the process tube assemblios had been funotiondng satisfiactorily and that the abnormal pressure was due to the dummy loading in the process tube.

Three-group flux and power distributions across the overbore block in 0 Reactor have been oalculated. The preliminary results Indicate a fairly flat power distribution across the blook; the higher fast and epithermal contributions to the fission power tend to oompensate for the lower thermal contribution. The maximum power generation expected is $112 \mathrm{kw} / \mathrm{ft}$ in the peripheral overbore columns (normalized to a $70 \mathrm{kw} / \mathrm{ft}$ maxjmum in the CIIN columns).

The actual performance in 0 Reactor cannot yet be assessed precisely, but the power generation rate appears to be in reasonably good agreement with theoretical predictions. As equilibrium is achteved and splining operations are reduced, more preclse evaluation will be possible.

\section{NEW PRODUCTION REACTOR}

N Reactor Fue. Development

Three 17-inch NIEl elements and two 17-inch NIE1 elements with capped jacket defects for failure testing in the PRTR rupture loop have been irradiated in KERT-1 I0op to an average exposure of $1320 \mathrm{MLD} / \mathrm{T}$. Two more I7-Inch NIEl elements wi th capped jacket defects added to the charge on $7 / 19 / 6 \mathrm{~L}$. have reached an
exposure of $360 \mathrm{MID} / \mathrm{T}$.

The fuel loading in KER-2 was clscharged $7 / 31 / 61$ because of $100 \mathrm{p}$ operating difficulties. The five 23-Inch NINI elements had reached an exposure ol: $2090 \mathrm{INVD} / \mathrm{T}$. The one 23-inch NIEI added to the charge on $5 / 28 / 61$ was discharged at $905 \mathrm{MWD} / \mathrm{T}$, and the second 23-inch NIEI element added to the loading on $7 / 19 / 61$ was discharged at $150 \mathrm{NT} / \mathrm{T}$. 


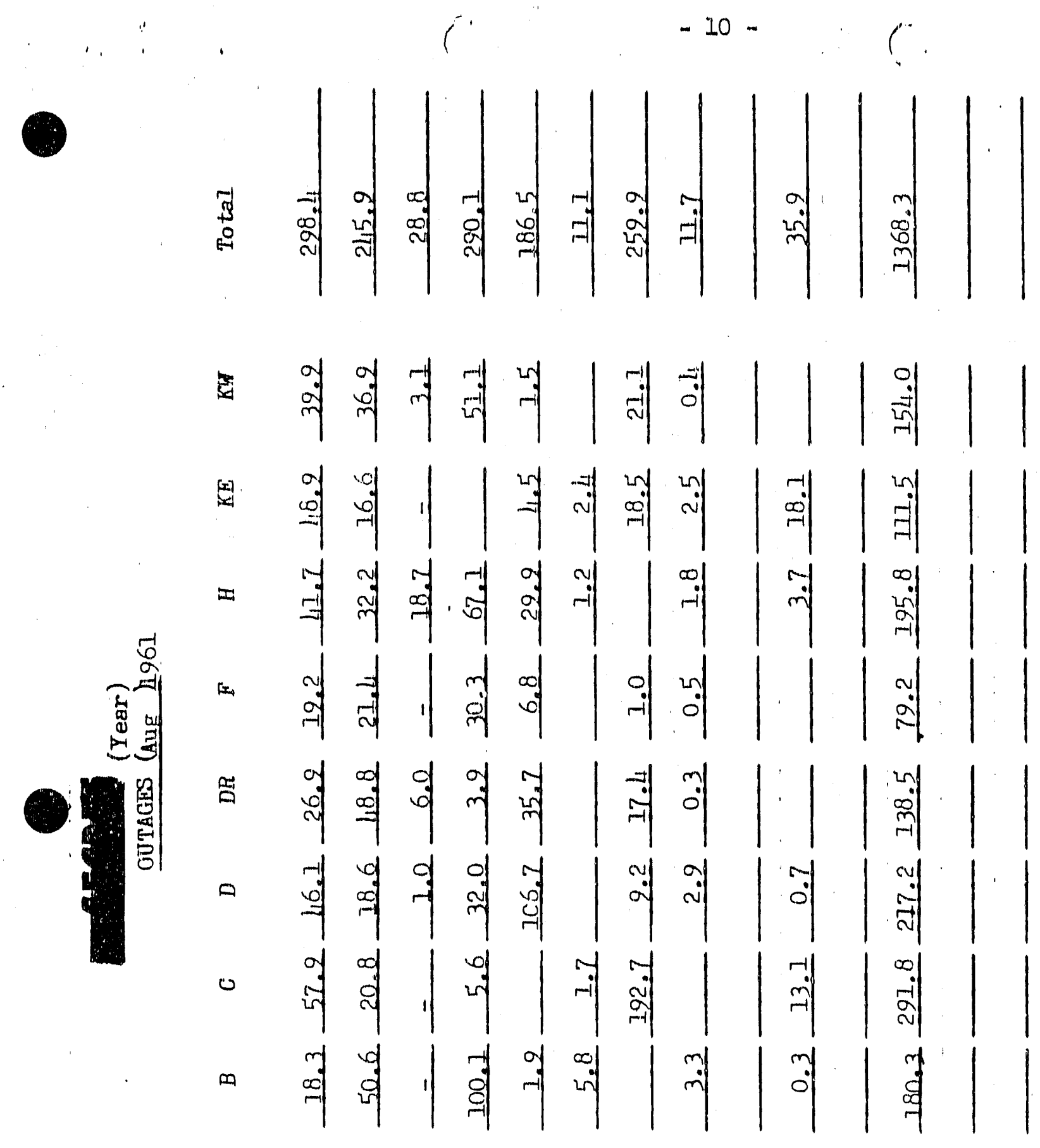

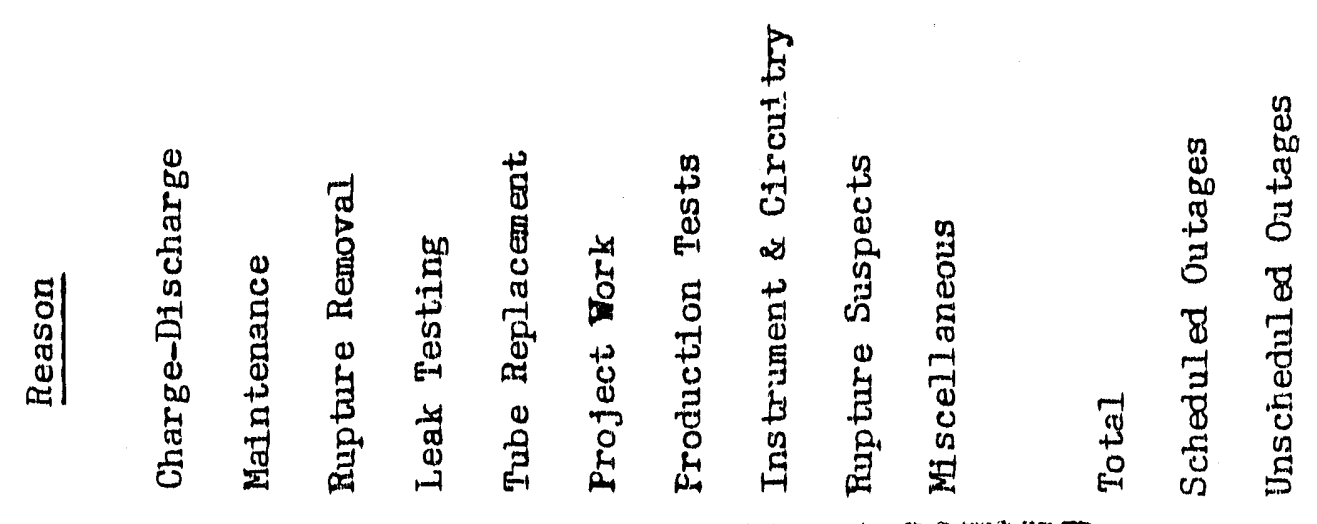




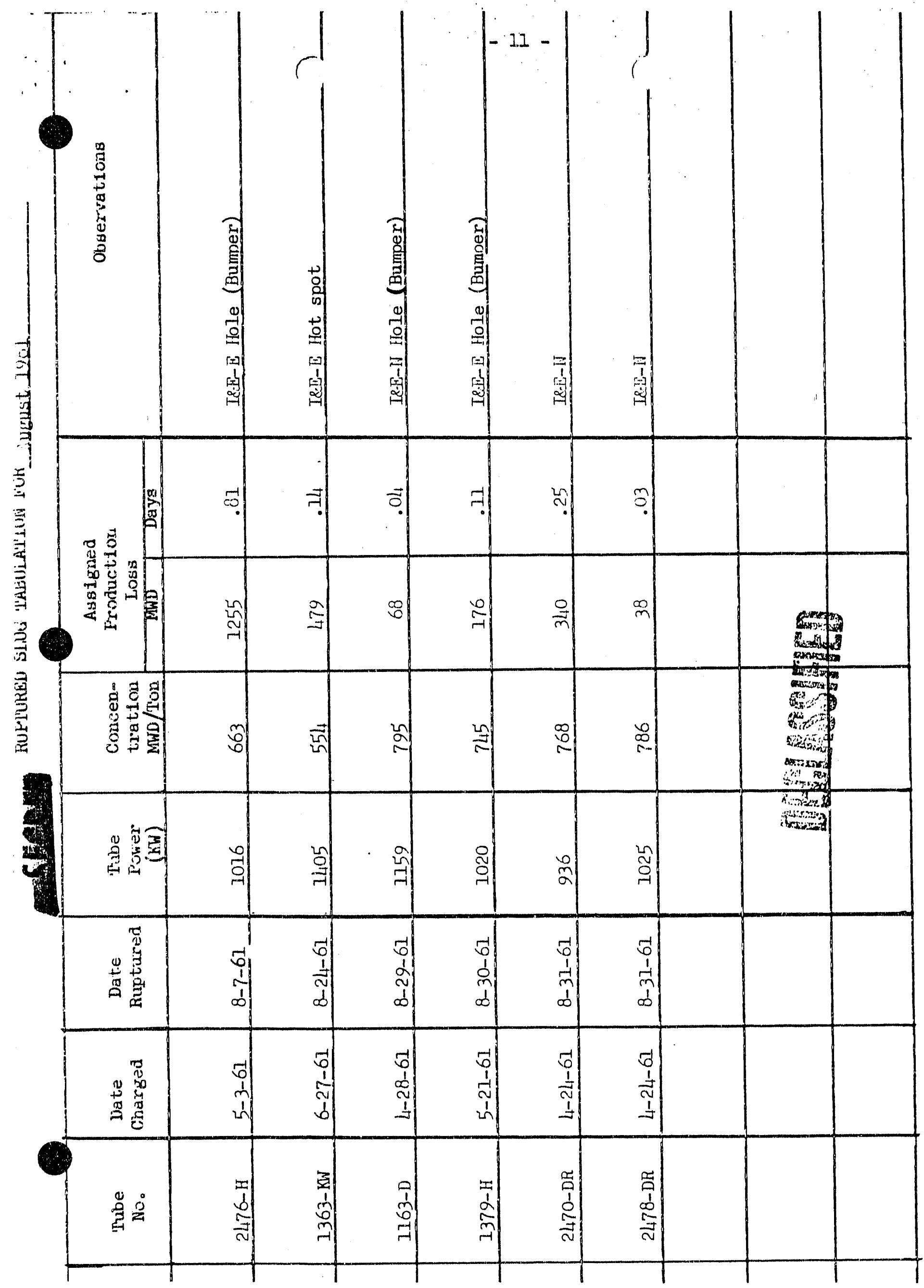




\section{$\ldots$ \\ Office Memorantedessiften

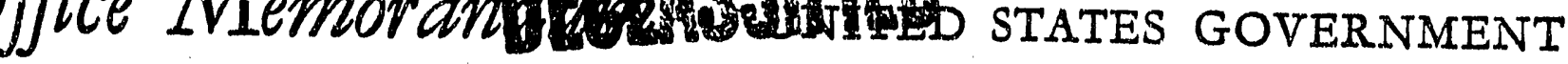

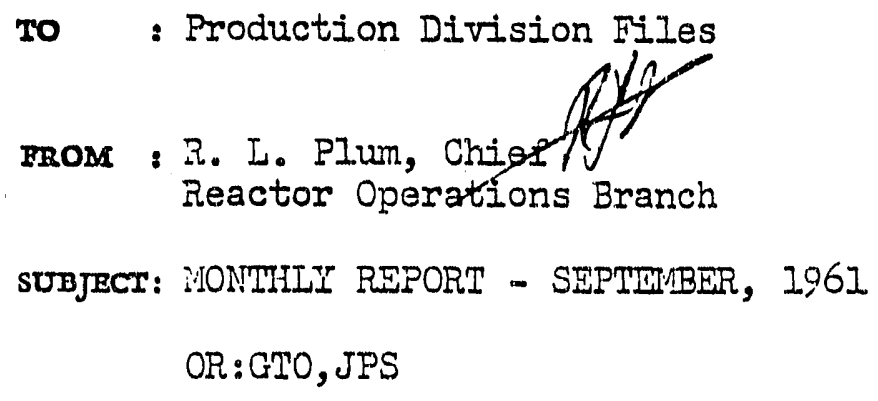

OPERATIXIG EMPEIVIENCI
DATE: October 10, 1961

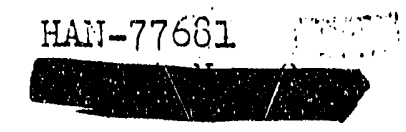

\section{Production}

Reactor input production (NinD) was $7.5 \%$ below forecast; $15.3 \%$ below at the six old reactors and $3.6 \%$ above at the $\mathrm{K}^{\prime} \mathrm{s}$.

\section{Efficiency}

Over-all time operated efficiency was $71.3 \%$ ( $80.6 \%$ forecast); 66.6\% at the six old reactors and $35.3 \%$ at the $\mathrm{K}^{\prime} \mathrm{s}$. Efficiency was low at the old reactors due largely to tube replacement, water leaks, and block discharges at DR and $\mathrm{H}$ reactors.

\section{Power Level}

There was no increase in the combined reactor instantaneous power level nor in the individual reactor record power levels.

Fuel. Ruptures

Nine ruptures, eight I\&E enriched metal and one I i. regular, were removed from the reactors. Three of the enriched muptures were at $\mathrm{F}$, two at $\mathrm{DR}$, two at $\mathrm{H}$ and one at $\mathrm{D}$. The regular metal rupture was at $D$. Three of the Iuptures, one regular metal and two enriched, were caused by charging machine damage.

\section{Power Level Linits}

During this report period the power levels at all reactors were restricted by bulk outlet temperature limits.
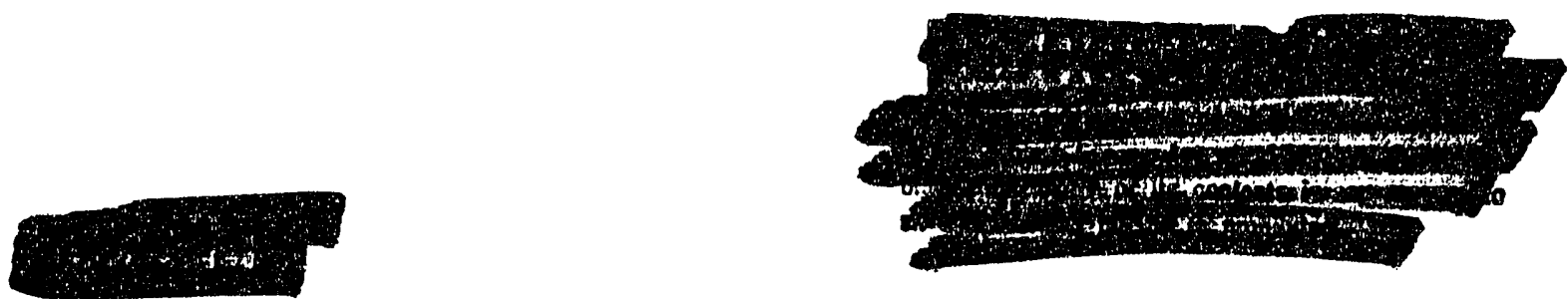


\section{$-2-\quad$ October 10, 1961}

Reactivity Loss - DR Reactor

A major attempt was made to remove $3 \mathrm{X}$ balls early in the month. The reactivity gain has been evaluated to be about $2 \mathrm{mk}$ (compared to a total loss of about $15 \mathrm{mk}$ ). With the block discharge occurring during the same outage, the possible inaccuracy in determination was probably equal to about $50 \%$ of the measured change.

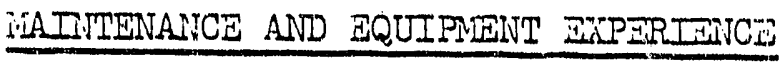

Tube Replacement and water Leaks

Two-hundred ninety-six new process tubes were installed; 87 at $B, 86$ at $H, 47$ at DR, 43 at D, 31 at $F$, one at $\mathrm{KE}$ and one at III. Twenty-one tubes and two Van Stone leaks were corrected. Ten of the tube leaks were at $H, 7$ at $D, 2$ at $B$ and 2 at $F$. One Van Stone leak was at $B$ and one at $H$.

Graphite Distortion

Ingineering and technological assistance has been requested from the General Engineering Laboratory concerning the graphite distortion problem. Initial efforts will be directed toward evaluation of alternate materials for use as sleeves in the vertical safety rod channels.

VSR Channels, $100 \mathrm{C}$ and $100 \mathrm{DR}$ Reactors

Graphite distortion data collection continued at 105-C reactor with baroscope and traverse measurements completed on VSR channel No. 37. This channel, which is centrally located in the rod pattern, is relatively straight when compared to measurements previously obtained on channels in the rod pattern fringe; however, the channel is oostructed by a protruding block at a location below the full rod position. Hine VSR channels at DR Reactor were visually examined with a closed circuit television system. Observed graphite breakage was tyoical of that noted during previous boroscope examination. Photographs were obtained of typical graphite damage and of $3 \mathrm{X}$ balls lodged in the gaps between graphite blocks. Statistical methods employed to determine the probable graphite damage have estimated 344 broken blocks adjacent to the rod channels.

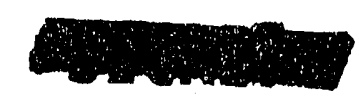


Repair of 105-C Tar Iffluent Iine Expansion Bos

In inspection of the far effluent line expansion box at 105-C revealed that the packing in both expansion joints was gone and that structural failure vas occurring on the domstream portion of the box and on the floor slab. Ieakage through the broken valls and floor slab was the cause of the cave-in adjacent to the box.

\section{Gunbarrel Flange Snan Ring Failure - ir Reactor}

In investigation to determine the cause and remedy for inservice cracking of $\ddot{i}$ Reactor gunbarre $]$ flange retaining rings is undervay. Preliminary investigation indicate that the problem is one of materials. A quantity of 100 each of cadmium plater steel, beryllium copper, and phosphor bronze rings have been procured and are being tested. 1 production test has been prepared to authorize trial installation of some of these rings on the reactor.

REACTOR OUTAGIS

Date Dorm Date
UD Outage Hours

\section{B Reactor}

$9 / 8$

$$
9 / 14
$$

120.9

$9 / 14$

$9 / 14$

1.6

$9 / 24$

$9 / 28$

104.1

\section{Reactor}

$\begin{array}{llr}9 / 15 & 9 / 15 & 0.2 \\ 9 / 16 & 9 / 21 & 105.4\end{array}$

DReactor

$\begin{array}{lll}8 / 29 & 9 / 2 & 94.6 \\ 9 / 3 & 9 / 4 & 39.4\end{array}$

\section{Tiemarks}

Water leak. Tube replacement. Leak testing and tube replacement. Repair faulty thermocouple on tube 0274. Panellit trip. Scheduled charge-dis uharge.

Charge-discharge and tube replacement following mpture removal.

Removal of an IRis regular metal rupture from tube 1465 . 
Files

- 4- October 10, 1961

DReactor (cont'd)

$\begin{array}{lll}9 / 4 & 9 / 5 & 4.9 \\ 9 / 8 & 9 / 10 & 39.5 \\ 9 / 11 & 9 / 11 & 0.4 \\ 9 / 15 & 9 / 18 & 36.9 \\ 9 / 21 & 9 / 23 & 52.9 \\ 9 / 25 & 9 / 26 & 41.2\end{array}$

9/30 Still down

Removed pieces of broken spline from tube 3860 .

Tripped due to an Imoroper switching procedure at 151 building. Leak testing \& miscellaneous maintenance.

Tripped due to the loss of 7 nump resulting from an improper procedure at 151 building.

Removal of an In: I-metal rupture from tube L.072.

Charge-discharge \& tube replacement.

Panellit trip due to intermal leak in tube 4 I30.

Tube Replacement.

Water leak. Charge-discharge and tube replacement.

Leak testing.

DR Reactor

$\begin{array}{lll}8 / 31 & 9 / 2 & 40.5 \\ 9 / 2 & 9 / 2 & 0.6 \\ 9 / 5 & 9 / 11 & 136.0 \\ 9 / 18 & 9 / 20 & 41.5 \\ 9 / 20 & 9 / 20 & 0.3 \\ 9 / 26 & 9 / 28 & 46.8\end{array}$

Miscellaneous maintenance folloring rupture removal.

Panellit trip due to a stub being pulled from spline cap on tube 0779.

Scheduled charge-discharge, tube replacement on Ball 3X :rork.

Removal of IRI I-metal rupture from tube 25661. ifiscellaneous maintenance and chargedischarge.

Panellit trip due to oscillating gauge.

Removal of an Ise II-metal rupture from tube 0766. Charge-discharge and miscellaneous maintenance. 
Files

EReactor

$\begin{array}{lll}9 / 5 & 9 / 6 & 38.5 \\ 9 / 12 & 9 / 14 & 61.9 \\ 9 / 15 & 9 / 16 & 30.6 \\ 9 / 19 & 9 / 21 & 54.9 \\ 9 / 21 & 9 / 21 & 0.6 \\ 9 / 26 & 9 / 28 & 44.8\end{array}$

I Reactor

$\begin{array}{lll}8 / 30 & 9 / 1 & 35.7\end{array}$

$9 / 2 \quad 9 / 3 \quad 32.1$

$\begin{array}{lll}9 / 3 & 9 / 3 \quad 1.2\end{array}$

$\begin{array}{lll}9 / 6 & 9 / 7 & 28.5\end{array}$

$9 / 10 \quad 9 / 15 \quad 128.4$

$9 / 19 \quad 9 / 19 \quad 0.2$

$9 / 19 \quad 9 / 19 \quad 0.1$

$9 / 19 \quad 9 / 21 \quad 33.2$
$-5-$

October 10, 1,61
Removal of an In: i-metal rupture from tube 2178.

Leak testing. Charge-Discharge.

Removal of an Iñ I-metal rupture from tube 238L.

Removal of an Ia'i I-metal rupture from tube 2795.

Tube replacement.

Remove poison piece stuck in PCCr machine.

Leak testing and miscellaneous maintenance.

Removal of an Inis I-metal rupture (bumper) from tube 1379.

Charge-Discharge.

Removal of Icie I-metal mupture from tube $2667^{2}$.

Replaced faulty ball valve on tube 0860 .

Removal of an IR.i I-metal rupture from tube 1581.

Leak testing.

Scheduled charge-discharge, tube replacement and leak testing.

Panellit trip due to faulty bourcion tube.

Unexplained Panellit trip.

Panellit trip when spline cap failed while pulling spline. Charge-discharge and miscellaneous maintenance. 
Files

II Reactor (cont'd.)

$\begin{array}{lll}9 / 21 & 9 / 21 & 0.2\end{array}$

$9 / 24 \quad 9 / 29 \quad 274.4$

9/30 StiIl dom

IE Reactor

$\begin{array}{lll}8 / 30 & 9 / 1 & 58.6\end{array}$

$\begin{array}{lll}9 / 3 & 9 / 4 & 31.3\end{array}$

$9 / 17 \quad 9 / 19 \quad 37.0$

$9 / 24 \quad 9 / 26 \quad 35.9$

IW Reactor

$9 / 19 \quad 9 / 23 \quad 85.8$

$\begin{array}{lll}9 / 23 & 9 / 23 \quad 1.4\end{array}$
$-6-$

Octoioer 10, 1,061
Unexplained low Panellit trip on gauge 1974 .

Scheduled Iiv charge-discharge.

Tube replacement and miscellaneous maintenance.

Leak testing and tube replacement.

Scheduled charge-discharge.

Panelit trip.

Unexplained Panelitit trip. !Iscellaneous maintenance ci charge-discharge.

Tripped due to an unexplained instmument failure on IER loop I neutron monitor. Charge-discharge.

Scheduled charge-discharge.

Internal mupture of HCR if 3 cooling ratar line.

Repair rear cap leak on tube 1447. 


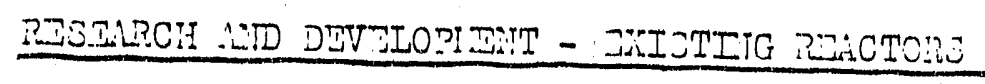

Operational Tueling Iacility

Operational fueling cycles vere nerformed at $105:$ ieactor on Alugust 30, September 18 and September 2L, 1061. A complete record of nozile pressure varaiations ras recorded. Jifficulty since corrected, tas experienced on tio occasions ith check ralves :rhich rould not seat. This problem was dealt vith by discharging the
tuibe and leaving it emptyr.

Flush discharge tests vere performed in the laboratory ith overbore fuel elements. The overbore fuel can be flusined, but rith somerihat
more difficulty than normal. size.

\section{I-ii Load}

The second core of the if leactor $\mathrm{D}-\mathrm{il}$ loading was charged during
the month.

\section{Overbore Tuel Development}

Thenty channels were bored, fitted with overbore size smooth-oore Zr-2 process tubes, and equipped with hardware during the $0-10-51$ outage at $C$ ileactor. The tubes were charged rith 10 CVIis fuel
elements each.

Channel 1459-C was equipped with an overbore size smooth-bore Zr-2 process tube and fitted rith hardware during the $9-16-61$ outage. - The tube was chargeri rith $18 \mathrm{CVINS}$ fuel elements and has a flow rate of $62.2 \mathrm{gpm}$.

Three of the newly installed tubes were observed to have flow rates of about $5 \mathrm{spm}$ lower than the others. On one of these tubes the Panellit pressure vas observed to slowly increase $19 \mathrm{psi}$ in tiro days; and on lugust 28, the reactor vas shut dom to investigate the cause of the low flor.

Of the possible reasons for the lorer flow rates, cocking of the solid aluminum dummies used to throttle flow in the short charge tubes appears to be the most probable. These solid durmies are unsupported and significant reduction in flo:s area is possible should a solid aluminum be completely misaligned, i.e., one 
Overbore Thel Develooment (contid.)

solid aluminum held against the top of the tube rhile the others rest normally on the bottom. It vas determined analyticaliy that such a condition vould result in a $4-5$ rom floir decrease when compared to the fully aligned charge flow rate.

The three offending tubes were discharged and recharged, the rear Lardware vas replaced, and the dormstream clumm pattems on all LI colums vere inspected. The dummy patterms in all tubes using solid aluminum spacers have been replaced rith self-supported solid aluminum spacers. Io abnormal sanellit pressures have since been observed.

\section{Self Supported Thel Development}

Thirty-two columas of self-supported fuel vere discharged and recharged into $C$ Reactor during the 9-16-0́l outage vithout difficulty. There was no reported increase in the radiation levels at the piclap clute area above normal background..

Two colums of self-supported fuel elements were charged into smootil-bore $2 r-2$ process tubes in $\mathrm{it}$ reactor on $3-14-61$. These colums reached an average exposure of about $200 \mathrm{lLID} / \mathrm{T}$ on 9-20-ól.

\section{Bumper Euel Develonment}

Ten colums of bumper fuel elements charged into in lieactor on 6-27-6I reached an estimated exposure of $600 \mathrm{IND} / \mathrm{T}$ on $9-20-61$.

Scheduled goal exposure is $1200 \mathrm{i} \cdot \mathrm{WD} / \mathrm{T}$.

Thenty-six colums of bumoer fuel charged into $D$ Reactor on 8-G-6I as part of the UT-2 Fuel Core Tester evaluation have reached an estimated exposure of $27 \mathrm{IID} / \mathrm{T}$.

To date, 1320 tubes of bumper material have been irradiated and discharged from D Reactor; 1500 tubes (both natural and enriched) are currently under irradiation. Three failures have occurred in bumper fuel at $D$ Ractor during this report period; however, none of the failure mechanisms were associated with the bumper support concept. Two were internal coolant channel (hole) failures and the other was a mechanical dama:je failure.

Niclsel Plated Fuel

Seventy colums of nickel plated OIII fuel elements iere charged 
Iichel Plated FueI (contid.)

In DR Reactor cluring the $0-5-61$ outage. Thenty of tise to columns vere charged as monitor colums and tivo ramainine so irere lot-charged. Tiro plate thiclnesses, a nominal .5 mil and a nominal. .2 mil, are represented equally bur the monitor columns. Epecial effluent sampling arrangements have boen made for montoring the effluent activity from tro tujes charsad itit: . ́mil plata.

Cosxtruded Iñ Iuel

Sirm colums of coextmaded in suel elements chared into :ai Feactor on $3-11-51$ have raached an estimatod azposura of 320 iivD/T.

Iffluent ivater Data

The table belor shows the average concentration of radioisotopes in reactor effluent vater from the samples taisen during iugust, 1961. Concentrations are in units of (10-12 Curies/CC).

\begin{tabular}{|c|c|c|c|c|c|}
\hline Reactor & $1 s-76$ & $P-32$ & $2 n-55$ & $N p-239$ & Cr -51 \\
\hline$B$ & 95 & 2.3 & 36 & 80 & 330 \\
\hline C & 125 & 2.1 & 30 & 70 & 240 \\
\hline C & 75 & 6.1 & 52 & 200 & 490 \\
\hline $\mathrm{DR}$ & 30 & 3.5 & 94 & 90 & 360 \\
\hline$\Gamma$ & 50 & 4.0 & 48 & 30 & 270 \\
\hline II & 90 & 2.3 & 9 & 30 & 280 \\
\hline 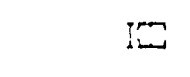 & 50 & 2.3 & LO & 50 & 200 \\
\hline E.I & 40 & 3.7 & 6 & 50 & 350 \\
\hline
\end{tabular}

A change ras made in the alum feed rate at the $\mathrm{W}$ area because the concentration of $\mathrm{P}-32$ vas tivice that experienced in 1060 . 
Iffluert Tater Jata (cont'd.)

and much hisher than the concentrations obserred at othor areas. The rater plant control criteria for :..I area ras chaniged on zeptemoer 1 to producing vater vith minimum turbiditj. This resulted in reducing tile alum feed rate from $10 \mathrm{pom}$ to aicout i ppm. Insurficient time has elapsed to obserre tie erfects of tiris change.

\section{Process Tubes}

The critical problem of prolonging existing reactor nrocess tube Iife is being evaluated. Designs for reri process tuives and assemblies are being considered, as rell as transyerse process tube cracking and interim measures such as pil adjustment. i study has been initiated to evaluate modifying the excisting process tube equipment or to provicle net equipment for tize 105 $\therefore$ Teactors.

\section{RتACTOR IODITICATION PROGREI}

\section{Overbore Performance}

The trenty-tube block installed at $105-0$ is performing as predicted. The lonest tube porrer in the block (center) is about $87 \%$, of the average potrer in the edge tubes. Jighteen spike $I$ columns have been charged to compensate for the reactivitij loss. The maximum power generation average over the surrounding normal sized tubes is $63 \mathrm{IIJ} / \mathrm{ft}$. The ratio of maximum porer zeneration in the block to maximum porser generation in the surrounding colurms is tinus 1.59. This compares with a 1.60 ratio predicted from the threegroup calculations and reported in last montin's report.

\section{Charge Platform : :odification Program}

All charge platiorms lave been weighed in preparation for a review of capacitir of the equipment. تiaughton Ilevator Company engineers have completed prelininary inspection of the ioist equipment, platform structures and load distribution; related stress studies are under vay. V'eanirile, efforts tere alle completed to remove miscellaneous equipment rhich is not vital to efficiency of the operation. 
ZER PRODUCTIOA: NASTOR

if Reactor Tuel Development

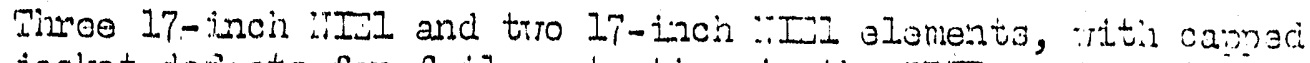
jacket do.iecte for failurs tosting in the rim mapturs $100 \%$, are Jeen irradiated in : $=-1$ to an arerare axposura of 170

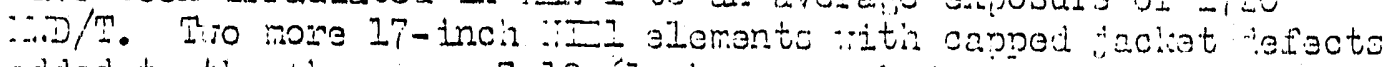
added to the charge on 7-19-5I, hava reacises an 3izosure of is $75 \mathrm{inD} / \mathrm{m}$.

The short; term fuel loading in : =-2 coneistin IIII elentent, one 23-inch IIIL element, and one 23-incil :III element ras discharged on ?-17-6. The disciarge exposure of tize VIIl element vas $230: M D / T$ and the exposurs of the VIII element itas $200: \mathrm{iD} / \mathrm{T}$.

D2-2 vas charged on 9-17-6́l with five trenty-timese inch :III elements for a long term irraciation. These elements have an exposure of less titen 10 intid $/ T$. 

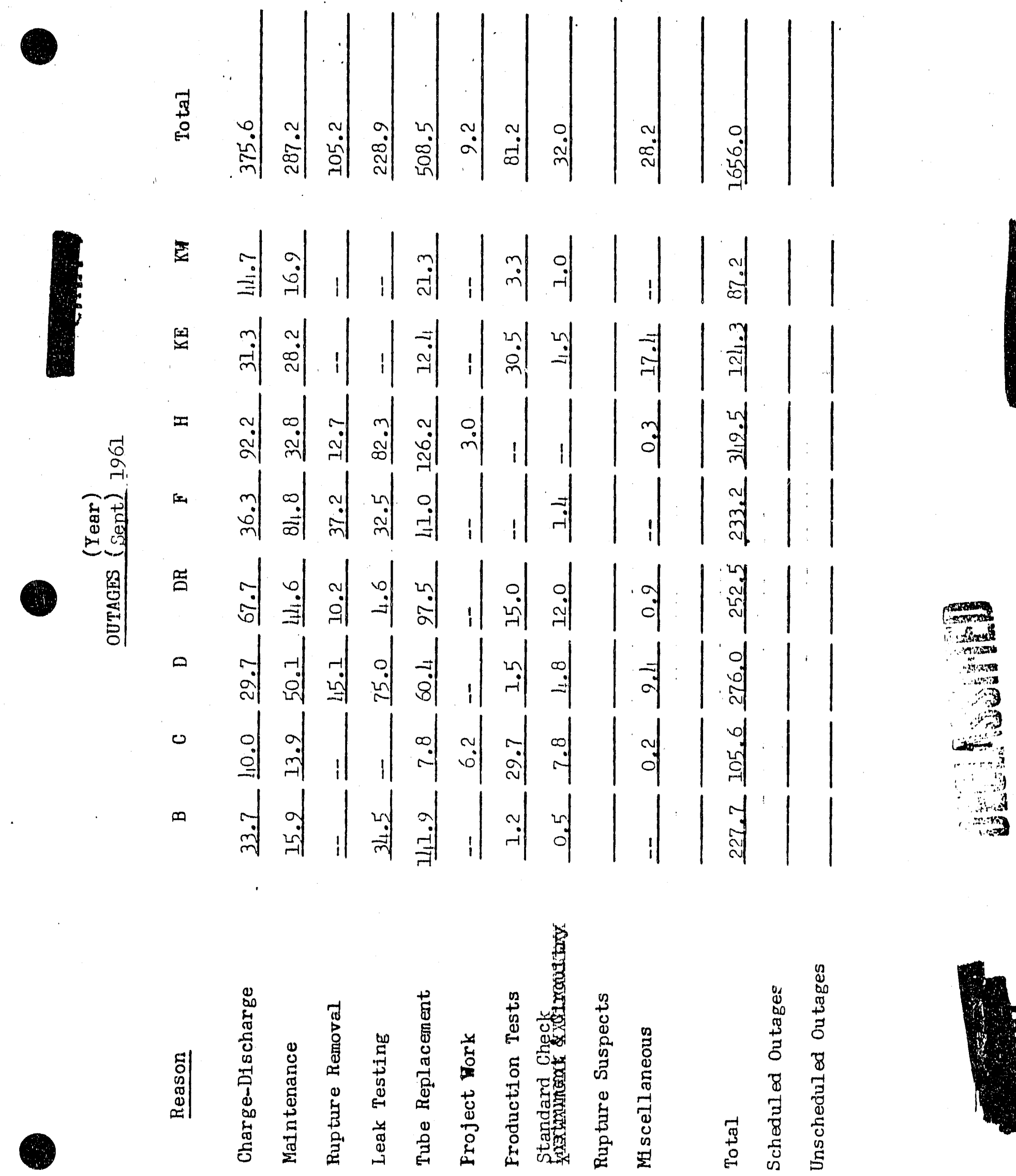


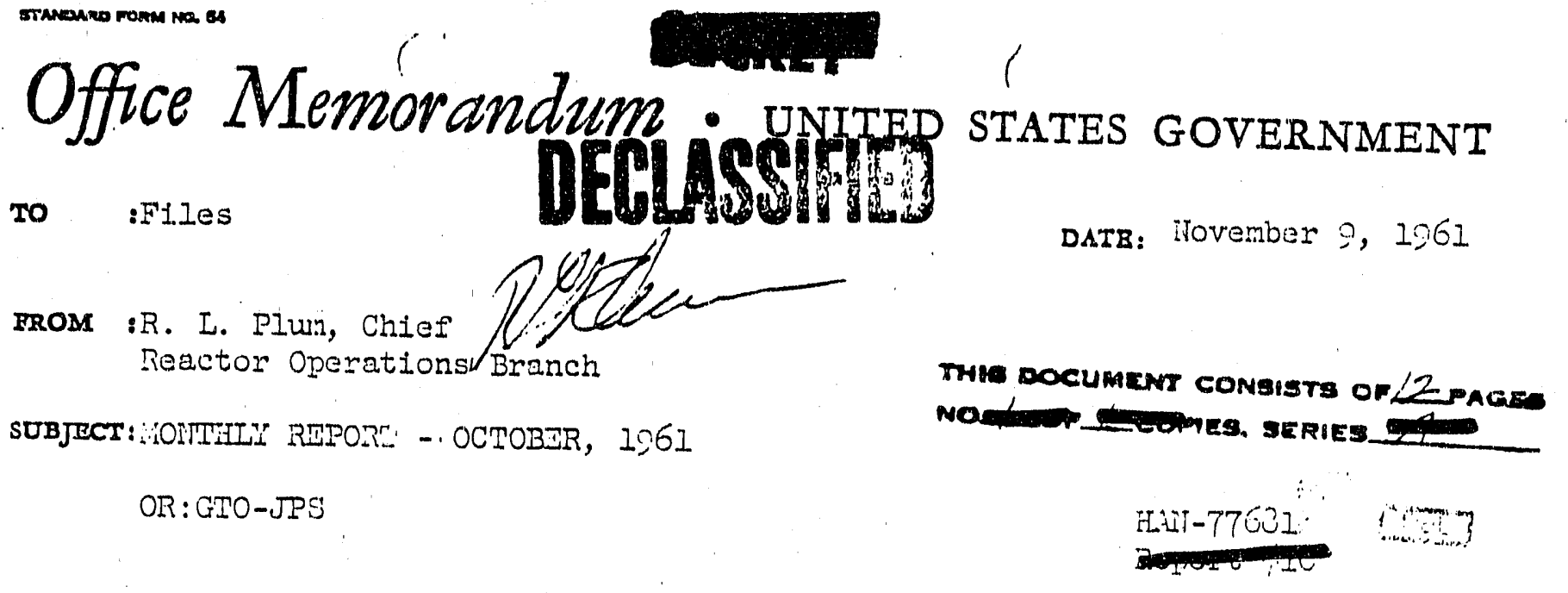

OPERATIIT DYPTREITCE

Production

Reactor input production (ND) was $1.1,10$ above forecast; $3.3 \%$ below at the six old reactors and $6.7, \%$ above at the $x^{\prime \prime} s$.

Efficiency

Over-all time operated efficiency vas $75.9 \%$ (73.4\% forecast); $72.3 \%$ at the six old ractors and $35.2 \%$ at the $K ' s$. Ifficiency was low at the old reactors due to process tube water leairs and fuel element ruptures.

Porver Level

There was no increase in the combined reactor instantaneous power level or in the individual reactor record power levels.

Fue1 Ruptures

Ileven miptures, eight I\&d enriched metal and three Irat regular, vere removed from the reactors. Five of the enriched ruptures were at $D R$, two at $C$ and one at II. Tro regular metal ruptures vere at $F$ and one at $D$. Tho of the enriched ruptures vere caused by charging machine damage.

\section{Powel Level Limits}

During this report period the power levels at all reactors were restricted by bulk outlet temperature limits.

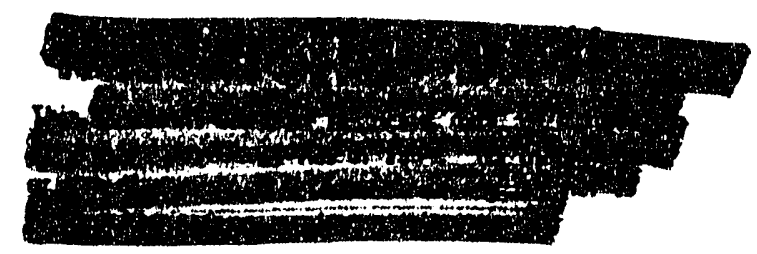




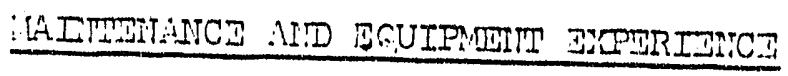

Tube Replacement and Tatar Leaks

One hundred eleven nev process tubes were instailed; 62 at $F$, 28 at $D, 13$ at $B, 6$ at DR, one at $C$ and one at $H$.

Thenty-four tube and two Van gtone lealis were corrected. Ilight of the tube leais wers at $B, 3$ at $I, 5$ at $D, 2$ at $F$ and one at C. The Van Stone leaks vere at 3 and DR.

Moise ibatement

i.easurements of sound levels were made at the $190-\mathrm{C}$, IVI and $\mathrm{KTV}$ Buildings and the $165 \mathrm{kE}$ and $\mathrm{KN}$ control rooms as a follow up to the completion of acoustic control worls recently completed. The measurementi indicate a reduction in acoustic energy in the range of $5 c-00 \%$ as a result of this work.

\section{Graphite Distortion}

Studies on the problem of graphite distortion at 105-C Reactor are progressing. Distortion data has been collected by television traverse and displacement measurements of a vertical safety rod channel and vertical and horlzontal traverses of process tubes located in the top portion of the reactor. The vertical rod channel broach used successfully at 105-DR Reactor has been adapted for use at $C$ Reactor. Also a contract was negotiated wth the General Engineering Laboratory to conduct graphite distortion studies and to evaluate alternate solutions to the associated problem of blockage of the vertical safety rod channels.

\section{REACTOR OUTAGES}

Date Date Outare

Dorn Up Hours

B REACTOR

$\begin{array}{llll}10 / 2 & 10 / 4 & 39.2 & \text { Leak testing. } \\ 10 / 4 & 10 / 6 & 33.7 & \text { Leak testing. } \\ 10 / 10 & 10 / 12 & 53.3 & \begin{array}{l}\text { Leak testing. Replaced four tubes due } \\ \text { to tube leaks and one tube due to a } \\ \text { rear Van Stone leak. }\end{array}\end{array}$


B RELICTOR ('́ont'd.)

$\begin{array}{llll}10 / 17 & 10 / 19 & 55.1 & \text { Laais testins. } \\ 10 / 24 & 10 / 26 & 39.0 & \text { Laai: tasting. } \\ 10 / 26 & 10 / 26 & 0.2 & \text { Unemiained Beclarian trip. }\end{array}$

C RE:CTOR

$10 / 12 \quad 10 / 15 \quad 60.3 \quad$ Removal of an ISI- I metal muture from tube 2576 and charce-discharge.

$10 / 23 \quad 10 / 25 \quad 54.1 \quad$ Charge-discharge and meintenance folloring a trip when a rear piotall and elbor came off.

$10 / 25 \quad 10 / 25 \quad 0.6 \quad$ Unexplained Penellit trip.

10/26 10/27 24.2 Renoval of an IRE-I netal mupture from tube 2271.

$10 / 27 \quad 10 / 27 \quad 0.6 \quad$ Panellit trip due to an oscillating gauge.

D RPACTOR

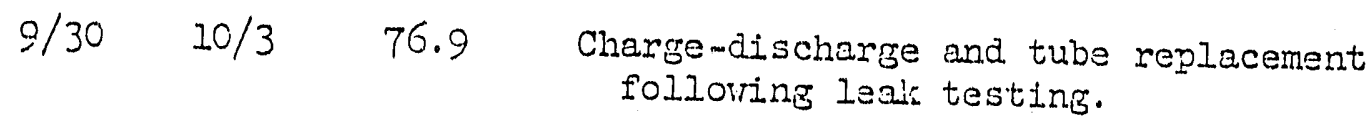

$10 / 5 \quad 10 / 5 \quad 0.2 \quad$ Unexplained Panellit trip.

$10 / 10 \quad 10 / 13 \quad 53.5 \quad$ Removal of an IRis regular metal rupture from tube 2762. Charge-discharge and leali testing.

$10 / 24 \quad 10 / 27 \quad 55.1 \quad$ Charge-discharge and leals testing.

1C/27 $10 / 27 \quad 1.7 \quad$ Removal of burner metal from tube 1892 due to high Panellit pressure.

DR REACTOR
$10 / 2 \quad 10 / 4 \quad 43.2$
Tripped due to fallure of gas loop compressor. Miscellaneous maintenance.
$10 / 6 \quad 10 / 8 \quad 44.7$
Removal of muptured production test capsule piece from tube 0574 (PT-IP-402A). 


\section{Files}

\begin{tabular}{lll} 
DR REICTOR (Cont'd.) \\
\hline $10 / 10$ & $10 / 12$ & 40.6 \\
$10 / 15$ & $10 / 17$ & 44.5 \\
$10 / 17$ & $10 / 17$ & 1.2 \\
$10 / 20$ & $10 / 22$ & 44.3 \\
$10 / 22$ & $10 / 22$ & 0.4 \\
$10 / 23$ & $10 / 25$ & 42.0 \\
& & \\
$10 / 25$ & $10 / 25$ & 0.3 \\
$10 / 27$ & $10 / 28$ & 42.1
\end{tabular}

$-4=$

November 9, 1961
Removal of an Tis-d metal muture from tube 3985 and tube repiacoment.

Removal of an Ifis-i netal ruptura from tube 1460 and miscallaneous maintenance.

Ponellit trip due to fluctuation of gaure 1431 .

Removal of a stuck Isis-ت metal mupture from tube 2650. Charge-discharge.

Unexplained Panellit trip on gauge 0670 .

Removal of an Ifis-D matal mpture from tube 4173. Charge-discharge and maintenance. Tro Beckmans inadvertent Iy reached trip
points.

Removal of an TRE-E metal rupture from tube 2987.

F. REACMOR

$10 / 3 \quad 10 / 8 \quad 123.0$

Charge-discharge and scheduled tube replacement.

$10 / 24 \quad 10 / 26 \quad 63.4 \quad$ Charge-discharge and leali testing.

$10 / 29 \quad 10 / 31 \quad 38.4$

$10 / 31 \quad \frac{\operatorname{sti11}}{\text { down }}$
Removal of an ID: regular metal mupture from tube 2377 . Hiscellaneous maintenance.

Rerioval of an Inir regular metal mpture from tube 2369 .

H RE.3CTOR
$9 / 30 \quad 10 / 1 \quad 26.0$
Ieak testing and tube removal.
$10 / 5 \quad 10 / 6 \quad 37.2$
Removal of an I\&E-T metal mupture from tube 1973. Miscellaneous maintenance.

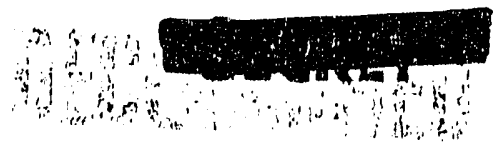


H REICTOR (Cont'd.)

$\begin{array}{llll}10 / 14 & 10 / 15 & 25.5 & \begin{array}{r}\text { Ior pressure trip on tube } 1333 . \text { Looir } \\ \text { testing. }\end{array} \\ 10 / 23 & 10 / 24 & 29.0 & \text { Loal testing. } \\ 10 / 28 & 10 / 29 & 23.3 & \text { Leak testing. }\end{array}$

IE STACTOR
10/16 10/19 76.7 Scheduled charge-discharge and miscellaneous maintenance.
$10 / 19 \quad 10 / 19 \quad 0.4$
Panellit trip due to an oscillatino gauge.
$10 / 28 \quad 10 / 31 \quad 64.4$
Miliscellaneous malntenance follorting a Panellit trip. Installed $i-t$ pe tube in channel 3674 as authorized by project CG-839.

KN REACTOR
$10 / 22 \quad 10 / 26$
79.5
Heat cycle 5 hours prior to scheduled charge-discharge.
$10 / 26 \quad 10 / 26 \quad 1.2$
Panelift trip due to an oscillating gauge.

\section{RTSEARCA AID DEVELOPUWNT - EXISTIIG REACTORS}

\section{Rear Tace P1pins Tramination}

Planning and procurement for removal of a crossleader at 105-DR Reactor for metallurgical examination has been complated. The timing for the actual replacement is being studied to detemine that most convenient in light of reactor outage schedule.

\section{Polson Splines}

A soline-straightener device, to aid in the recovery and re-use of splines ut1lized during reactor startup, was given acceptance tests and is ready for demonstration.

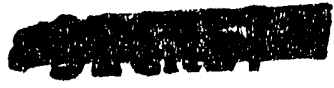




\section{Control Efficlency Studies}

Specifications have been tentatively proposed for half-strenith and pertial-poison-length splines. Initial theoretical siudies Inclicate that the Iupture potential with the proposed iplines should be less than for tubes vith no splines; 1.e., the poison effect of the splines should offset the flow reluction. The lealiafe problem between the spline and. seal with narrover solines has not jet been resolved.

Nthough the reactivity status was clouded by numerous rater ledis, botis the hot and cold reactivity of the second cycle modified. i-it loading at If Reactor appeared to be six to eight mi: lower than with the greater E-to-N ratio of the first. This result is consistent with previous theoretical determinations and reduces the requirement for use of supplemental poison during outages.

\section{Effluent Vater Data}

The table below shows the average concentrations of radiolsotupes in reactor effluent water from samples taken during september, 1961. Concentrations are in units of 10-12 curies/cc.

\begin{tabular}{|c|c|c|c|c|c|}
\hline Reactor & As 76 & P32 & $\ln 65$ & In 239 & $\mathrm{C}_{2} .51$ \\
\hline$B$ & 64 & 5.5 & 14 & 82 & 390 \\
\hline $\mathrm{C}$ & 55 & 4.9 & 22 & 56 & 390 \\
\hline$D$ & 66 & 5.8 & 27 & 100 & 970 \\
\hline $\mathrm{DR}$ & 81 & 4.3 & 17 & 90 & 67 \\
\hline$F$ & 55 & 10.9 & 29 & * & \\
\hline $\mathrm{H}$ & 52 & 5.1 & 9 & 63 & 24 \\
\hline 江 & 50 & 4.7 & 12 & 55 & 400 \\
\hline $\operatorname{sivi}$ & 75 & 12.3 & 13 & 70 & 280 \\
\hline
\end{tabular}

Changes were made in the alum feed rate at $K \nabla d$ in an attempt to reduce the concentration of $\mathrm{P} 32$ which had been higher than that experienced during the same period of 1960 . Instead of attempting a flxed feed rate, the objective in water treatment was to produce vater with minimum turbidity. This resulted in a reduction in alum feed rate and produced an incresse in the $\mathrm{P} 32$ concentration in the effluent water. A step-wise increase in alum feed concentration vas then begun and is still continuing.

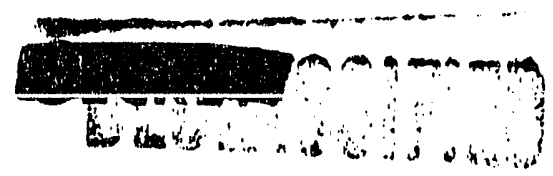


ST Reactor has been feeding low DH $(6.6)$ process watar under a production tast to reduce process tube corrosion. A stailar tect ras recently initiated at : Reactor. Although the pja ectivity ram 5 remains higher than that observed in the other reactors, a similar increase has not been apparent three veelis after the Initiation of lor pit at is.

The above $2^{32}$ figures represent an average 1ncrease of $2.7 \mathrm{ppm}$ over lugust, 1061 but reinain 2.3 ppr below the average for September of 1959 and 1960. The seneral increase over August is attributed to an increase in phosphate concentration in the river water and to occasional difficulties rith bauite-feed equipment. operational difficulty with baurite-feed equipment is to be expected while experience in operation is being obtained and equipment faults corrected.

\section{Dlsaster Planning Study}

The task force study of operational and shelter requirements for maximum reactor safety in the event of enemy attack was reactivated. The tasi force comprises representatives of the lanufacturing, Research and Ingineering, and Facilities Engineering Operations.

Operational. Fueling

Tro refueling cycles with aluminum dunmy fuel elenents were completed during equilibrium operations at 105-IN Reactor.

\section{Vertical Safety Rod Channel Rehabilitation}

Development of three critical pieces of equipment is in progress: a mocis-up for testing machinery; a thermal shiela boring machine; a channel shaping tool. A model of the first shaping tool ras fabricated for test of concept.

Televiston Device for VTr Channel Eramination

A $2-1 / 2$ inch television camera has been adapted, with special lighting and leads, to permit examination of vertical safety rod channels. This device not only has appreciably improved the optical conditions of such examinations, but permits location of the viering device in such areas as the Reactor Control Room. The device vas used successfully in examining channels in both the 105-DR and 1C5-C Reactors. 


\section{Bumper Thel Development}

Ten columns of KIVI-B fuel elements charged into Kil Reactor on $6 / 27 / 61$ reached an estinated exposure of $300 \mathrm{iWD} / \mathrm{T}$ on $10 / 20 / 61$. Scheduled goal exposure is $1200 \mathrm{imD} / \mathrm{T}$.

To date, 1660 tubes of bumper fuel elements have been irradiated and discharged from D Reactor; 1550 tubes (both natural and enriched) aro currently under irradiation.

\section{Ilcliel-Plated Fuel Program}

Seventy columns of nickel-plated oIIn fuel elements charced. into DR Reactor during the $9 / 5 / 61$ outage have reached an exposure of about $300 \mathrm{kTN} / \mathrm{T}$.

\section{Coextruded IEoT FueI}

Six columns of coextmuded Iow fuel elements charged into $k T$ Reactor on $3 / 14 / 61$ have reached an estinateci exposure of 530 WWD/T.

\section{KIIIR Thibes}

Visual examination of the exterior surface of the zircaloy-2 process tube removed on August 9,1961 , from KTER Loop-3 revealed that a black oxide film tas formed while the tube vas in-reactor. The tube was sectioned in the 105-iW basin and samples provided to Radiometallurgy for further examination. Visual, in-cell examination of the samples confirms the presence of the oxide film. The grain structure of the sample has not permitted a conclusive determination of hydride concentration by metallographic techniques. The samples are to be anodized for better resolution in the determination of hydride concentration.

\section{E-IT Load}

Discharge of the first E-II core ras completed september 25. Dicciarsing difficulties resulted in some intermingling of the desired four separate batches. Original planninf of the $\mathrm{D}$-iv test vas for the majorlty of the yield date to be acquired from the second core loadins. Data were to be obtalned from the first core loading as a baclup and to permit earlier verification of E-N Incentives. In view of these difficulties with the first core special efforts will be expended to lnsure the procurement of adequate data from the second loading. 


\section{REACTOR HODIFICATION FROGRIN}

\section{Char je PIatform liodification Program}

Hauchton Fivvator Company has authorized the follorint increaces in the allorable load on the charce platforms of the si: old reactors: 3,000 to $16,00 C$ pounds at the $105-\mathrm{B}, \mathrm{D}, \mathrm{F}, \mathrm{DR}$ and $\mathrm{H}$ Reactors and 13,000 to 24,000 pounds at 105-6 Raactor. The increases in allowable lood in all cases is subjact to position-

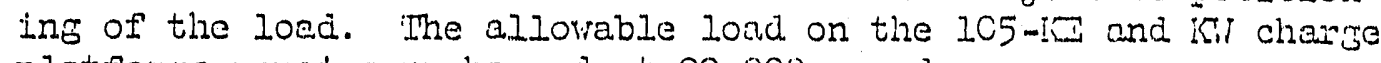
platfoms remains unchanged at 29,000 pounds.

\section{Overbore Thel Develonment}

Nine columns of overbore-size fuel elements were discharced and eight nev columns charred. Forces up to 4000 pounds tere required to discharge eight of the columns. Normal charging forces on these heary fuel elements ran as high as 3000 pounds.

Thibe nurber 4434-C rould not discharge with 5000 pounds force applied to the front. Four thousand pounds apolied from the rear folloved by 4200 pounds from the front were required to discharge this tube. The tube was leali-tested, found not to leak, and left empty pending a visual examination of its internal surface vith the Boroscope.

Fuel exposures in the nine tubes discharged ranged from 766 to 95.. $\mathrm{Mm} / \mathrm{T}$. The fuel elements are being examined at the 1C5-C fuel examination facility.

\section{NEW PRODUCTIONT REACTOR}

IN Reactor Fuel Development

Three seventeen-inch NITI elements end tro seventeer-inch NITI elements with capped jaclet defects for failure testing in the PRTR mupture loop have been irradiated in $i T R-1$ to an average exposure of $2180 \mathrm{i} / \mathrm{T} / \mathrm{T}$. Tro more seventeen-inch IIII elements with capped jacket defects added to the charge on July 19, 1961, have reached an exposure of $1040 \mathrm{lTH} / \mathrm{T}$.

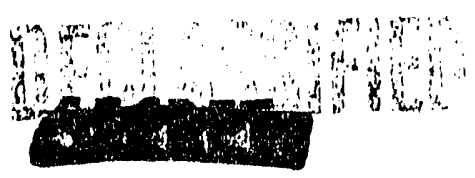




\section{Carbon Steel Pling}

A section of 14-inch Jchedule-1CC carbon-stael plpe ras removed frorn the large purm test loop in the 314 Bullding for inspection. Thi. $100 \mathrm{p}$ had been operatod intermittant $1 \mathrm{y}$ for about 2.7 vears at te:meratures and pressures comparable to ITS operatine

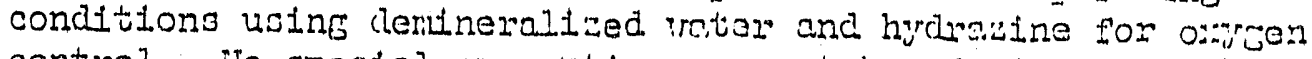
control. ITo special precalitions iere talen durluc pum changes to provent oxycen entexing the oystan tivough tile fire rater surface. Infrequent lapies o." vator quality contiol occurrod durins the operational period.

The pipe apposed to be undamaged bevonc a jeneral notal discoloration and clepoeits of pordery red-urom iron oxicle at crevlces near flanges and fittinga. lio pitting tras obserred. ihe machined ridges on the ID of flange fittings rere clear, recular and smooth.

\section{Bell $3 X$ Control Strangth}

Prelininary results have been obtained of exponential pile testins of a single colum of IIPR ceramic balls. These indicate that the IIPR ceramic balls WIII be slightly stronger than predicted and vill. sat1sfy all IIPR control requirements. 


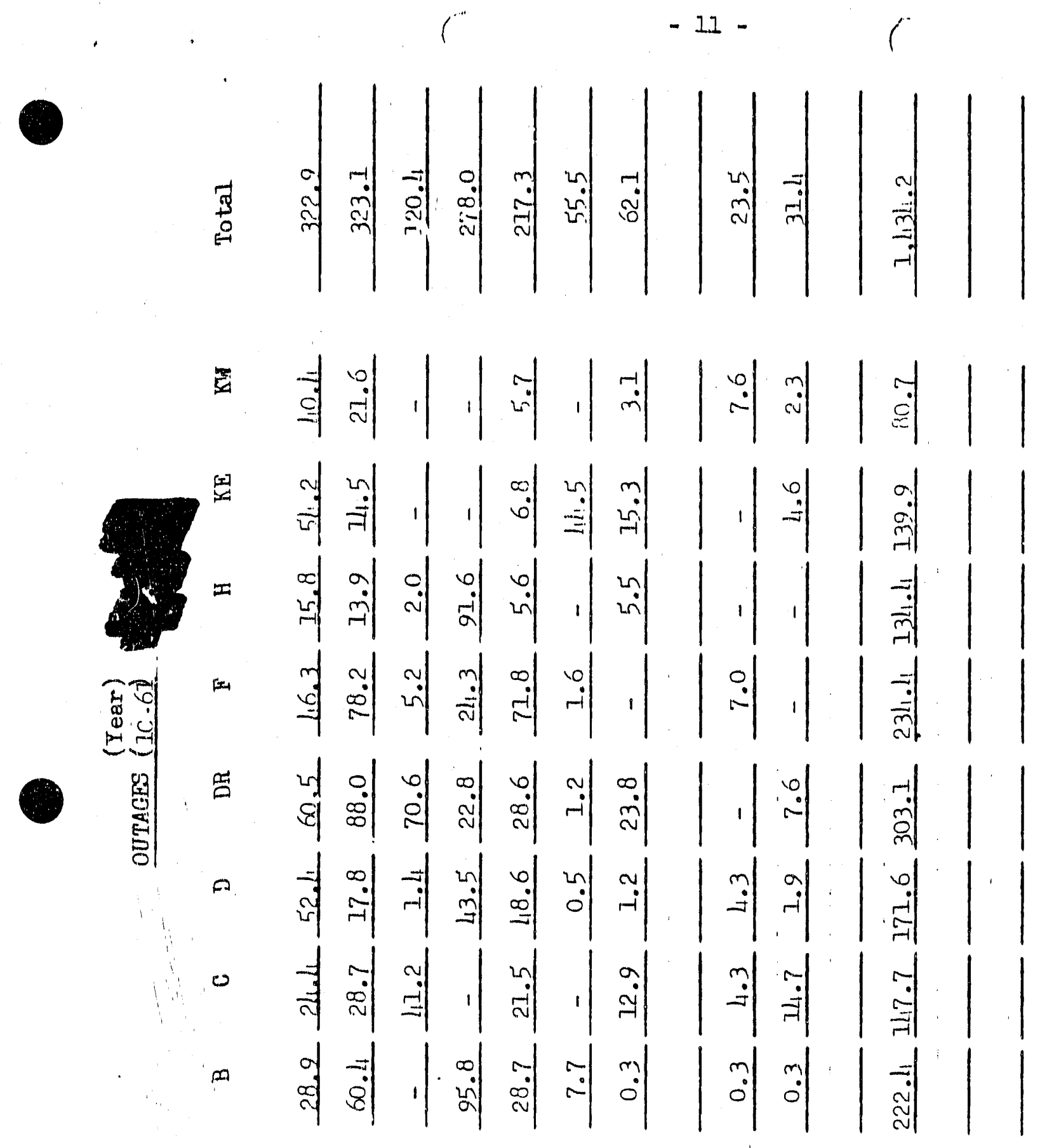

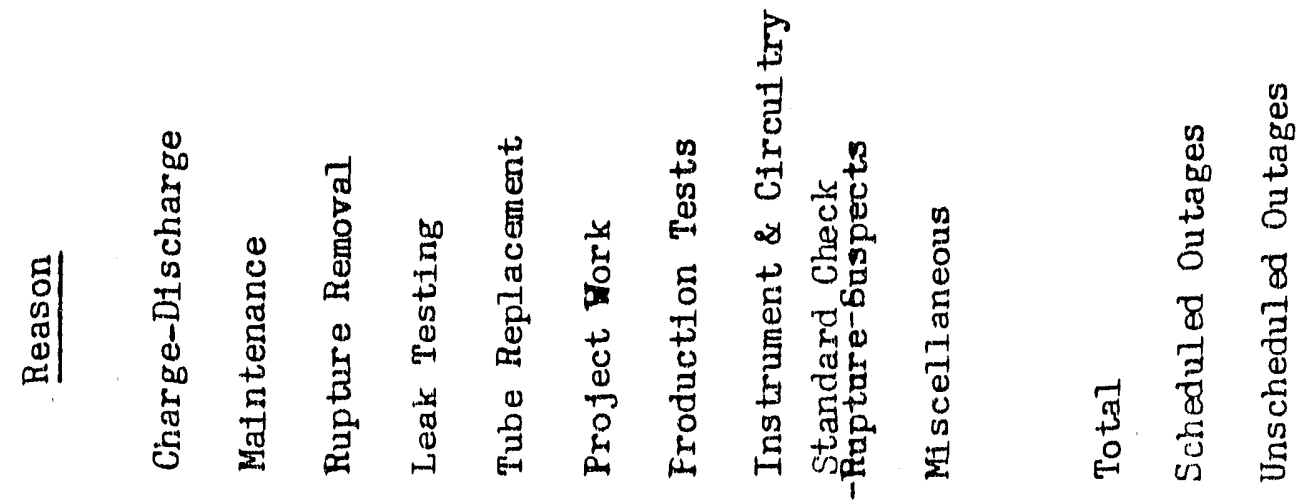




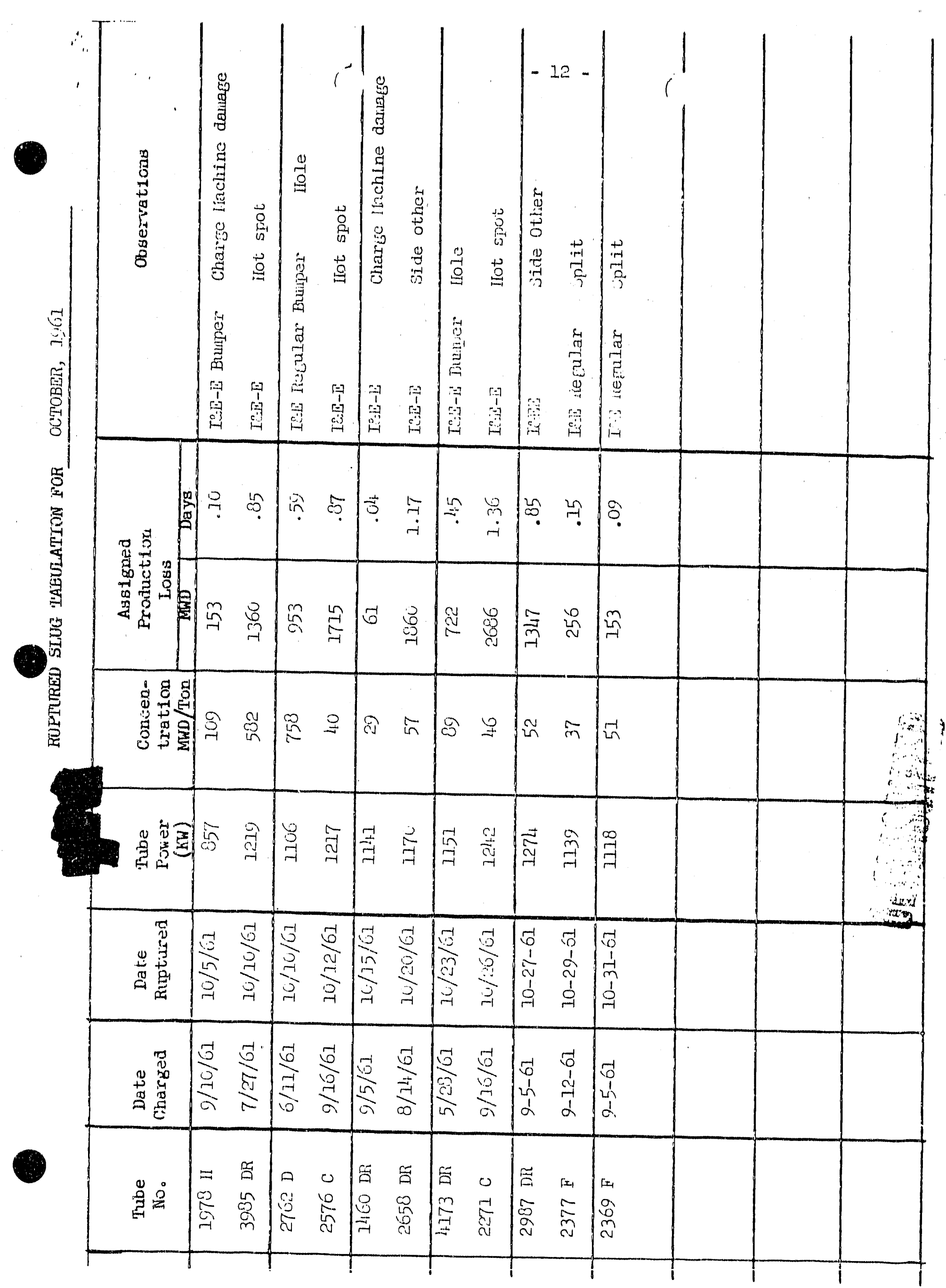




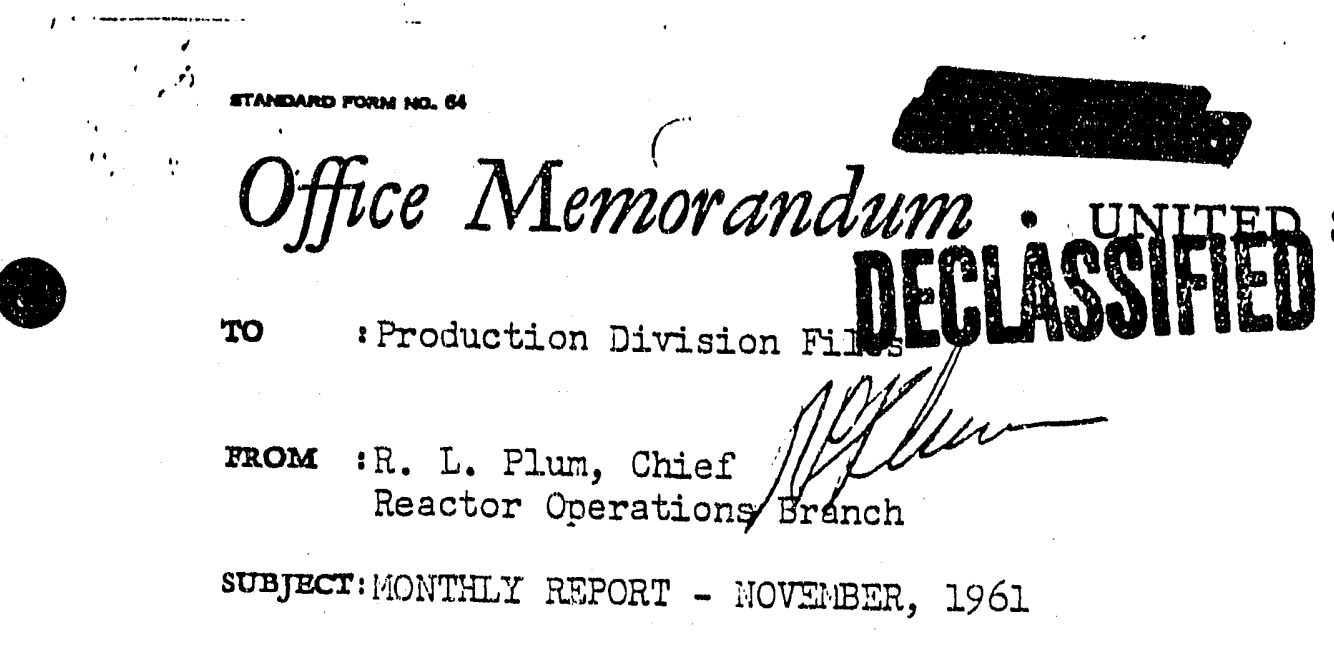

STATES GOVERNMENT

DAIR: December 8, 1961

OR:GTO

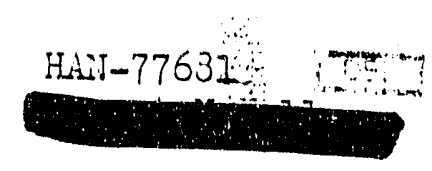

THS POCUMENT CONSISTS OFL 2 PAGES
FES. SE

\section{OPERATING EXPERIENCES}

Production

Reactor input production (iNiD) was $1.4 \%$ below forecast;

$12.7 \%$ below at the six old reactors and $14.3 \%$ above at the $K^{\prime} \mathrm{s}$.

\section{Efficiency}

Over-all time operated efficiency was $74.4 ; 0$ ( $80.8 \%$ forecast); $69.2 \%$ at the six old reactors and $90.0 \%$ at the $K^{\prime} s$. Efficiency was low at the old reactors due to process tube leaks and tube replacement.

\section{Power Level}

There was no increase in the combined reactor instantaneous power level. The individual reactor record power levels were increased 35 megawatts at $C$ (2180 to 2265) and 45 megawatts at $\mathrm{KT}:$ ( 4115 to 4160$)$.

Fuel Ruptures

One rupture, an I $D$ enriched element, was removed from D reactor. This is the second month during the operation of eight reactors that only one rupture has occurred. The first was during July of this year.

\section{Power Level Limits}

Power levels at $B, D, D R, F$ and $E$ were restricted by bulk outlet temperature limitations. Fuel performance considerations currently limit the power level at $\mathrm{C}$ reactor. The $\mathrm{K}$ reactors are operating slightiy under permissible outlet bulk temperature limits because of tube corrosion considerations.
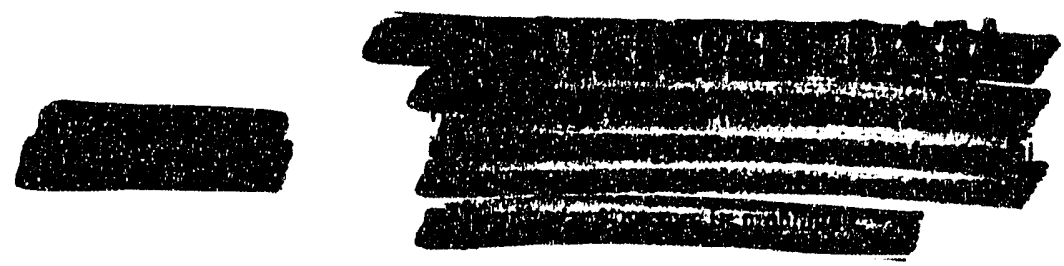
IUATITENAITCE AND EQUITIENT EXPPRITINCE

Equipment Experience

1. Three hundred and nineteen new process tubes vere installed; 128 at $B, 73$ at $\mathrm{H}, 68$ at $D, 32$ at $F, 16$ at $D R$ and 2 at $C$.

2. Forty-eight tube and 13 Van Stone leaks vere corrected. Nineteen of the tube leaks were at $B, 19$ at $D, 5$ at $\vec{F}, 3$ at $i$ and 2 at DR. Seven Van Stone leaks vere at B, 2 at D, 2 at $\mathrm{A}$, one at $D R$ and one at $F$.

Tube Replacement

Equipment is being developed, or converted from other uses, to support increased effort on reactor process tube replacement during 1962. The current efforts include conversion of an operational fueling actuator for use as a remotely operated tube puller-chopper; development of a hydraulic tube splitter that can be inserted and withdrawn from the front face; modifj.cation of graphite overbore equipment to serve as a substitute for the broaching operation; and assembly of improved communication equipment to facilitate multiple operations.

\section{Process Tubes}

Nineteen process tube leaks caused by uransverse tube cracks have occurred in 105-H reactor during the past two jears, and at an increasing rate. Metallurgical examinations of failed sections from five process tubes have been made and results are being evaluated. Seventy per cent of the failures have occurred at the rear trunnion block where conditions of high temperature and high bending stress both exist. The study is continuing and additional data are being collected.

Rear Face Piping

In recent years there have been some failures of rear face piping at the five older reactors due to high stress from thermal expansion and vibration in the crossheaders. To overcome this condition, prototype expansion joints and crossheader guides were instailed eight months ago at the 105-H and $D R$ reactors. Favorable performance experience with these test installations has led to plans for applying a full-scale installation to a lead reactor.

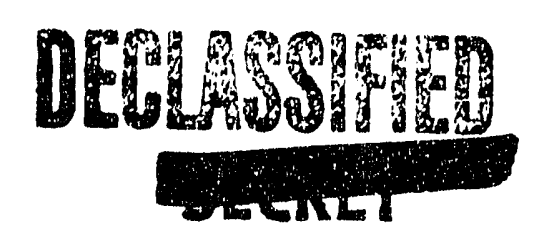




\section{L500 HP Stator Program}

The 190 Building motor rehabilitation program continued with ihe installation of two stators with modified Class A insulation on the windings. Of the 40 motors in service, 33 have now been rehabilitated; 25 modified Class $A$ and eight Class $B$.

Horizontal Control loods

Preparations for installation of graphite sleeves in the lio. 17 horizontal rod channel at 105-is ractor are complete, and channel saddle-block removal and sleeve installation tools have been tested in the mockup. Installation of these sleeves is scheduled for the next available reactor outage.

Nuclear Instrumentation

The nuclear instrumentation program includes flux level monitoring equipment for use at equilibrium power, linear-rate-of-rise equipment for use in the decade down from equilibrium power, logarithmic power and period instrumentation for use several decades down from equilibrium, and in-core flux monitoring equipment for measurement and display of flux distribution. High-level monitoring and rate equipment was installed in $K E$ reactor in June, using the octant monitoring chambers already there. The performance of the level equipment has been very satisfactory. The present magnetic amplifier comparators in this equipment are not of a fail-safe design, and a new comparator circuit has been developed as a replacement.

Logarithmic power and period instrumentation from one of the three vendors who have paricicipated in this program was installed in July at $K E$ reactor. Its performance has been exemolary to date.

Aluminum gamma-sensitive in-core chambers under test in ki: reactor are not giving satisfactory results, but the test is being continued for information purposes. Strinless steel in-core neutron chambers procured for the NPR project and installed in $K: I$ reactor on November 20 are functioning satisfactorily. 
REACTOR OUTACES

Date Date Outage

Down Up Hours

Remarics

B Reactor

$11 / 1 \quad 11 / 6 \quad 105.0 \quad$ iiater leak. Charge-discharge and reulacement of process tubes.

$11 / 6 \quad 11 / 6 \quad 3.6$

Loss of building ventilation due to excessive vater in tunnel. *

$11 / 12 \quad 11 / 16 \quad 87.1$

Low pressure Panellit trip on 2882 due to a tube leak. Process tube replacement.

$11 / 1311 / 21 \quad 54.6$ iater leak. Process tube replacement.

$11 / 21 \quad 11 / 21 \quad .3$ Unexplained trip on Vo. I Safety Circuit caused by seismoscope.

$11 / 26 \quad$ Still

down

Water leak. Tube replacement and miscellaneous maintenance.

C Reactor

$11 / 1 \quad 11 / 1 \quad 0.3 \quad$ Panellit trip due to a flux imbalance.

$11 / 7 \quad 11 / 12 \quad 100.4 \quad$ Scheduled charge-discharge and maintenance.

$11 / 12 \quad 11 / 12 \quad 3.5 \quad$ Correct neutron leak on tube 4484 .

$11 / 30$ Still Electrical ground in safety circuit. down Charge-discharge.

D Reactor

$11 / 4 \quad 11 / 7 \quad 64.3 \quad$ Water leak. Tube replacement.

$11 / 12 \quad 11 / 14 \quad 50.6 \quad$ Water leak. Charge-discharge and replacement , of tubes.

*) Resulted from effluent water backing up in one C-reactor effluent line when the other was taken out of service for repair, together with concurrent failure to start a sump pump in the $B$ pipe tunnel. 
D Reactor (Cont'd.)

$11 / 20 \quad 11 / 23 \quad 55.9$

$11 / 24 \quad 11 / 26 \quad 41.4$

$11 / 2.7 \quad 11 / 29 \quad 50.5$

$11 / 20,11 / 29$

DR Reactor

$11 / 14 \quad 11 / 17 \quad 86.0$

$11 / 29 \quad$ still

down

\section{F Reactor}

$10 / 31 \quad 11 / 1 \quad 31.6$

$11 / 17 \quad 11 / 21 \quad 88.2$

$11 / 22 \quad 11 / 23 \quad 37.3$

$11 / 28 \quad 11 / 30 \quad 46.5$

$11 / 30 \quad 11 / 30 \quad .6$

$11 / 30 \quad$ StiII

down

H Reactor

$11 / 1 \quad 11 / 2 \quad 26.1 \quad$ Vater leak. Tube replacement.

$11 / 6 \quad 11 / 8 \quad 35.4$ Water leak. Tube replacement.

$11 / 14 \quad 11 / 18 \quad 100.7$

$11 / 18 \quad 11 / 18 \quad .3$
Water leak. Leak testing and tube replacement. Vater leak. Leak testing and tube replacement. Removal of an IRE- $E$ netal rupture from tube $077 \%$. Tube replacement.

Panellit trip due to a faulty gauge.

Water leak. Charge-discharge and tube rew placement.

Water leak. Charge-discharge and tube replacement.

Rupture removal concluded.

Water leak. Charge-discharge and tube replacement.

Tiater leak.

water leak. Tube replacement.

Panellit trip due to loose rear cap.

Water leak.

Scheduled tube replacement and miscellaneous maintenance.

Tripped due to failure of rear pigtail at the nozale connector. 
Files

H Reactor (cont'd.)

\begin{tabular}{|c|c|c|c|}
\hline $11 / 18$ & $11 / 19$ & 2.7 & Unexplained trip. \\
\hline $11 / 19$ & $11 / 19$ & .8 & Unexplained Panellit trip. \\
\hline $11 / 20$ & $11 / 20$ & 1.3 & Unexplained Panellit trip. \\
\hline $11 / 23$ & $11 / 24$ & 28.9 & $\begin{array}{l}\text { Panellit trip on tube } 2767 \text {. The Hoke valve } \\
\text { was partially closed with a rustij } \\
\text { substance. Charge-discharge. }\end{array}$ \\
\hline
\end{tabular}

$11 / 26 \quad 11 / 27 \quad 27.9$

$11 / 29 \quad 11 / 30 \quad 27.0$

$11 / 30 \quad 11 / 30 \quad .2$

KE Reactor

$11 / 20 \quad 11 / 23 \quad 76.2$

IS.J Reactor

$11 / 14 \quad 11 / 17 \quad 67.6$
-6 -

December 3, 1,961 


\section{RESTHRCH ARD DEVELOPIENT - TYTSTING RTHCTORS}

Self-Supported Fuel Development

Tho columns of KVII-S fuel elements charged into isi reactor on $6 / 27 / 61$ were discharged on $11 / 14 / 61$ at an average exposure of
$763 \mathrm{iT} / \mathrm{T}$.

\section{Bumper Tuel Development}

Ten columns of iIT/i-B fuel elements charged into isi reactor on $E / 27 / 61$ were discharged at an average exposure of $1136 \mathrm{hTD} / \mathrm{T}$ on $11 / 14 / 61$.

Seventeen remaining columns of OIIIN-B fuel charged into $D$ reactor on $3 / 6 / 61$ as part of the UT'-2 Fuel Core Tester evaluation have reached an estimated exposure of $750 \mathrm{imD} / \mathrm{T}$. One column was discharged early on $10 / 25 / 61$ at $456 \mathrm{~W} / \mathrm{D} / \mathrm{T}$, elght were dj.scharged on $11 / 22 / 61$ at about $600 \mathrm{i} \cdot \mathrm{II} \cdot \mathrm{D} / \mathrm{T}$.

Production Test IP-432, "Evaluation of the Corrosion Characteristics of Elliptical Bumper Rails," has been issued. The test authorizes charging of 20 colums of OIIN fuel into D reactor, 10 control columns with bumper rails of the present design and 10 test columns with the new streamlined elliptical bumper rail.

Nickel Plated Fuel Program

Seventy columns of nickel plated OIIN fuel elements charged into $D$ reactor during the $9 / 5 / 61$ outage have reached an estimated exposure of $440 \mathrm{iND} / \mathrm{T}$.

Coextruded Ins truel

Four columns of coextruded IBeE fuel elements charged irito KMV reactor on $8 / 11 / 61$ have reached an estimated exposure of 730 $\mathrm{MND} / \mathrm{T}$. One column was discharged on $10 / 22 / 6.1$ at $600 \mathrm{NWD} / \mathrm{T}$ and one column on $1.1 / 14 / 61$ at an estimated 74.0 IT:D/T.

\section{E-iv Load}

The second E-N core loading has now reached about 50\% of goal exposure. Three batches of ei.ght columns each have been discharged at half goal, and they are being held for conversion-ratio determination. 
Files

- 8- December 8, 1961

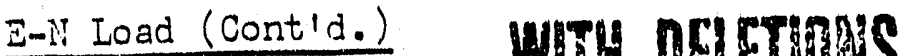 \\ Hith DCETHES}

The difficulties in segregation of the itthim-aluminum slugs which were discharged f'rom the first i-it core have been resolved. While segregation into four batches as originally desired cannot be accomplished, it has been possible to divide all the material discharged into three batches with known exposure on each.

\section{Kenon Instability}

i study of the relative stabllity of the NPR and $\ddot{n}$ reactors against xenon oscillations was completed. It was found that the xenoninstability problem will be less severe at NPR than it is for the $K$ reactors for the same total pile power, mainly due to the lower average flux in the IPR and the absence of a positive overall power coefficlent.

\section{Effluent rater Data}

The table below shows the average concentrations in reactor effluent water from samples taken during October 1961. Concentrations are in units of picocuries/cc.

\begin{tabular}{|c|c|c|c|c|c|}
\hline Reactor & $\mathrm{As}^{76}$ & $\mathrm{p} 32$ & $\mathrm{zn}^{65}$ & $\mathrm{~Np}^{237}$ & $\mathrm{Cr}^{51}$ \\
\hline B & 54 & 5.3 & 6.3 & 94 & 510 \\
\hline C & 88 & 6.6 & 13.6 & 90 & 630 \\
\hline D & 100 & 7.4 & - & 130 & 850 \\
\hline$D R$ & 76 & 7.5 & 12.6 & 130 & 540 \\
\hline F & 40 & 6.5 & 9.1 & .200 & 330 \\
\hline H & 52 & 3.1 & 7.7 & 64 & 220 \\
\hline iE & 42 & 5.4 & 8.3 & 39 & 510 \\
\hline$K ! Y$ & 92 & 14.0 & 15.0 & 100 & 360 \\
\hline
\end{tabular}

The alum feed rate at. KN reactor was held at about 12 PPI from October 4 to month end as part of an investigation of the interaction effects among water treatment process variables and the resultant effect on effluent activity.

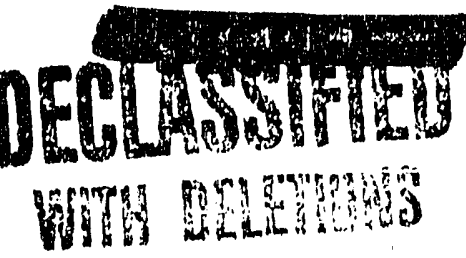




\section{Feactor Control and Safety Rods}

With the replacement of No. $15 \mathrm{HCR}$ with a boron-containing rod, all but five of the original. cadmium-containing HCR's have been replaced; of these five only iNo. 4 HCa is used during normal equilibrium operation, and it is calculated to have several months of effective Iife left. Another TSR was replaced it th a "B" type rod, bringing the total of smaller rods in the ISR system to seven.

\section{REACTOR : YODIFICATION PFOGRAI}

Overbore Fuel Development

Visual examinations and post-irradiation measurements of nine recently discharged columns of overbore fuel have been completed at the 105-C Hetal Examination Iacility and the data forwarded for machine jrocessing.

Visual examination of the metal from tube $4484-C$ failed to indicate a cause for the high discharge forces.

A number of the discharged overbore fuel elements have exhtbited damaged supports. Selected elements have been scheduled for further examination.

Two fringe zone (smooth-bore aluminum) tubes and one central zone (smooth-bore zircaloyr) tube. have reached scheduled goal exposures of $800 \mathrm{iMN} / \mathrm{T}$. They will be discharged during the next scheduled C reactor outage.

\section{Reactor Overbore Experience}

Tube $4484-C$, a smooth-bore overbore size aluminum tube which contained a stuck charge reported previously, was removed from the reactor on $11 / 3 / 61$. The channel will be retubed with a spare overtore zircaloy-2 tube during December. 
Files

IEWI PRODUCTION FIEACTOR

IN Reactor Fuel Development

TIVe NIII elements, two with capped jacket defects for failure testing in the PRIR mpture 1000, charged in KFR-1 on $5 / 27 / 61$, and two more ivil elements with capped facket defects added to the charge on $7 / 19 / 61$, were discharged $10 / 2 \% / 51$. The origical elements had reached an exposure of $237 \mathrm{C} \ldots 1 \mathrm{~T} / \mathrm{T}$, and the added el.lements an exposure of 1190 iTit/T.

Five 17-1nch iIII elements were charged in $:$ WR-1 on 10/2\%/61, to obtain swelling information at $1000 \mathrm{iTD} / \mathrm{T}$ exposure. The elements have reached an exposure of 380 ili:D/T.

The five 23 -inch VIII elements charged in $x \in R-2$ on $9 / 17 / 61$ for long-term irradiation have reached an exposure of $96011 \% \mathrm{D} / \mathrm{T}$.

NPR Graphite Irradiation

Approval was received from AIC-IDO for use of two positions in the GETR for test irradiation of specimens of NPR core graphite to high exposure levels. The formal purchase order form AEC-22 was executed by HOO, approved by IDO and accepted by GE-APED. The first test capsule was inserted in the CIIR during the November 27, 1961 outage. 


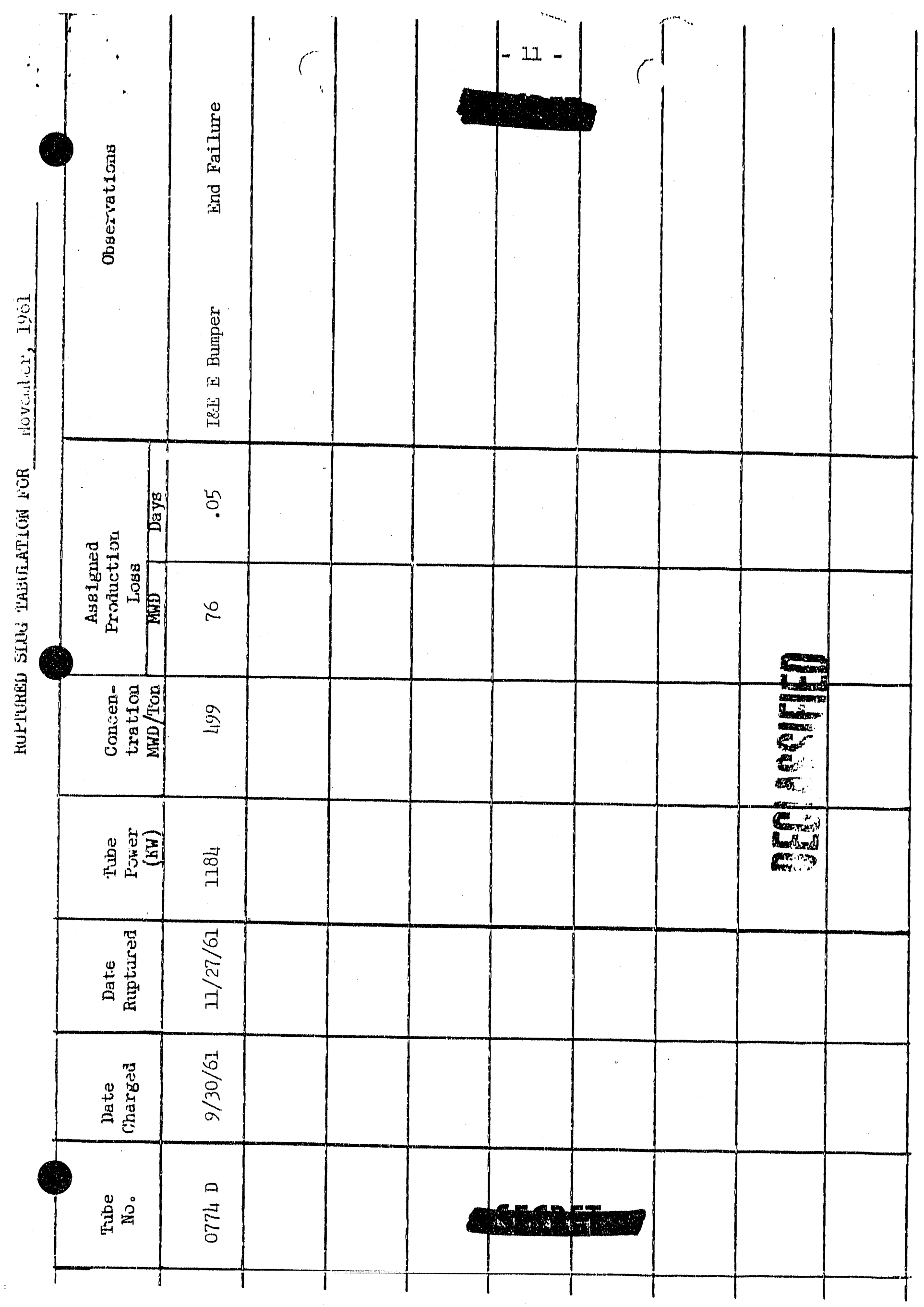



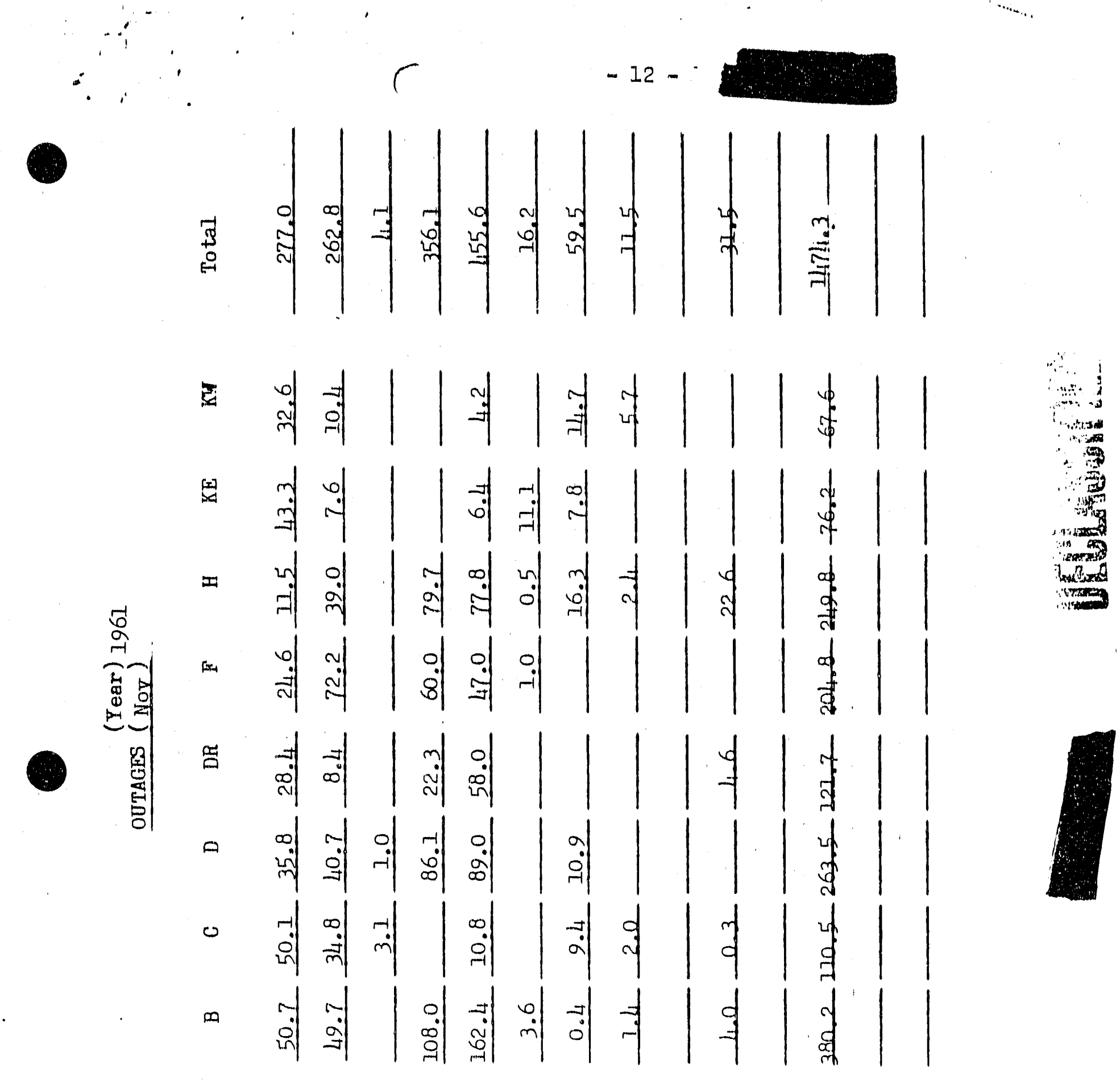

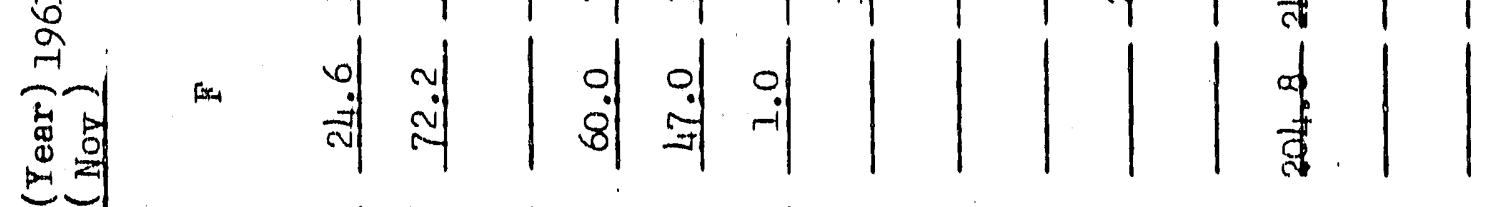

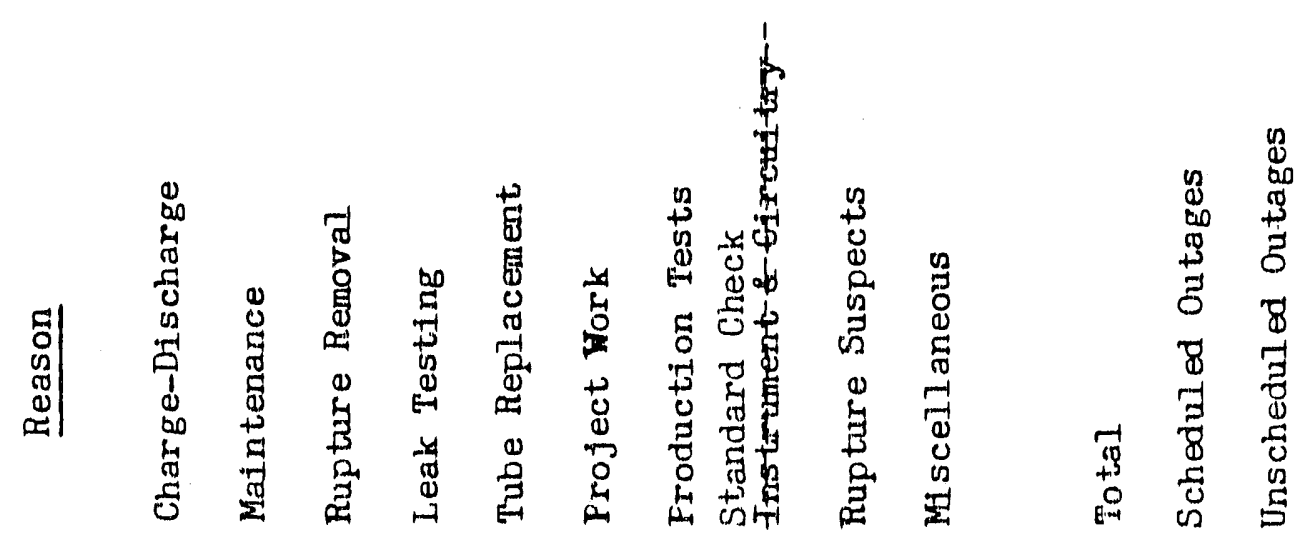



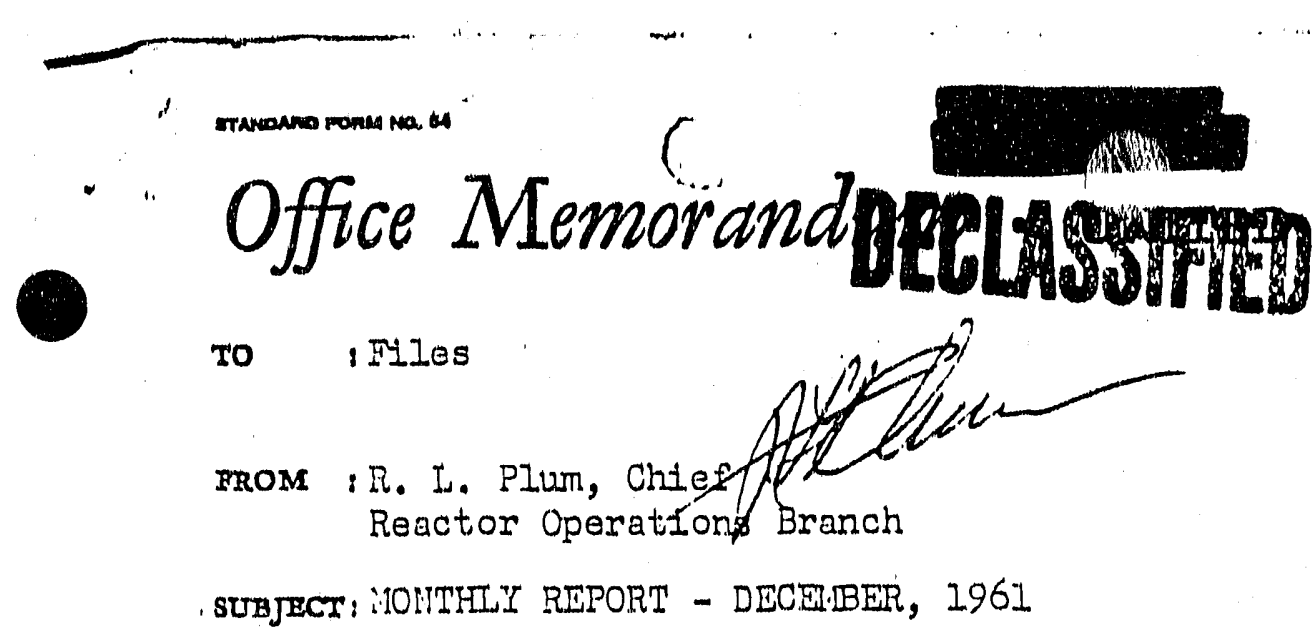

OR:GTO-JTR-IIRS

STATES GOVERNMENT

DATE: January 9, 1,962

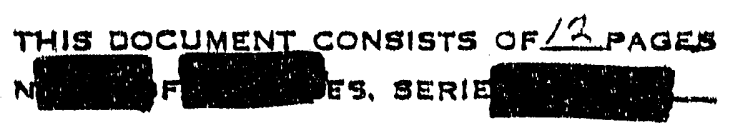

OPERATING TXPERIEIICE

Production

Reactor input production was $5.6 \%$ below forecast; $15.9 \%$ below at the six old reactors and $8.4 \%$ above at the ${ }^{\prime}{ }^{9} \mathrm{~s}$. Production for the fourth quarter was 2.1,4 below forecast and calendar year 1961 production was $0.2 \%$ below forecast.

\section{Efificiency}

Overall time operated efficiency was $72.1 \%$ (80.0\% forecast); $67.9 \%$ at the six old reactors and $84.9 \%$ at the $K^{\prime} s$. Efficiency was low at the six old reactors primarily because of process tube water leaks and tube replacement outages at the $B, D, D R$, $\mathrm{F}$ and $\mathrm{H}$ reactors and the overbore program at $\mathrm{C}$ reactor.

\section{Power Level}

There was no increase in the combined reactor instantaneous power level. Individual reactor record power levels were increased 130 megawatts at $\mathrm{KW}(4085$ to 4215$)$ and 10 megawatts at $\mathrm{C}$ (2265 to 2275). A montrly production record was achieved at init reactor, exceeding their January, 1961 record by $4.9 \%$

\section{Fuel Ruptures}

Seven ruptures, five I\&D enriched and two IAE regular, were removed from the reactors. Four of the enriched muptures were at $\mathrm{H}$ and one at $\mathrm{C}$. The two regular metal ruptures were at DR.

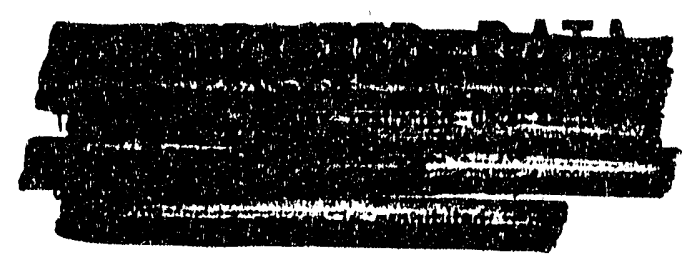




\section{Power Level Itimits}

Porver levels at $B, C, D$, and if reactors are restricted by bulkk outlet temperature limitations. $D R, F, I G$, and $k i ;$ power levels are being restricted by tube corrosion considerations.

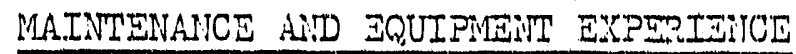

Process Tubes

One hundred eighty-nine new process tubes were installed; 104 at $\mathrm{D}, 36$ at $\mathrm{F}, 30$ at $\mathrm{B}, 11$ at $\mathrm{H}, 5$ at $\mathrm{in}, 2$ at $\mathrm{DR}$ and 1 at $\mathrm{C}$.

liater Leaks

Twenty tube and 11 Van Stone leaks were corrected. Stx of the tube leaks were at $F, 5$ at $H, 4$ at $B, 4$ at $D$ and $I$ at DR. Six of the Tan Stone leaks were at $H$ and 5 at $B$.

Safety Circuit Grounds

On $11 / 30 / 61$, $105 \ldots$. Was shut down because of an indicated short in the IX safety circuit which could not be located and corrected during operation. The cause was later found to be molsture collection in electrical circuitry. On $12 / 1 / 61$, 105-H reported a ground in the IX safety circuit which was, however, traced to a defective TSR clutch circuit and corrected during operation.

General reactor safety criteria governing the treatment of safety circuit grounds and the use of ground detectors are currently being generated.

Critical Reactor Component Examination

All the snap rings on the inlet tube sleeve flanges on 1 i. reactor were examined. There were gaps 3/8-inch and larger in 17 rings and one ring was cracked.

\section{Pigtall Changeout at $C$ Area}

A routine examination of front face pigtails removed from channels to be overbored was performed at C Area during the outage of December 8-12. This examination revealed that some of the flares on the tubing connections at crossheader and venturi in many cases were too small to provlde assurance against the tubing pulling out during operation. Accordingly, all pigtails on the front face were removed and replaced with available connectors

\section{DEvaremath}


Pigtail Changeout at C Area (Cont'd.)

of inconel tubing. Inconel has been shown to be equal or superior to existing stainless steel tubing on vibration tests performed on plant. The flares on the new cornectors are all significantir greater than those on the questionable pigtails removed. Commission personnel inspected the changeout operation to assure that the installation was satisfactory and that there vas no evidence of recurrence of the previous conditions.

Equipment Application Engineering

The reweighing of all reactor cilarge platforms has been completed excint for $105-F$. Tiork currently under way in support of general functional and safety upgrading includes the following:

1. Establishment of optimum load distribution for existing platform structures.

2. Examination of alternatives to permit increased loadings by redistribution of counterweight function and truss reinforcement.

3. Negotiation of a service contract which provides for detailed functional inspection of a lead reactor area as a guide to intensified maintenance activity.

4. General review of safety features and supporting engineering to assure continued function as combined platform and manned hoisting capability.

5. Technical support of work in progress ained at reducing platform live and dead loads. 
Files

REHCTOR OUTAGES

\begin{tabular}{lrr}
$\begin{array}{l}\text { Date } \\
\text { Down }\end{array}$ & $\begin{array}{c}\text { Date } \\
\text { Up }\end{array}$ & $\begin{array}{r}\text { Ouliage } \\
\text { Hours }\end{array}$ \\
B Reactor & \\
$11 / 26$ & $12 / 2$ & 150.4 \\
$12 / 2$ & $12 / 2$ & 1.6 \\
$12 / 5$ & $12 / 7$ & 42.0 \\
$12 / 9$ & $12 / 11$ & 39.7 \\
$12 / 14$ & $12 / 18$ & 101.2 \\
$12 / 26$ & $12 / 27$ & 42.5 \\
0 Reactor & \\
\hline $11 / 30$ & $12 / 2$ & 34.7 \\
$12 / 8$ & $12 / 21$ & 313.2
\end{tabular}

$12 / 21 \quad I i / 21 \quad 0.8$

$12 / 21 \quad 12 / 21 \quad 10.9$

$12 / 23 \quad 12 / 23 \quad 0.4$

$12 / 26 \quad 12 / 28 \quad 35.9$
Leak testing, tube replacement, and miscellaneous maintenance.

$\underline{\text { Remarlss }}$

Failure of loop header back-up water supply.

Leak testing and tube replacement.

Leak testing and tube replacement.

Scheduled charge-discharge and tube replacement.

Leak testing.

Charge-discharge. Corrected a ground in the $D C$ circuit of the upper limit siritch on \#40 VSR.

Removal of an I $\mathbf{i} \equiv-\Xi$ metal rupture from tube 3762. Scheduled overboring, charge-discharge, replacement of front pigtails and miscellaneous maintenance.

Panellit trip.

Thermocauple repair on tube 2764.

Panellit trip.

Miscellaneous maintenance work after a manual trip due to a loose front pigtail connector.

D Reactor
$12 / 1 \quad 12 / 2 \quad 42.0$
Low pressure Panellit trip on tube 1086. iliscellaneous maintenance.
$12 / 12 \quad 12 / 14 \quad 41.5$ 
Files

D Reactor (Cont'd.)

$12 / 14 \quad 12 / 14 \quad 0$.

$12 / 15 \quad .12 / 22 \quad 150.1$

$12 / 25 \quad 12 / 27 \quad 41.5$

DR Reactor

$\begin{array}{lll}11 / 29 & 12 / 2 & 65.3 \\ 12 / 3 & 12 / 3 & 0.3 \\ 12 / 14 & 12 / 16 & 46.0 \\ 12 / 27 & 12 / 29 & 53.0\end{array}$

12/31 Still down
Unexplained Panellit trip.

Scheduled charge-discharge. Tube replacement and miscellaneous maintenance.

Leak testing and tube replacement.

Charge-discharge and tube replacement.

Manual trip due to a reactivity change while flushing a ball valve tube.

Removal of a stuck Izes regular metal rupture from tube 3264. Charge-discharge.

Removal of a stuck Io: $\mathrm{I}$ regular metal rupture from tube 0867. Leak testing.

Scheduled charge-discharge and tube replacement.

F Reactor

$\begin{array}{llll}11 / 30 & 12 / 1 & 26.8 & \begin{array}{l}\text { Leak testing and tube replacement. } \\ 12 / 6\end{array} \\ 12 / 9 & 68.3 & \begin{array}{r}\text { Leak testing, tube replacement and } \\ \text { charge-discharge. }\end{array} \\ 12 / 9 & 12 / 9 & 0.9 & \begin{array}{r}\text { Panellit trip due to improperly installed } \\ \text { rear cap on tube } 1677 .\end{array} \\ 12 / 23 & 12 / 27 & 92.7 & \begin{array}{r}\text { Panellit trip due to a leak in tube } 3971 . \\ \text { Scheduled charge-discharge and leak testing. }\end{array}\end{array}$


H Reactor

12/4 1.2/5 $29.8 \quad$ Leak testing and tube replacement.

$12 / 8 \quad 12 / 9 \quad 25.7 \quad$ Leak testing.

$12 / 13 \quad 12 / 14 \quad 32.1 \quad$ Removal of an I $30- \pm$ metal rupture from tube 2864.

$12 / 15 \quad 12 / 16 \quad 28.5$

Panellit trip on tube 1469 due to a vater leak. Leak testing and tube removal.

12/21 12/22 28.9 Leak testing and tube replacement.

12/23 12/23 1.8 Removal of an I\&E-I metal rupture from tube 4177 .

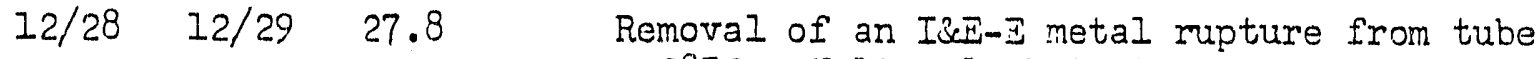
2872. Helium leak testing.

12/31 Still down

Removal of an ICE-E metal mupture from tube 2667. Charge-discharge.

iE Reactor
$12 / 3 \quad 12 / 5 \quad 42.3$
Charge-discharge and miscellaneous maintenance following a Loop 2 trip.
$12 / 14 \quad 12 / 16 \quad 59.7$
Panellit trip due to a grounded gauge. Charge- discharge and miscellaneous maintenance.
$12 / 27 \quad 12 / 30 \quad 61.3$
Scheduled charge-discharge and miscellaneous maintenance.
$12 / 31 \quad 12 / 31 \quad 0.4$
Panellit trip due to the inadvertent opening of a toggle valve.

K:i: Reactor
$12 / 4 \quad 12 / 7 \quad 61.1$
Scheduled charge-discharge.
$12 / 7 \quad 12 / 7 \quad 0.4$
Panellit trip due to an oscillating gauge 0370 . 


\section{Files}

\section{RESEARCH AIN DEVELOPMENT - EYISTIIT REICTORS}

\section{Self-Supported Fuel Development}

Some support rail damage at $C$ reactor was obsemed during chargedischarge operations while using the displacement method (i.e., the irradiated fuel being discharged with a new fuel charge). Then the irradiated material vas discharged using dumies, the nev material could be charged satisfactorily. The problem is under investigation.

\section{Bunper Fhel Development}

Seventeen columns of OIIIIY-B fuel charged in D reactor to evaluate UT-2 fuel core tester will reach their scheduled discharge exposure goal of $900 \mathrm{irN} / \mathrm{T}$ during January.

Thenty columns of OIIIiJ-B fuel elements, tan with current production type bumpers and ten rith new streamlined. elliptical bunpers, were charged into $D$ reactor during the 12/16/61 outage. The columns were charged into new process tubes in pairs; i.e., adjacent column, each with a different type of bumper rail.

Nickel Plated Fuel Program

Serenty columns of nickel plated OIIN fuel charged in DR reactor during the $9 / 5 / 61$ outage have reached an estimated exposure of 650 $1 \mathrm{ID} / \mathrm{T}$. Seventeen columns will be discharged at half goal during the 12/31/61 scheduled outage at the request of Operations, since they are in thin tubes which have been scheduled for replacement. Fuel from these tubes vill be specially examined.

Coextruded IR.E Fuel

Four columns of coextruded Iors fuel charged into ini reactor on $8 / 1 / 61$ have reached an estimated average tube exposure of 1000 $\mathrm{MD} / \mathrm{T}$. One column has reached $1025 \mathrm{MTD} / \mathrm{T}$ and is scheduled for discharge during the next outage.

Control Efficiency Studies

The second core of the $H$ reactor E-il load is nearing goal exposure, and it is scheduled to be replaced with natural uranium early in Febmuary. The recent high incidence of mutures (four in December, tivo January 1-9) may require earlier discharge. The blanket loading will be continued through most of 1962. Twenty-four E-metal columns from the sixth lattice unit and twenty-four from the fifth lattice unit were picked up separately for scheduled conversion-ratio determinations. 


\section{Shielding Studies}

i comprehensive manual on prints and descriptions of present reactor shields was issued during the month as 1 i:-71109, Shielding Rejerence
Nanual, Hanford Production Reactors.

\section{Pile Reactivity Studies}

Recent 200-Area isotopic determinations based on itass spectrograph analysis, only recently made available, indicate plutonium-2LO buildup to be $L-10 \%$ greater than would have been predicted from test batch data to which prediction tables have been normalized. The possibility is being considered of extending tube-by-tube accounting to plutonium-2l.0 content as vell as to the normal total plutonium prediction.

Considerable effort has been spent during the month on analyaing in detail the partial calioration of the horizontal control rod system at $H$ reactor. Results indicate that the HCP's are approximately $20 \%$ less effective in the $\mathrm{I}-\mathrm{N}$ loading. These results are due in part to the blacker lattice in the $E-i$ loading and in part to the reduced value through the fringe poison blanket. Reductions in local safety control strength of the observed order of magnitude were previously assumed in safety calculations for the $\bar{y}-\mathrm{N}$ load.

Effluent :Tater Data

The table below shows the average concentrations of radioisotopes in reactor effluent water from samples taken during lovember, 1961. Concentrations are in units of picocuries/cc.

\begin{tabular}{|c|c|c|c|c|c|}
\hline Reactor & As76 & $\underline{p 32}$ & $\mathrm{Zn}^{65}$ & In 239 & $\mathrm{Cr}^{51}$ \\
\hline$B$ & 57 & 5.9 & * & $*$ & $*$ \\
\hline C & 100 & 7.6 & 32 & 120 & 590 \\
\hline$D$ & 85 & 7.0 & 19 & 100 & 500 \\
\hline$D R$ & 80 & 10.4 & 20 & 130 & 730 \\
\hline$E^{\prime}$ & 67 & 8.4 & 84 & 240 & 840 \\
\hline $\mathrm{H}$ & 66 & 5.1 & 7 & 75 & 510 \\
\hline $\mathrm{iE}$ & 52 & 8.0 & 1.2 & 67 & 490 \\
\hline int & 92 & 13.0 & 18 & 90 & 620 \\
\hline
\end{tabular}

The alum feed rate at $\mathrm{KW}$ was held at $12 \mathrm{ppm}$ to December 6 , when it was increased to $18 \mathrm{ppm}$. At month end all reactors were feeding alum at $18 \mathrm{ppm}$. 
Files

VSR Channel Liners

Compression and flexural test specimens of ceramic materials being in C reactor for evaluation. aluminum silicate, and silicon carbide.

Equipment is being developed to overbore some C-reactor vertical safety-rod channels for installation of liners.

Reduction of Radioactive Discharge to the River

The following process systems have potential application to the problem and will be studied in detail to assess their relative economic and technological feasibility.

(1) Open cycle recirculation systems with effluent circulated from existing retention basins through cooling towers, cooling

(2) Closed cycle recirculation systems with effluent circulated in a closed loop through heat exchangers cooled by raw river water. (3) Reactor effluent disposal through an artificial lake which would
provide increased hold up time and additional radioactive decay.

(4) For recirculation systems, both pressurized and non-pressurized reactor coolant loops will be considered. Pressurization would be required to maintain existing oroduction levels due to the

Decontamination Sulfamic acid compositions were used for the first time for rear-face
piping decontamination at $105-C$ reactor.

REACTOR ISODIFICATION PROGRAY

Overbore Fuel Development

Installation of twenty more overbore channels at $C$ reactor during the $12 / 8 / 61$ outage completed the authorized test facility and brought the central flow zone, completed the central-zone blonnels, located in will be used to obtain preliminam converal-zone block pattern which to providing further qualitative conversion ratio data in addition behavior of the large diameter fuel to characterize the irradiation were fitted with Zircaloj-2 smooth elements. The overbored channels 19 CVINS fuel elements each. 
Overbore Tuel Develonment (Cont'd.)

Tourteen columns of overbore fuel were discharged during the 12/3/61 outage without difficulty. The discharge exposures ranged from a high of about $1000 \mathrm{LTD} / \mathrm{T}$ to a low around $700 \mathrm{is} / \mathrm{T}$.

Combining the results of observations made durin $n_{\tilde{E}}$ post-irradiation metal examinations and metal charging, it is concluded that some of the self-support rails are currently being damaged during the charging overation. iork is in progress to correct this.

\section{Orerbore Hardware}

Cadmium plated steel snap rings were installed on the front and rear of original overbored orocess tube nozzles at $C$ reactor. Some of the original type 420 stainless steel snap rings installed at the outlet end of the tubes had cracked from stress corrosion.

\section{NEW PRODUCTION REACTOR}

iv Reactor Fuel Development

The five 17-inch NIEI elements charged in KER-I on 10/29/61 to obtain low-exposure swelling information were discharged $12 / 14 / 61$ at an exposure of $7 \mathrm{LL}$ irl $\mathrm{N} / \mathrm{T}$.

KER-I Loop was recharged with five 23-inch NIEI elements on 12/14/6I to evaluate the effect of pre-irradiation warp condition on fuel behavior. Current exposure is $60 \mathrm{lniD} / \mathrm{T}$.

Five 23-inch NIII elements, charged In KIR-2 on $9 / 17 / 61$ to evaluate high-exposure distortion and swelling, have reached an exposure of $1390: \pi \mathrm{D} / \mathrm{T}$.

\section{NPR Graphite Irradiations}

Performance of the first test capsule containing NPR graphite samples charged in the GETR is satisfactory. A second capsule has been constmucted and will be charged into the GITR in early January.

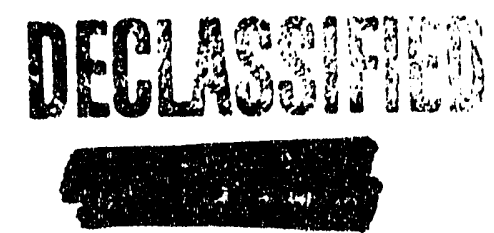




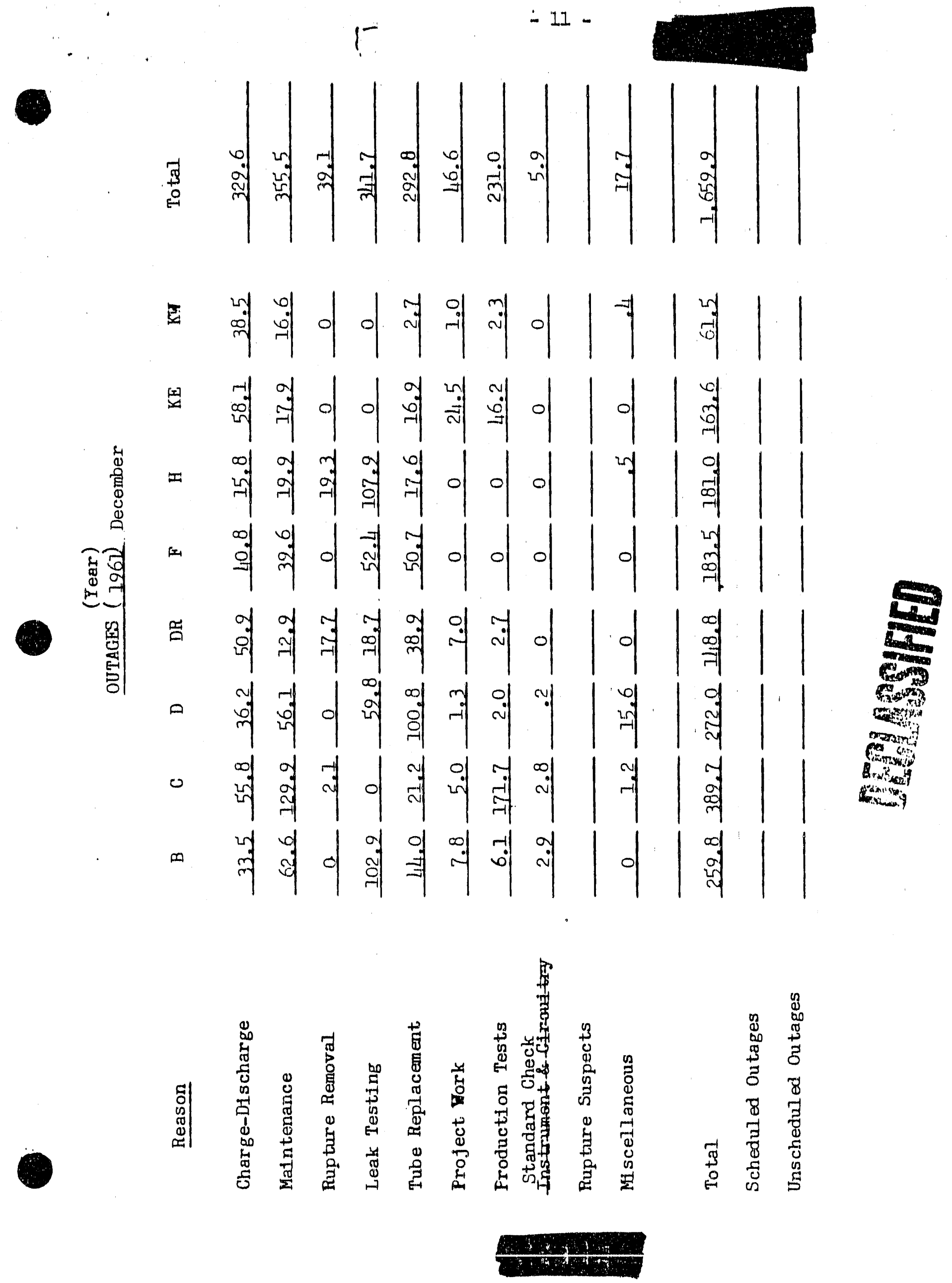




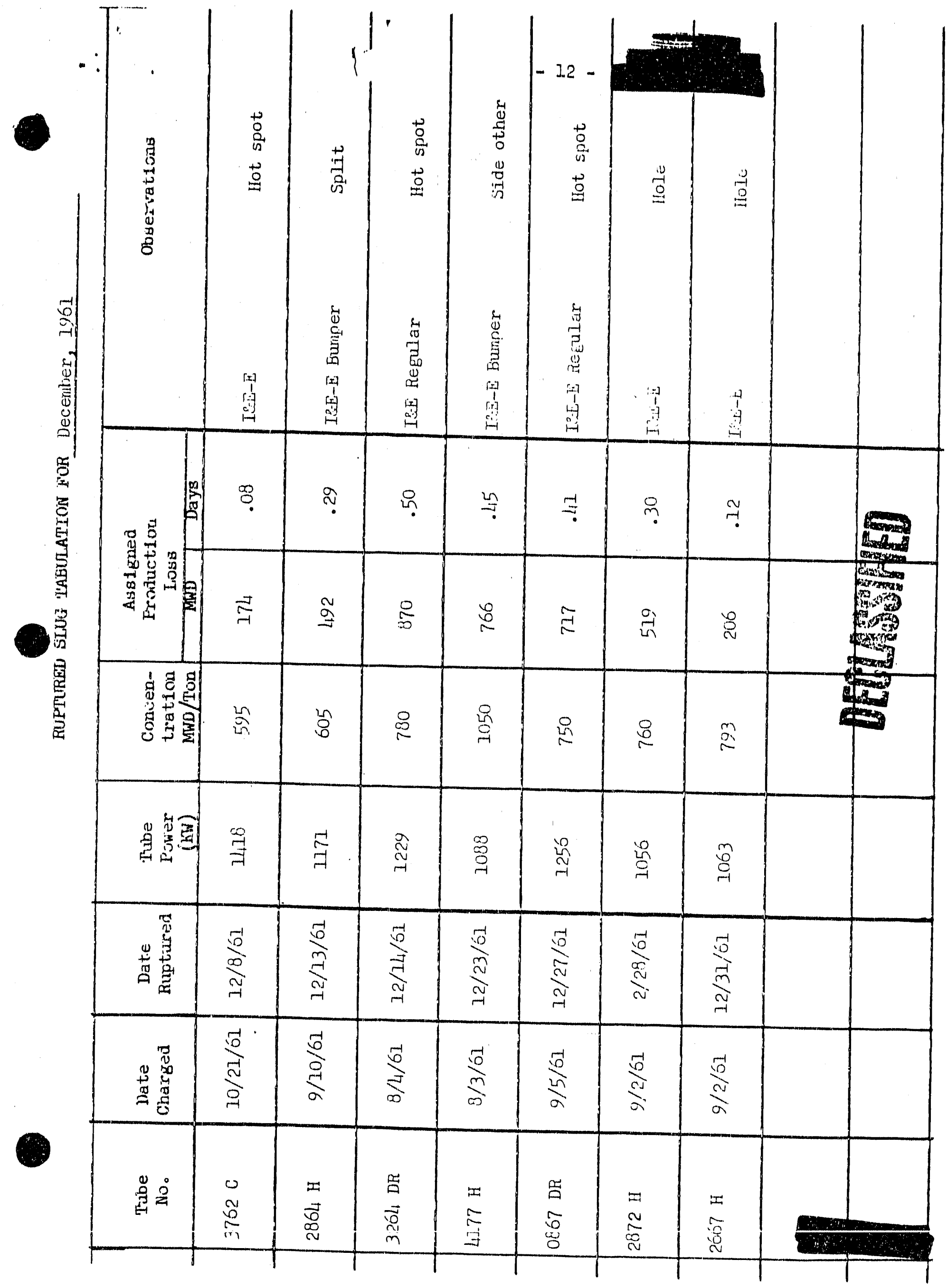



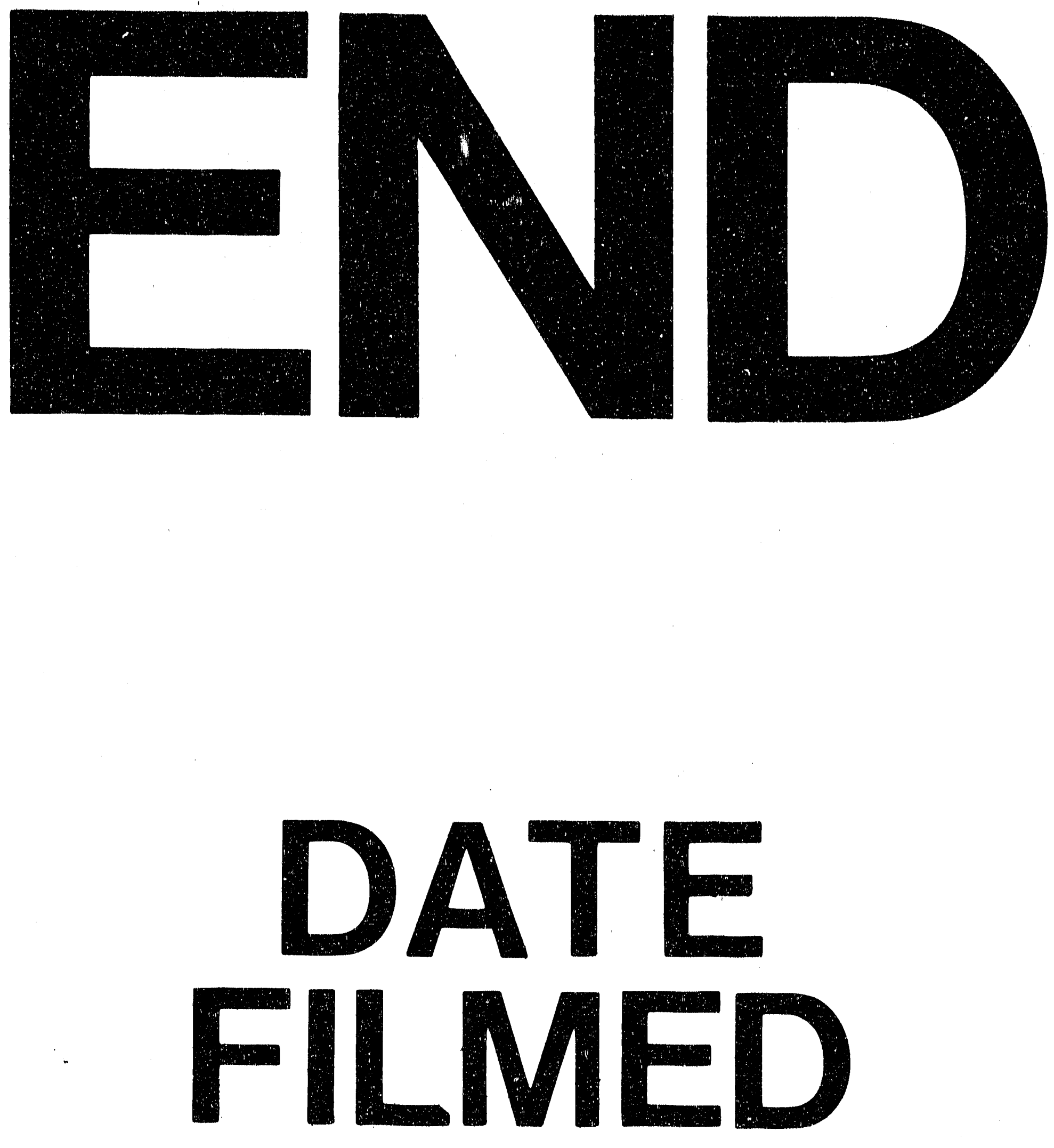

$\stackrel{1}{\prime \prime}$

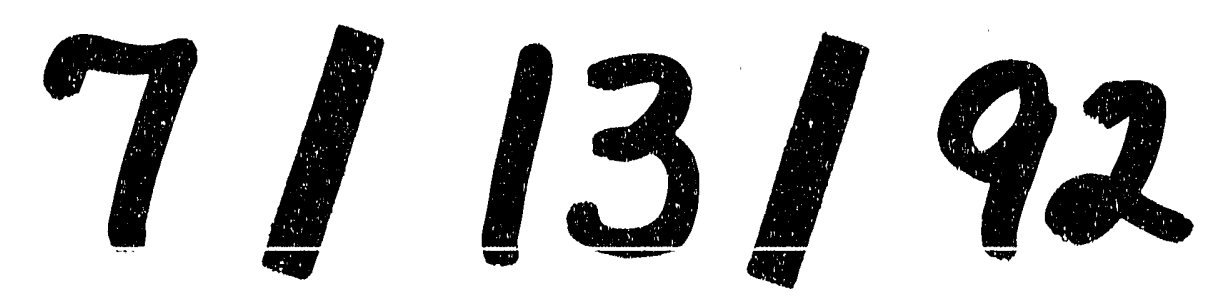


